\title{
From Cavolinia longirostris to twenty-four Diacavolinia taxa, with a phylogenetic discussion (Mollusca, Gastropoda)
}

\author{
S. van der Spoel ${ }^{1}$, J. Bleeker ${ }^{1} \&$ H. Kobayasi ${ }^{2}$ \\ ${ }^{I}$ Institute of Taxonomic Zoology, University of Amsterdam, P.O. Box 4766, 1009 AT Amsterdam, The \\ Netherlands; ${ }^{2}$ Plankton Div. Ocean Research Institute, University of Tokyo, 1-15-1 Minamidai, Nakano \\ Ku, Tokyo, Japan
}

Keywords: Taxonomy, Pteropoda, Cavoliniidae, Diacavolinia, new species, phylogeny

\begin{abstract}
The six already known infraspecific taxa in Cavolinia longirostris (De Blainville, 1821), presently in the genus Diacavolinia, are raised to species rank and sixteen species and two formae new to science are described in this genus from different oceanic areas. Some shell structures in the Cavoliniinae are described for the first time and the phylogeny of the group is discussed.
\end{abstract}

\section{Résumé}

Les six taxa infraspécifiques décrits dans Cavolinia longirostris (De Blainville, 1821), à présent dans le genre Diacavolinia, ont été élevés au rang d'espèces. Deux formae et seize espèces nouvelles pour la science sont décrites de diverses régions océaniques. Quelques structures de la coquille des Cavoliniinae sont pour la première fois décrites, et la phylogénie de ce groupe est discutée.

\section{Introduction}

The discrimination of the genus Diacavolinia Van der Spoel, 1987 was based on the development of the shell being strongly different from the shell growth in Cavolinia. It was also the start of a study of this highly variable and diverse group of pteropods. In the present paper the taxonomy of the group is given.

In Diacavolinia, that consists of what formerly (Tesch, 1913, 1946, 1948) was considered the species Cavolinia longirostris (De Blainville, 1821), three subspecific taxa have been recognized already for a long time, viz.: angulosa Gray, 1850, strangulata (Deshayes, 1823), and longirostris (De Blainville, 1821). Recently limbata (d'Orbigny, 1836) was reintroduced (Van der Spoel, 1970) and two infraspecific taxa were added: flexipes Van der Spoel, 1971 and mcgowani Van der Spoel, 1973. A proper identification to the subspecific level of a large material of the "species" was frequently impossible as many specimens had a combination of characters "typical" of the different vaguely described subspecies. In case the material seemed to be correctly identified to a subspecies it showed larger variation in size and shape than in any other pteropod species. So it was doubtful if the taxonomy of the group was treated correctly.

During the Amsterdam Mid North Atlantic Plankton Expeditions (1980-1983) it was discovered that nearly identical shells may be associated with strongly different soft parts. The colour and shape of the wings differed distinctly between specimens that all had a strangulata-like, though much larger, shell (Fig. 1). The discovery of these differently coloured soft parts induced us also to make a more accurate study of the whole "Cavolinia longirostris" group.

In total six of the many described taxa are so far expected to be good taxa and all are raised to species level. In this paper these taxa are redescribed, and 18 taxa new to science are described. In order to enable the description of the shell, some terms not commonly used in pteropod literature are introduced and defined below, together with some 

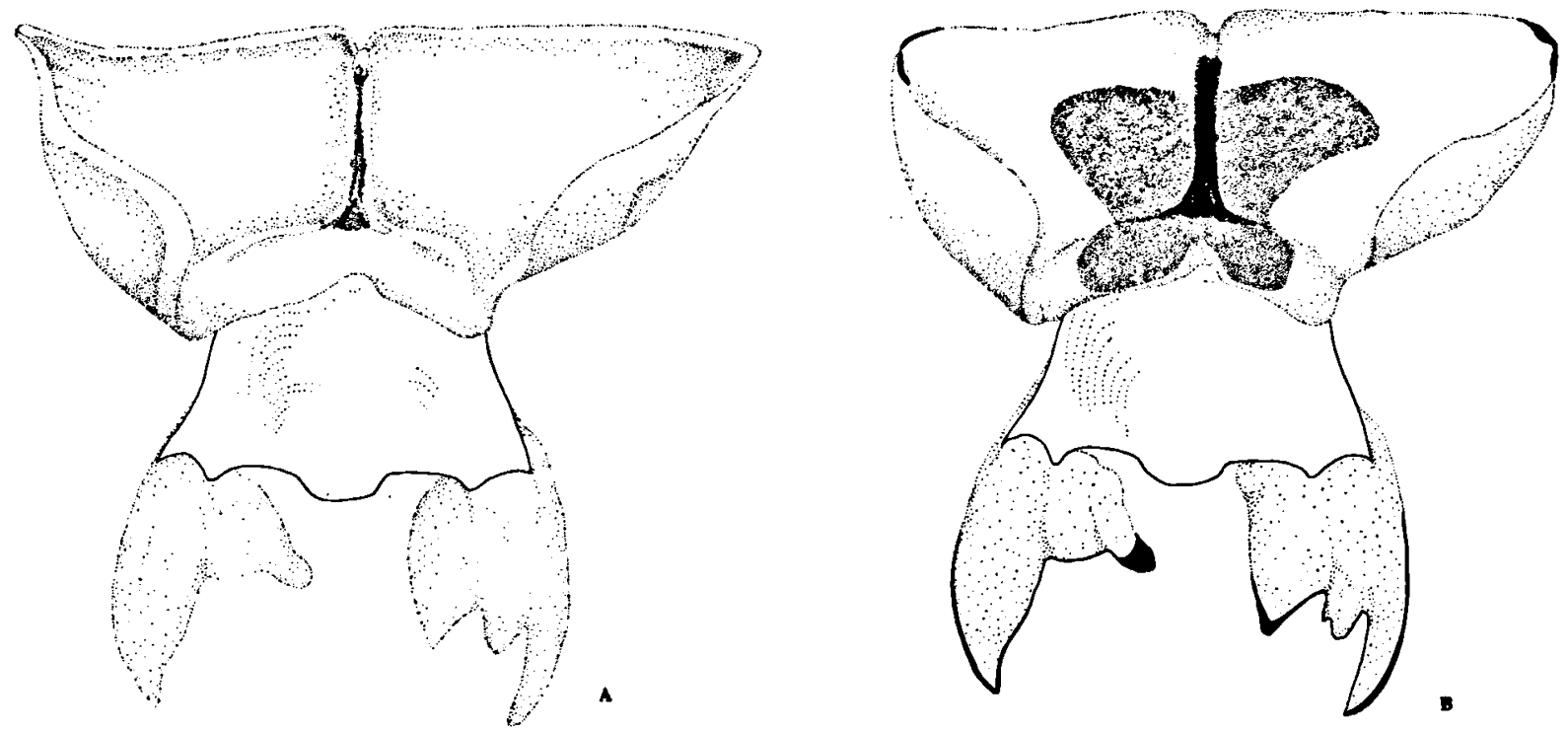

Fig. 1. Two N.E. Atlantic specimens of Diacavolinia with nearly identical shells drawn from colour slides and from notes on the living specimens. The left one, D. I. africana (A), has a light purple colour over nearly the whole wing surface; the right one, $D$. atlantica (B), has a dark brown colour on the tips of wings and "balancer", and in the centre of the wings.

terms in common use for the description of cavoliniid shells (see Fig. 2).

It seems contestable that a common taxon, occurring sometimes abundantly, was considered for more than 170 years as one valid species while it is now falling apart into 24 taxa. It is impossible to consider most variants merely as subspecies or formae as no geographic patterns could be found in the variation; moreover, no intermediates or zones of intergradation are found. Sympatry of different taxa is the role and not the exception. The adult specimens of the different species can be accurately separated in mixed samples.

In two cases the concept forma was used to classify infraspecific taxa. Though formae are not considered in the nomenclatorial rules of the International Code of Zoological Nomenclature, they are treated below as valid taxa for which names, descriptions, and types are given. The special status here given to formae is explained by Van der Spoel (1971 a, b).

There are two reasons to suppose that active radiation may be present in the group. Morphologically it is a unique group with a very specialised growth strategy so that it can occupy new niches. Secondly, the sexual organs are more complicated than in any other pelagic opisthobranch mollusc so that precopulatory barriers may develop easier than elsewhere in the Pteropoda. As the reproductive system in Diacavolinia is very characteristic with regard to the other Cavoliniidae, it is, like the shell growth, discussed separately.

It is surprising that the diversity of the group was never studied before; statements like that of Tesch (1946) that "angulosa" and "strangulata" forms are not present in the Atlantic Ocean prove that no attention was given to the diversity already known for these planktonic molluscs. The fact that the lock system in Diacria and the second lock system in Diacavolinia described in this paper stayed unnoticed for so long a period is another proof of inaccurate observations in the past.

Many populations with "strangulata" and "angulosa" characters are found in the Atlantic and the group thus urgently needs a revision. The present material does not permit to give a complete zoogeography of the genus and many areas are insufficiently sampled for these species so that the present revision will not be a final one. 


\section{Terminology (cf. Fig. 2)}

In alphabetic sequence the terms used in this paper to describe the species are given:

Aperture (20 in Fig. 2B): the opening of the shell through which the animal can expand (never used for the mouth in the soft parts).

Caudal fold (13 in Fig. 2B): part of the caudal margin of the shell not occupied by spines or caudal joint, formed by an uninterrupted shell wall where ventral and dorsal side merge into each other gradually.

Caudal joint (4 in Figs. 2B \& C): part formed by the closure of the protoconch II after loss of the protoconch $I$, in the centre of the caudal shell margin. Diacavoliniid species first develop a bowl-shaped embryonic shell (protoconch I), on which a conical part is formed. Very quickly this part broadens and a transversal slit starts to separate dorsal and ventral side. All soft parts retract into this "bivalve-like" shell and the embryonic shell with the conical part is shed. The opening left at the underside of the "bivalve-like" part is closed by bending of the ventral and dorsal side and secretion of extra shell material, but no septum is formed. This fusion gives rise to the joint.

Central dorsal rib (10 in Figs. 2A \& C): undular elevation of the dorsal shell side usually running from the rostrum to close to the caudal joint.

Constriction: the narrowing of the aperture by two dents or lateral folds of the dorsal lip near the base of the rostrum.

Dorsal lip (8 in Fig. 2C): prolongation of the dorsal shell side over the aperture.

Dorsal side (1 in Fig. 2C): the dorsal side or "valve" of the shell.

Flank (16 in Figs. 2A \& B): the usually somewhat flattened lateral sides of the ventral surface of the shell.

Growth lines: the concentric rings formed by stagnations in growth of the shell.

Gutter: see lip gutter.

Gutter corner (14 in Fig. 2B): the most posterior corner of the shell aperture through which the "balancers" can be expanded.

Height of aperture (G in Fig. 2F): the maximal height of the shell aperture, in straight ventral view.

Height ventral lip (F in Fig. 2F): the maximum width of the lip, in straight ventral view.

Inner hump (23 in Fig. 2B): the line in the aperture marking the underside of the hump.

Lateral line ( 2 in Fig. 2C): the line between spine and the lock area seen with the shell in ventral view.

Laterodorsal rib (11 in Figs. 2A \& B): undular elevations of the dorsal shell side at both sides of the central rib.

Length of rostrum ( $\mathrm{H}$ in Fig. 2F): the length of the dorsal lip between rostrum tip and inner hump. In species without a hump the length can not be measured exactly, though the rostrum is present.

Lip angle (III in Fig. 2E): the angle between the line through the tip of the dorsal lip and the lock tubercle and the line through the lock and the gutter corner.
Lip belly (19 in Fig. 2B): the bulging outwards of the dorsal lip. Lip flap (24 in Fig. 2B): the part of the dorsal lip that is curled inwards.

Lip gutter (21 in Fig. 2B): the longitudinal groove in the dorsal lip.

Lip rim: the line bordering the lips, that can be either sharp or thickened. Usually the ventral lip is more thickened than the dorsal one.

Lip shoulder (25 in Fig. 2B): the part of the dorsal side of the lip visible with the shell in ventral view.

Lip gutter (21 in Fig. 2B): the hollow inside of the central dorsal rib continuing in the rostrum.

Lock angle ( $\mathrm{I}$ in Fig. 2E): the angle between the line through the lateral spine tips and the line through the right point of the joint and the right lock tubercle.

Lock area (26 in Fig. 2B): the place near the corners of the ventral lip, where dorsal and ventral side are connected with the main lock mechanism.

Lock link (29 in Fig. 2D): the hook at the inner ventral shell side, fitting in between the lock tubercles.

Lock rib (27 in Fig. 2A): the rib at the dorsal side on top of the lock area, usually not continuing far posteriorly and mainly composed of the thickening under the lock tubercles.

Lock tubercles $(28,30,31$ in Fig. 2D): the knob on the inner shell side visible from the outside; in total three tubercles (the main (28), the lunar (30) and the minor (31) tubercles, visible from the inside) may be present in the main lock.

Maximum width (B in Fig. 2F): the distance between the spine tips.

Median lip depression (18 in Fig. 2B): the concave central part of the ventral lip.

Mouth: the opening of the buccal mass (never used for the shell opening).

Nose: a small thickening seen in lateral view near the tip of the dorsal lip.

Notch: the, usually asymmetrically, "V"-shaped constriction in the tip of the rostrum of some species.

Outer hump ( 9 in Fig. 2C): the bulging of the dorsal side at the base of the lip.

Posterior foot lobe: the foot lobe ventral to the mouth.

Protoconch I: shell formed in the egg.

Protoconch II: part of the shell made by the veliger stage, protoconches $1+$ II together forming the embryonic shell.

Rostrum (22 in Fig. 2B): the anterior part of the dorsal lip projecting as a snout before the shell. In some species it is well separated from the rest of the dorsal lip. In this part of the shell many discriminating characters are located.

Second lock (32 plus 33 in Fig. 2D): a usually simple extra lock mechanism between ventral and dorsal shell sides, at the upper side of the lateral spines.

Side angle (II in Fig. 2E): the angle between the line through the lateral spine tips and the line through the right spine tip that hits the left lip belly.

Spine (12 in Fig. 2B) or lateral spines: lateral prolongation of the shell near the aperture corners; it shows different shapes in the different species and is bent dorsally in some. 
Spine tip ( 3 in Figs. 2B \& C): the tip of the spine.

Spine surface (15 in Figs. $2 A \&$ B): the area of the spine between the tip and the border of the dorsal shell side.

Total length ( $\mathrm{L}$ in Fig. 2F): the distance between rostrum tip and caudal joint.

Valve angle (IV in Fig. 2C): the angle between dorsal and lateral shell sides as described by Richter (1982); the size of the angle is difficult to measure as no exact position of the dorsal and ventral sides or "valves" can be defined.

Ventral lip basis ( 6 in Figs. 2B \& C): the ridge in between ventral lip and ventral shell surface.

Ventral lip (7 in Figs. 2B \& C): prolongation of the ventral shell side over the aperture.

Ventral ribs (17 in Fig. 2B): sculpture lines transversally over the ventral side, usually congruent with but not homologous to the growth lines; they are composed of tubercles that may grow together as one ridge or that may grow out into a comblike pattern.

Ventral side ( 5 in Figs. 2A-C): the ventral side or "valve" of the shell.

Width of lateral spine ( $E$ in Fig. 2F): the distance between gutter corner and spine tip.

Width at aperture basis ( $A$ in Fig. 2F): width of the shell in ventral view between the lock tubercles.

Width of the fold (D in Fig. 2F): the distance between joint and gutter corner.

Width of the joint ( $C$ in Fig. 2F): the size of the area between the two fold areas.

\section{Material}

The material used for the present study has been collected mainly by the Dana Expeditions (Jespersen \& Táning, 1934), the Deepwater Dumpsite 106 Project (N.W. Atlantic) (Krueger et al., 1977), the Amsterdam Mid North Atlantic Plankton Expeditions (AMNAPE) (Van der Spoel, 1981, 1985; Van der Spoel \& Meerding, 1983), and the Snellius II Expedition (Banda Sea) (Schalk, 1988).

The illustrations are made with a preparing microscope and camera lucida with 12 and 25 times enlargement. As the dorsal side is usually convex it is difficult to get the specimens adjusted exactly in ventral view. The asymmetry shown in most illustrations is, however, due to real asymmetry in the shells and not to incorrect adjustment, as the specimens were embedded in fine sand to give them the correct position.

In the descriptions the number of ventral ribs and the valve angle are given; both characters are difficult to measure. The ribs fade over into growth lines and the position to measure the valve angle is not exactly defined. Still both sizes are given as they may have an important indicative value. For the observation of the lock systems, the ventral and dorsal valve of the shell had to be separated. The shape of the lock mechanism, usually composed of three dents at the dorsal side, is described for most species. It is, however, unknown if this is a variable structure; too few specimens could be crushed to see this structure, and the shape seen from the outside is completely different from the structure seen from inside. Still it is supposed to be a promising discriminating feature.

The type material of the newly described taxa is preserved in the Zoological Museum of the University of Amsterdam (ZMA) and the Zoological Museum of Copenhagen (ZMUC).

\section{Taxonomy}

\section{Diacavolinia Van der Spoel, 1987}

Ref.: Diacavolinia Van der Spoel, 1987: 78.

Type species: Diacavolinia longirostris (De Blainville, 1821).

Diagnosis. - Shell, transparent, straight, calcareous, seems to be composed of a ventral and dorsal valve; roughly triangular in ventral view; lateral spines present; no whorls present. A large dorsal lip and a smaller ventral lip border the aperture. More or less clear longitudinal dorsal ribs are present. The sculpture consists of growth lines and transversal ribs mainly on the ventral side, sometimes also on the dorsal side. The embryonic shell is shed in adults; no septum is present; an irregular slit marks the closing of the underside of the adult shell. The aperture is slit-like; it reaches the caudal part of the shell and the borders are usually slightly thickened; there are closing knobs. An operculum is absent. The soft part can retract into the shell; when alive, long "balancers" are protruding from the posterior corners of the aperture slit, they are tapering behind the swimming animal; mouthparts and wings are protruding through the shell aperture. The lips of the mouth and the inner side of the wings are sometimes intensively coloured. The foot is transformed into two lateral swimming lobes and a posterior one; a dorsal pair of small tentacles is present; the eyes are rudimentary. The mouth is in between the wings; a proboscis is absent. The radula formula is 1-1-1. Sexual dimorphism is absent.

The following 24 taxa are now recognized in this genus:

Diacavolinia angulosa (Gray, 1850)

Diacavolinia aspina $\mathrm{n} . \mathrm{sp}$.

Diacavolinia atlantica $\mathrm{n}$. sp.

Diacavolinia bandaensis $\mathrm{n}$. sp.

Diacavolinia bicornis $\mathrm{n}$. sp.

Diacavolinia constricta n. sp. 


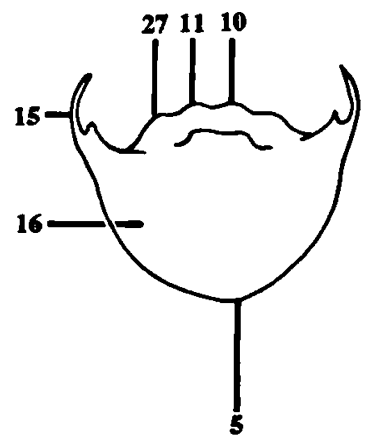

A
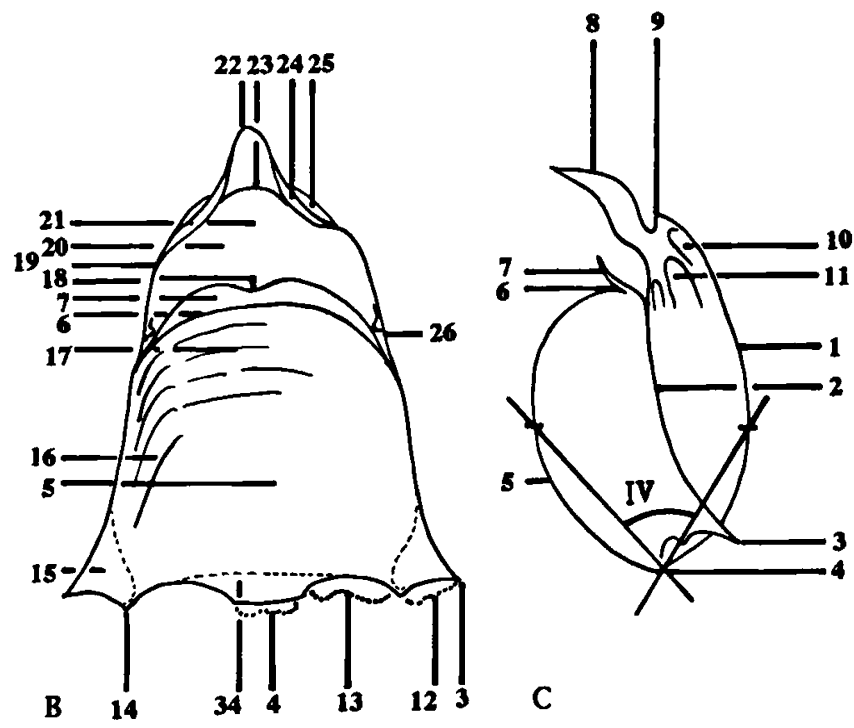

C<smiles>Cc1ccccc1C</smiles><smiles>CCCCCCC(C)C</smiles>

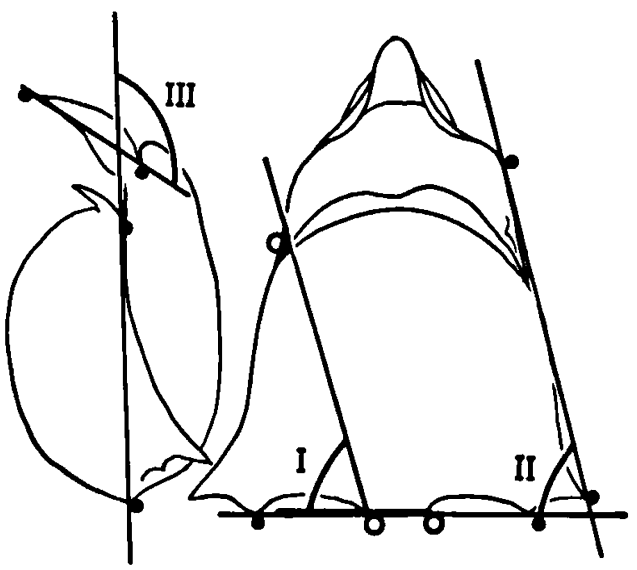

E

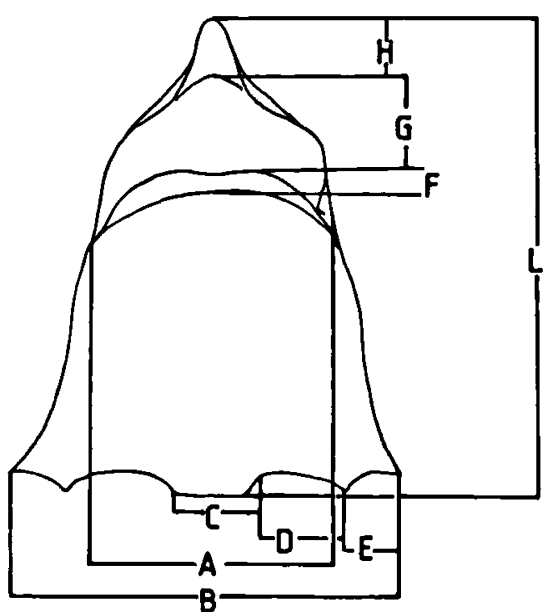

$\mathbf{F}$

Fig. 2. Diacavolinia shell from caudal (A), from ventral (B), and from lateral (C); detail of lock area from outside and with the sides opened, from inside (D); shell from lateral and ventral to show the angles measured (E); shell from ventral with measurements taken (F). Legenda: $\mathbf{A}=$ width at aperture basis, $\mathbf{B}=$ maximum width, $\mathbf{C}=$ width of joint, $\mathrm{D}=$ width of fold, $\mathrm{E}=$ lateral spine width, $\mathrm{F}=$ ventral lip height, $\mathbf{G}=$ aperture height, $\mathrm{H}=$ rostrum length, $\mathrm{L}=$ total length, $\mathrm{I}=$ lock angle, $\mathrm{II}=$ side angle, III $=$ lip angle, IV $=$ valve angle, $1=$ dorsal side, $2=$ lateral line, $3=$ spine tip, $4=$ caudal joint, $5=$ ventral side, $6=$ ventral lip basis, $7=$ ventral lip, 8 = dorsal lip, $9=$ outer hump, $10=$ central dorsal rib, $11=$ laterodorsal rib, $12=$ spine, $13=$ caudal fold, $14=$ gutter corner, $15=$ spine surface, $16=$ flank, $17=$ ventral ribs, $18=$ median lip depression, $19=$ lip belly, $20=$ aperture, $21=$ lip gutter, 22 = rostrum, $23=$ inner hump, $24=$ lip flap, $25=$ lip shoulder, $26=$ lock area, $27=$ lock rib, $28=$ main lock tubercle, $29=$ lock link, 30 = lunar lock tubercle, 31 = minor lock tubercle, 32 = secondary lock tubercle, 33 = secondary lock link, $34=$ protoconch II part. 
Diacavolinia deblainvillei $\mathrm{n} . \mathrm{sp}$.

Diacavolinia deshayesi $\mathrm{n}$. sp.

Diacavolinia elegans $\mathbf{n} . \mathbf{s p}$.

Diacavolinia flexipes (Van der Spoel, 1971)

Diacavolinia grayi $\mathrm{n}$. sp.

Diacavolinia limbata (d'Orbigny, 1836)

forma africana $\mathrm{n}$. forma

Diacavolinia limbata (d'Orbigny, 1836)

forma limbata (d'Orbigny, 1836)

Diacavolinia longirostris (De Blainville, 1821)

Diacavolinia mcgowani (Van der Spoel, 1973)

Diacavolinia ovalis $\mathbf{n} . \mathbf{s p}$.

Diacavolinia pacifica $\mathrm{n}$. sp.

Diacavolinia robusta $\mathrm{n} . \mathrm{sp}$.

Diacavolinia souleyeti $\mathrm{n}$. sp.

Diacavolinia strangulata (Deshayes, 1823)

Diacavolinia striata $\mathbf{n}$. sp.

Diacavolinia triangulata $\mathrm{n} . \mathrm{sp}$.

Diacavolinia vanutrechti $\mathrm{n}$. sp.

forma meisenheimeri $\mathbf{n}$. forma

Diacavolinia vanutrechti $\mathrm{n}$. sp.

forma vanutrechti $\mathrm{n}$. forma

In the species $D$. longirostris, $D$. angulosa, $D$. grayi, and $D$. pacifica, specimens and sometimes entire populations are found with long-spined shells and others with short-spined shells. There are no separate taxa described for these different shells since it seems to be only a difference in growth that gives the spine length variation.

The type species of the genus is presented below first; the other species follow in an arrangement according to morphological resemblance.

Diacavolinia longirostris (De Blainville, 1821)

(Figs. 3A-B; Pl. I figs. 1-4)

Refs.: Hyalaea longirostris De Blainville, 1981a: 81. Cavolinia longirostris forma longirostris Van der Spoel, 1976: 53 (synonymy); Richter, 1979: 19.

Juveniles of the Diacavolinia group, in the past indicated as "laevigata" are not considered in this study.

Type material. - The type specimens could so far not be located. Type locality. - The type locality is not exactly given, probably it is the Atlantic Ocean.

Description. - The shell length range is $7.28-5.20$

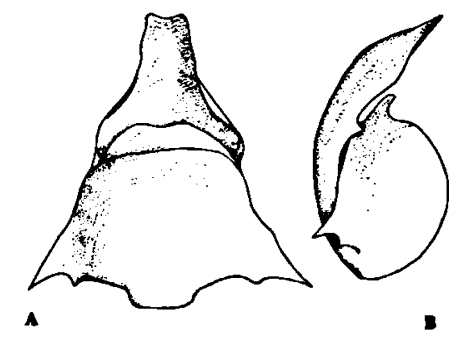

Fig. 3. Diacavolinia longirostris (De Blainville, 1821), from ventral (A) and lateral (B).

$\mathrm{mm}$ and the width range is $6.80-4.96 \mathrm{~mm}(n=20)$. The hyaline shell is triangular and it has a brown colour, especially near the ventral lip border and near the centres of the dorsal and ventral sides.

The large dorsal lip has a notch and a gutter in the broad rostrum but no constriction. In some specimens this notch may be very shallow when growth is not yet finished (Pl. I fig. 1). This phenomenon can be seen in all species that normally have a notch. The ventral lip is of moderate size and shows a distinct median depression. The sharp lateral spines are slightly bent, laterally protruding and slightly hooked; the gutter corners are large. The ventral side is globular. The 17 ventral ribs are lineshaped and thin, composed of small tubercles. The lateral lines are a little bit convex and the flanks are slightly developed. The dorsal side is slightly convex, with well-developed central rib, lateral ribs, and lock ribs. The lock area is small with a blunt or sometimes sharp main tubercle (Pl. I figs. 2-3) and small link. The lunar and minor tubercle (PI. I fig. 4) are normally developed. A second lock mechanism is present. The growth lines are strong, also on the dorsal side. A hump is absent. The protoconch II area is not far projecting; it shows a curved caudal joint of about $1.28 \mathrm{~mm}$. The caudal fold, about $1.60 \mathrm{~mm}$ in length, is nearly straight and the left and right fold make an angle with each other. There is only an indication of lip flaps; the lip bellies and lip shoulders are small. The aperture is large, the lip angle is about $135^{\circ}$, the lock angle is $77^{\circ}$, and the side angle is $66^{\circ}$.

Remarks. - As the original description was rather unclear and as the type material could not be found, this redescription restricts the species only to the 
taxon that is certainly not described under another name than "longirostris". Specimens with elongated spines, so far only found in Indo-Malayan waters, are not considered to represent a separate taxon as growth differences seem to be at hand only. Morphologically related species are: $D$. souleyet $i$, with a much more slender rostrum, $D$. limbata, a much larger species, and $D$. deblainvillei that has much more ventral ribs and shorter, more sharply hooked lateral spines.

The ventral ribs in this species are always thin but in a few specimens transversal lines on the ribs make these comb-shaped.

\section{Diacavolinia limbata (d'Orbigny, 1836)}

Refs.: Hyalaea limbata d'Orbigny, 1836-1846: 101-103 (published 1836).

Hyalea limbata d'Orbigny, 1836-1846: Pl. 6 figs. 11-15 (published 1846).

Cavolinia longirostris forma limbata Van der Spoel, 1976: 54 (synonymy).

This species is split into two formae and not into species as these two taxa merge into each other gradually in some populations.

Diacavolinia limbata (d'Orbigny, 1836)

forma limbata (d'Orbigny, 1836)

(Figs. 4A-B; Pl. I figs. 5-6)

Type material. - A lectotype and two paralectotypes are preserved in the Laboratoire de Malacologie, Muséum d'Histoire Naturelle, Paris (see Van der Spoel, 1976).

Type locality. - Expedition to the Meridional Atlantic, $1826-1833$, between $24-22^{\circ} \mathrm{N}$ and $30-33^{\circ} \mathrm{W}$.

Description. - The shell length range is $\mathbf{1 2 . 7 5 - 8 . 3 3}$ $\mathrm{mm}$ and the width range is $10.37-6.12 \mathrm{~mm}(n=$ 20). The hyaline shell has a brown purple hue; it is triangular.

The very long dorsal lip has a small notch in the broad rostrum, and a gutter but no constriction. The ventral lip is of moderate size and shows a welldeveloped median depression. The ventral side is convex and does not show the flattened area as in the forma africana. The lateral spines are slightly

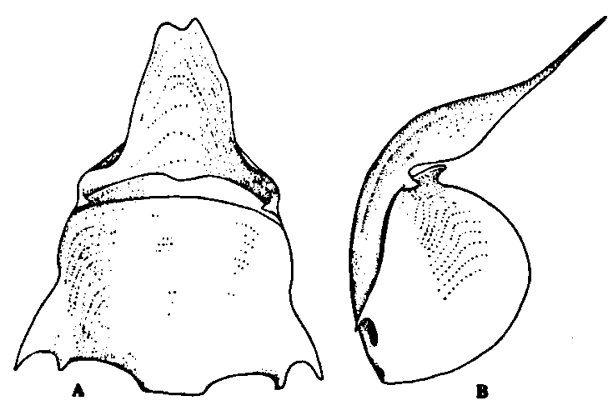

Fig. 4. Diacavolinia limbata forma limbata (d'Orbigny, 1836), holotype from ventral (A) and lateral (B).

bent, sharp, and hooked; the gutter corners are large. The 25 ventral ribs are line-shaped; there are two groups: an anterior group of 15 strong ribs and a posterior group of very weak ribs. The lateral lines are slightly convex. The flanks are not pronounced. The dorsal side is slightly convex, with well-developed central rib, lateral ribs, and lock ribs. The lock area is well developed and visible with a large main tubercle (Pl. I fig. 5) and link. There are no separate lunar or minor tubercles. In some specimens a double main tubercle is found (Pl. I fig. 6). A second lock mechanism is found at the upper level of the attachment of the spines to the lateral side. The growth lines are normally developed. A hump is absent. The protoconch II area is not far projecting, the relatively small caudal joint is about $1.87 \mathrm{~mm}$; the caudal fold, about $1.68 \mathrm{~mm}$ in length, is moon-shaped. There are no lip flaps; low and strong lip bellies and small lip shoulders are present. The aperture is wide, the lip angle is about $142^{\circ}$, the lock angle is $69^{\circ}$, and the side angle is $68^{\circ}$.

Diacavolinia limbata (d'Orbigny, 1836)

forma africana $\mathrm{n}$. forma

(Figs. 5A-B, Pl. I fig. 7)

Type material. - Holotype (ZMA Moll. 3.92.004) and 6 paratypes (ZMA Moll. 3.92.005) in ZMA.

Type locality. - AMNAPE sta. 24, trawl 2, 29 April 1980, RMT $8,29^{\circ} 48.1^{\prime} \mathrm{N} 29^{\circ} 57.5^{\prime} \mathrm{W}, 110-205 \mathrm{~m}$ depth.

Etymology. - The forma is very common off the Atlantic coasts of Africa, hence the name africana. 

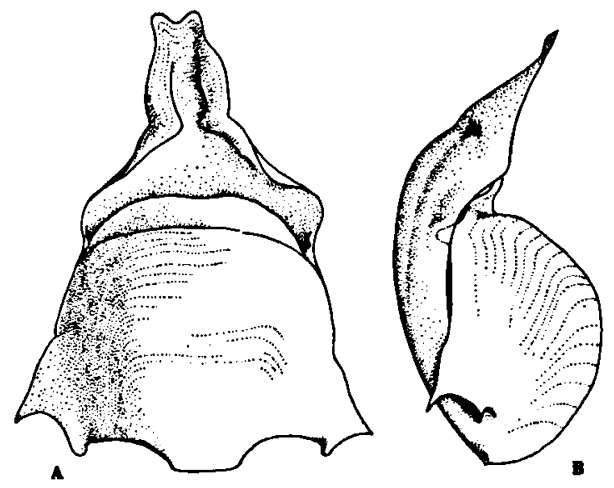

Fig. 5. Diacavolinia limbata forma africana $\mathrm{n}$. forma, holotype from ventral (A) and lateral (B).

Description. - The holotype has a shell length of $9.28 \mathrm{~mm}$ and a width of $8.16 \mathrm{~mm}$; the range for shell length is $10.40-7.84 \mathrm{~mm}$ and for width it is $8.64-7.04 \mathrm{~mm}(n=16)$. The shell is less triangular than in the preceding forma. It has a brown-purple hue and the wings are intensively purple coloured.

The dorsal lip, with notch in the broad rostrum, shows a small gutter and a constriction; there is also a small nose at the extreme tip of the lip. The ventral lip is of normal size and shows a median depression. The lateral spines are well developed and slightly bent dorsally; the gutter corners are well developed. The dorsal side is convex, the central rib and laterodorsal ribs are well developed, the lock rib is strong. The ventral ribs, 27 in number, are strongly developed, comb-shaped. The flanks are moderately developed and the lateral lines are slightly convex. The upper half of the ventral side is flattened in profile view. The lock area is visible but small and the lock mechanism is relatively large. A second lock mechanism is found at the upper level of the attachment of the spines to the lateral line (Pl. I fig. 7). The growth lines are well developed. There is no hump. The protoconch II area is not far projecting. In the holotype the caudal joint is $1.92 \mathrm{~mm}$, the caudal fold is $1.92 \mathrm{~mm}$ long and nearly straight. There are no lip flaps; the lip bellies are well developed and low, the lip shoulders are small. The aperture is well open. In the holotype the lip angle is $146^{\circ}$, the side angle is $75^{\circ}$, and the lock angle is $61^{\circ}$. The dorsal aperture rim is sharp and the ventral one is slightly thickened.

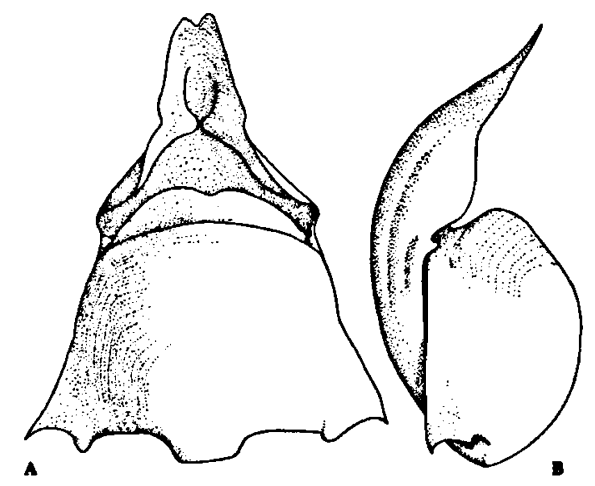

Fig. 6. Diacavolinia atlantica n. sp., holotype from ventral (A) and lateral (B).

Remarks. - This forma shows to be very variable in the development of the constriction in the rostrum. There are specimens with a constriction, and specimens without constriction but with a very long upper lip. As there are evidently intermediates between the two forms of this species, they are not separated as species but as formae. The shell length is on an average larger in the forma africana than in the forma limbata. Though the differences in shell shape between this species and $D$. atlantica are small, the striking difference in the colour of the soft part separates the two species clearly.

Diacavolinia atlantica $\mathrm{n} . \mathbf{s p}$.

(Figs. 6A-B; Pl. I fig. 8)

Type material. - Holotype (ZMA Moll. 3.92.006) and 12 paratypes (ZMA Moll. 3.92.007) in ZMA.

Type locality. - AMNAPE sta. 25, trawl 7, 30 April 1980, RMT $8,28^{\circ} 23.5^{\prime} \mathrm{N} 29^{\circ} 55.9^{\prime} \mathrm{W}, 40-100 \mathrm{~m}$ depth.

Etymology. - The occurrence in the Atlantic Ocean is expressed in the name of the species.

Description. - The holotype has a shell length of $10.37 \mathrm{~mm}$ and the width is $8.50 \mathrm{~mm}$; the length range is $10.88-8.33 \mathrm{~mm}$ and the width range is $9.60-7.14 \mathrm{~mm}(n=20)$. The hyaline shell is triangular; it has a brown hue over the whole surface. The central part of the wings is intensively brown coloured. 
The dorsal lip has a notch and constriction in the broad rostrum, which is gutter-shaped. The rather small ventral lip shows a distinct median depression. The lateral spines are slightly bent, rather long and the spine itself is sharp and hooked; the gutter corners are large. The 39 thick ventral ribs are comb-shaped. The flanks are not pronounced. The upper part of the ventral side is flattened in profile view. The dorsal side is slightly convex, with welldeveloped central and lateral ribs; the lock ribs are strong but small. The lateral lines are convex. The lock area is well developed, with large main, lunar and small minor tubercle and link. A second lock system is found at the upper level of the attachment of the spines to the lateral lines. The growth lines are normally developed. A hump is absent. The protoconch II area is slightly projecting. In the holotype the caudal joint is $1.44 \mathrm{~mm}$; the caudal fold, $2.21 \mathrm{~mm}$ in length, is straight. There are no lip flaps; the low lip bellies are well developed and the lip shoulders are moderately developed. The aperture is rather narrow. In the holotype the lip angle is $136^{\circ}$, the lock angle is $74^{\circ}$, and the side angle is $75^{\circ}$.

Remarks. - This species is very close to $D$. limbata forma limbata, and differs only in having a more narrow aperture by the bending of the dorsal shell lip. As we did found the two species separated, they can not be morphs of one species. The discovery of colour difference in the soft parts of this and the preceding species initiated the present study. The present species and $D$. limbata with its two formae have been consistently named "limbata" in older literature. They form a group of large taxa comparable in size to $D$. triangulata from the Pacific Ocean.

\section{Diacavolinia vanutrechti n. sp.}

As there are strong differences in size and rostrum development between the Indo-Malayan and the open Pacific populations, this species is considered to be composed of two formae, probably a neritic and an open ocean forma.

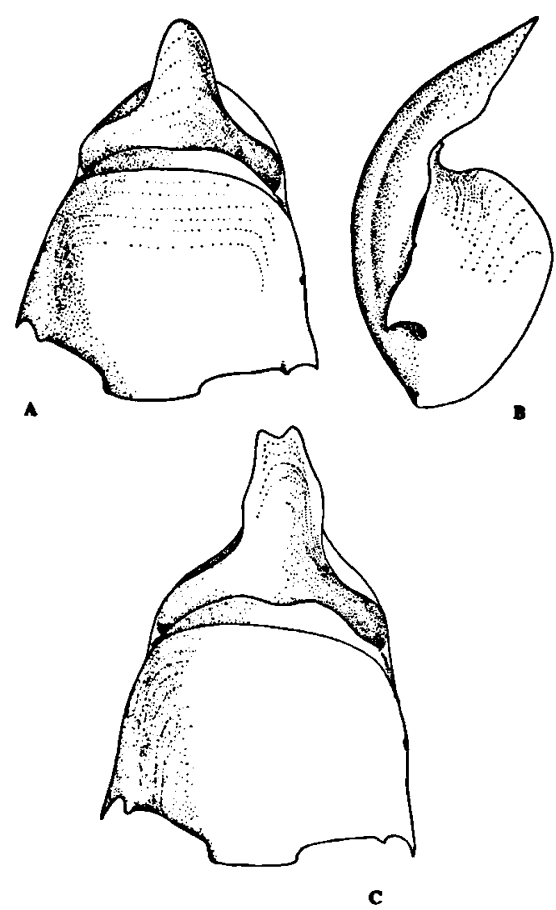

Fig. 7. Diacavolinia vanutrechti $\mathrm{n}$. sp. forma vanutrechti $\mathrm{n}$. forma, holotype from ventral (A) and lateral (B), and paratype from ventral (C).

Diacavolinia vanutrechti $\mathrm{n}$. sp. forma vanutrechti $\mathrm{n}$. forma

(Figs. 7A-C; Pl. I figs. 9-10)

Type material. - Holotype (ZMUC GAS 153) and 5 paratypes (ZMUC GAS 154) in ZMUC, 3 paratypes (ZMA Moll. 3.92.008) in ZMA.

Type locality. - Dana Exped., sta. 3731 iv, $14^{\circ} 37^{\prime} \mathrm{N} 119^{\circ} 52^{\prime} \mathrm{W}$, 0-100 m depth.

Etymology. - The name is given in honour of our friend and colleague Dr. W.L. van Utrecht, who kindly assisted the first author during many expeditions and research projects.

Description. - The holotype has a shell length of $4.36 \mathrm{~mm}$, the width is $3.64 \mathrm{~mm}$, the length range is $4.88-3.76 \mathrm{~mm}$ and the width range is $3.64-2.40$ $\mathrm{mm}(n=14)$. The hyaline shell is not very triangular and brown all over.

The dorsal lip has usually no notch in the slender rostrum; there is no constriction, a gutter is present. In a few specimens and in one paratype a notch is 
found (Fig. 7C). The ventral lip is of moderate size and shows a clear median depression. The lateral spines are strongly bent and hook-shaped; the gutter corners are small. The 14 thin ventral ribs are slightly comb-shaped. The lateral lines are convex and the flanks are well developed. The dorsal side is convex, with weak central rib, laterodorsal ribs, and lock ribs. The lock area is small, showing a small main tubercle and link, the lunar and minor tubercle are of the same size (Pl. I figs. 9-10). A second lock mechanism is present half in between the lateral spine and the normal lock area. The growth lines are normally developed. A hump is absent. The protoconch II area is moderately projecting. In the holotype the small caudal joint is $1.08 \mathrm{~mm}$; the caudal fold, $1.00 \mathrm{~mm}$ in length, is straight or even convex in some specimens and the left and right fold form an angle. There are no lip flaps; weak lip bellies and very small lip shoulders are present. The aperture is wide. In the holotype the lip angle is $150^{\circ}$, the lock angle is $76^{\circ}$, and the side angle is $73^{\circ}$.

Remarks. - Especially representatives without a notch resemble $D$. elegans, but the larger lip shoulder and the prominent second lock in the present species mark the differences.

Diacavolinia vanutrechti $\mathrm{n}$. sp. forma meisenheimeri $\mathrm{n}$. forma (Figs. 8A-B; Pl. I fig. 11)

Type material. - The holotype (ZMUC GAS 155) is preserved in the ZMUC.

Type locality. - Dana Exped., sta. 3580 iii, 18 $53^{\prime} \mathrm{S}$ $163^{\circ} 02.5^{\prime} \mathrm{W}, 0-300 \mathrm{~m}$ depth.

Etymology. - The name is given in honour of Dr. J. Meisenheimer who was the first (in 1905) to give a full overview of the distribution of pteropods.

Description. - The holotype has a shell length of $6.80 \mathrm{~mm}$, the width is $4.16 \mathrm{~mm}$, the length range is $7.76-4.32 \mathrm{~mm}$ and the width range is $4.96-2.96$ $\mathrm{mm}(n=22)$. The hyaline shell is not triangular and colourless.

The dorsal lip has usually a notch in the slender
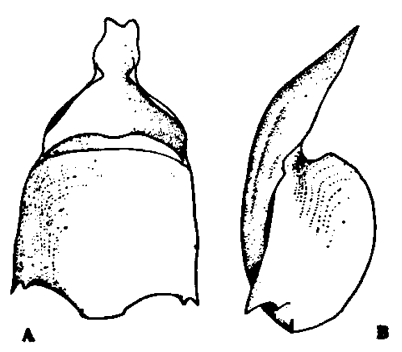

Fig. 8. Diacavolinia vanutrechti $\mathrm{n}$. sp. forma meisenheimeri $\mathrm{n}$ forma, holotype from ventral (A) and lateral (B).

rostrum. There is sometimes a constriction; a gutter is present. The ventral lip is of moderate size and shows a clear median depression. The lateral spines are strongly bent and hook-shaped; the gutter corners are small. The 21 thin ventral ribs are slightly comb-shaped. The lateral lines are convex and the flanks are moderately developed. The dorsal side is somewhat flattened, with moderate central rib, laterodorsal ribs and lock ribs. The lock area is small, showing a small main tubercle on a ridge, a small lunar, and very small minor tubercle; the link is also small. A second lock mechanism half in between the lateral spine and the normal lock area is present. The growth lines are normally developed. A hump is absent. The protoconch II area is moderately projecting with a moderate caudal joint. In the holotype the caudal joint is $1.12 \mathrm{~mm}$; the caudal fold, $1.20 \mathrm{~mm}$ in length, is slightly moon-shaped and the left and right fold form an angle. There are no lip flaps; weak lip bellies and moderate lip shoulders are present. The aperture is wide. In the holotype the lip angle is $152^{\circ}$, the lock angle is $75^{\circ}$, and the side angle is $83^{\circ}$.

Diacavolinia elegans n. sp.

(Figs. 9A-B, D; Pl. I fig. 12)

Type material. - Holotype (ZMUC GAS 156) in ZMUC and four adult and one juvenile paratypes (ZMA Moll. 3.92.009) in ZMA.

Type locality. - Dana Exped., sta. 375 iv, 12 July 1929, $3^{\circ} 40.5^{\prime} \mathrm{N} 137^{\circ} 53^{\prime} \mathrm{E}, 0-100 \mathrm{~m}$ depth.

Etymology. - The elegant shape of the dorsal lip without notches and constrictions was the reason to choose the name elegans for the species. 


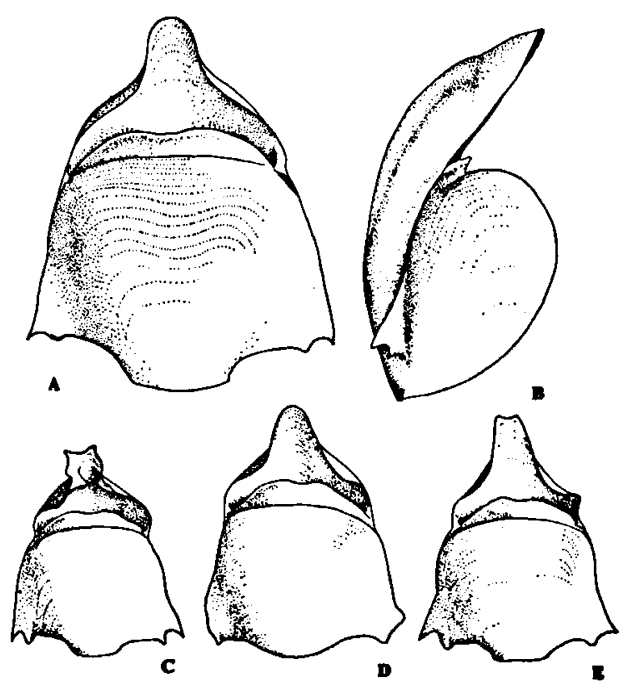

Fig. 9. Diacavolinia elegans $n$. sp., holotype from ventral (A) and lateral (B); for comparison, D. ovalis n. sp. (C), D. elegans n. sp. (D), and $D$. deblainvillei $\mathrm{n}$. sp. (E) from the same sample, figured with the same magnification, in ventral view.

Description. - The holotype has a shell length of $4.44 \mathrm{~mm}$ and a width of $3.52 \mathrm{~mm}$, the range for shell length is $6.16-3.36 \mathrm{~mm}$ and for width 5.44-2.80 mm $(n=24)$. The colourless, hyaline shell is not very triangular.

The dorsal lip has no notch in its rostrum and no constriction. The rostrum is short so that it does not look broad and it is hollow though a well separated gutter is not developed. The ventral lip is of medium size and shows a moderate median depression. The lateral spines bend only slightly dorsally and project laterally; the shape is hooked. The dorsal side is slightly convex, the central dorsal rib is well developed, the laterodorsal ribs are moderately developed and the lock ribs are small. The ventral ribs in the type material are weakly developed, 18 in number and line-shaped; in some non-type specimens from the Banda Sea these ribs are stronger developed, up to 24 in number. The flanks are not pronounced; the lateral lines are slightly convex. The lock area is visible and the lock mechanism is of medium size. The main tubercle is hooked, the lunar tubercle is small and the minor tubercle is absent. The second lock system is, though rudimentary, still present (Pl. I fig. 12). The growth lines are normally developed. There is no hump. The pro-

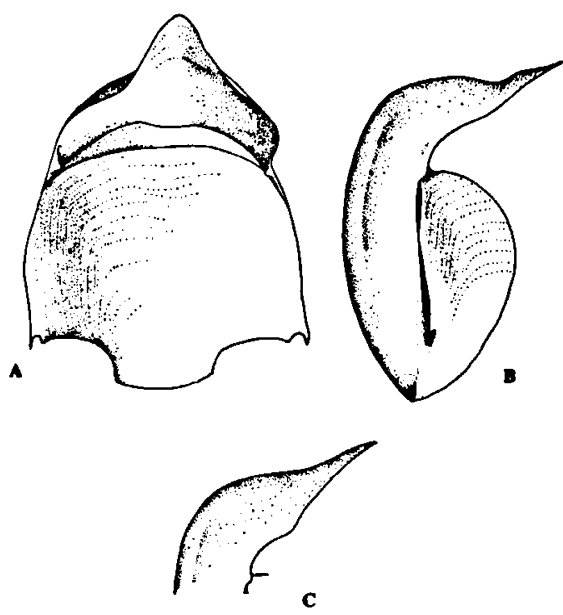

Fig. 10. Diacavolinia robusta $\mathrm{n}$. sp., holotype from ventral (A) and lateral (B), and rostrum of paratype (C).

toconch II area is moderately projecting. In the holotype the caudal joint, $1.16 \mathrm{~mm}$ in length, is clearly visible; the caudal fold, $0.84 \mathrm{~mm}$ in length, is moon-shaped, and the left and right fold form in ventral view a small angle. There are no lip flaps; the lip bellies are weak and the lip shoulders are small. The aperture is well open. In the holotype the lip angle is $161^{\circ}$, the side angle is $74^{\circ}$, and the lock angle is $73^{\circ}$. The dorsal aperture rim is sharp and the ventral one is slightly thickened.

Remarks. - The closest relatives are D. ovalis (Fig. 9C) and $D$. deblainvillei (Fig. 9E) which in general shape resemble strongly $D$. elegans (Fig. 9D). They differ, however, in having a notch or a constriction. The present species may be rather easily confused with juveniles of other species. Presence of a fully developed lock mechanism and thickening of the ventral lip rim should be controlled to determine the adult stage of the shell before it can be identified as D. elegans.

Diacavolinia robusta n. sp.

(Figs. 10A-C; Pl. I fig. 13)

Type material. - Holotype (ZMUC GAS 157) and I paratype (ZMUC GAS 158) in ZMUC, 2 paratypes (ZMA Moll. 3.92.010) in ZMA.

Type locality. - Dana Exped., sta. 3556 viii, 14 September 1928, $2^{\circ} 52^{\prime} \mathrm{N} 87^{\circ} 38^{\prime} \mathrm{W}, 0.50 \mathrm{~m}$ depth. 
Etymology. - The species has no long spines or rostrum and makes also by its square shape a robust impression.

Description. - The holotype has a shell length of $3.84 \mathrm{~mm}$, the width is $3.04 \mathrm{~mm}$, the length range is $5.36-3.84 \mathrm{~mm}$ and the width range is $4.48-3.04$ $\mathrm{mm}(n=10)$. The hyaline shell is not very triangular; it has a brown colour especially along the aperture rim, the joint, and the ventral side except for its borders.

The depressed dorsal lip has no notch in the rostrum and no constriction, but a gutter is present and a faint indication of a nose is found. The rostrum is not very long and not broad. The moderate ventral lip shows a small median depression. The lateral spines do not bend, they have sharp little hooks; the gutter corners are small. The 19 clear but thin ventral ribs are line-shaped. The lateral lines are convex and the flanks are well developed. The dorsal side is somewhat flattened, with weak central and laterodorsal ribs; the lock ribs are weak. The lock area is well developed with small main, lunar and minor tubercles and link. A second lock system is absent. The growth lines are normal. The hump is very small or absent as in the paratypes (Fig. 10C); an inner hump is never formed. The protoconch II area is far projecting. In the holotype, the convex caudal joint is $0.96 \mathrm{~mm}$; the caudal fold, $0.72 \mathrm{~mm}$ in length, is slightly moon-shaped. There are no lip flaps; strong lip bellies and strong lip shoulders are developed. The aperture is narrow. In the holotype the lip angle is $126^{\circ}$, the lock angle is $76^{\circ}$, and the side angle is $85^{\circ}$.

Diacavolinia bicornis $\mathrm{n} . \mathrm{sp}$.

(Figs. 11A-B; Pl. I fig. 14)

Ref.: Cavolinia longirostris forma limbata; Richter, 1979: 20-21, Pl. 3 figs. 34-36.

Type material. - Holotype (ZMUC GAS 159) in ZMUC, 2 paratypes (ZMA Moll. 3.92.011) in ZMA.

Type locality. - Dana Exped., sta. 3922 v, 12 December 1929, $3^{\circ} 45^{\prime} \mathrm{S} 56^{\circ} 33^{\prime} \mathrm{E}, 0-50 \mathrm{~m}$ depth.

Etymology. - The name is given as this species has a large notch, projecting like two horns in front of the shell.

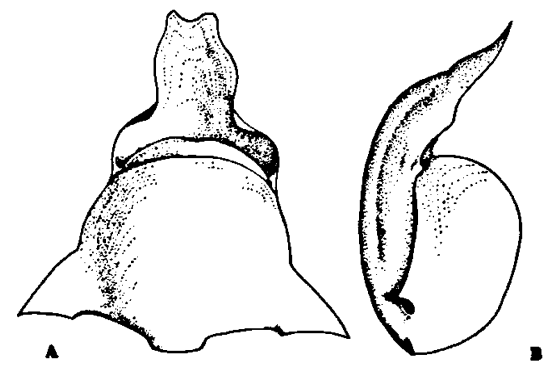

Fig. 11. Diacavolinia bicornis n. sp., holotype from ventral (A) and lateral (B).

Description. - The holotype has a shell length of $7.84 \mathrm{~mm}$, the width is $7.84 \mathrm{~mm}$, the length range is $7.84-4.60 \mathrm{~mm}$ and the width range is 7.84-3.88 $\mathrm{mm}(n=4)$. The hyaline shell is triangular; it has a brown hue especially on lower ventral and dorsal side.

The dorsal lip has no notch in the broad rostrum, and no constriction, but a gutter is present. Both ventral and dorsal lip show a thicker rim. The ventral lip is of moderate size and shows a weak median depression. The lateral spines do not bend, they are sharp lanceolate in shape; the gutter corners are small. The thin ventral ribs are line-shaped, only 5 were distinct in the holotype. The lateral lines are slightly convex and the flanks are not very clear. The dorsal side is convex, with well-developed central and lateral ribs; the lock rib is moderately developed. The lock area is of an average size like the main tubercle and link; the lunar and minor tubercle are rather small and all tubercles are placed close together (Pl. I fig. 14). A second lock mechanism is present (not figured). The growth lines are normal. A hump is absent. The protoconch II area is not far projecting. In the holotype it has a very small caudal joint of $1.20 \mathrm{~mm}$ (only $20 \%$ of shell width); the caudal fold, $2.00 \mathrm{~mm}$ in length, is moon-shaped. There is sometimes an indication of lip flaps; welldeveloped lip bellies are present and the lip shoulders are very small. The aperture is rather narrow. In the holotype the lip angle is $150^{\circ}$, the lock angle is $74^{\circ}$, and the side angle is $66^{\circ}$.

Remarks. - The closest relative is $D$. longirostris but that species has a smaller rostrum and the spines are bent dorsally. 

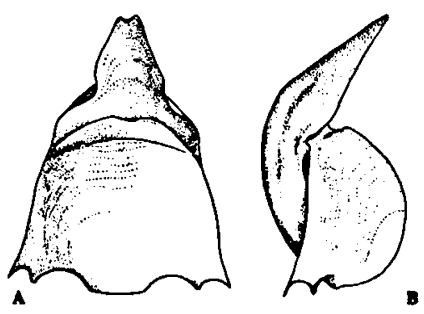

Fig. 12. Diacavolinia deblainvillei $\mathrm{n}$. sp., holotype from ventral (A) and lateral (B).

Diacavolinia deblainvillei $\mathrm{n}$. sp.

(Figs. 9E, 12A-B; Pl. I fig. 15)

Type material. - Holotype (ZMA Moll. 3.92.012) and 11 paratypes (ZMA Moll. 3.92.013) in ZMA.

Type locality. - Deepwater Dumpsite 106 project, cruise 2, sta. $67-\mathrm{M}$, July $1975,38^{\circ} 45^{\prime} \mathrm{N} 72^{\circ} 20^{\prime} \mathrm{W}, 0-100 \mathrm{~m}$ depth.

Etymology. - The name is given in honour of Dr. H.M.D. de Blainville who described many pteropod species.

Description. - The holotype has a shell length of $6.08 \mathrm{~mm}$ and a width of $4.48 \mathrm{~mm}$, the range for shell length is $6.88-3.60 \mathrm{~mm}$ and for width $5.36-3.04 \mathrm{~mm}(n=46)$. The hyaline shell is not very triangular and colourless.

The dorsal lip has a notch in the rostrum but no constriction; there is a shallow gutter. The ventral lip is of normal size and shows a median depression. The ventral side is convex. The short lateral spines bend dorsally; they are hooked and sharp. The dorsal side is convex, the central rib and laterodorsal ribs are well developed and the lock ribs are well developed though small. The ventral ribs, 23 in number, are strongly developed, comb-shaped. The flanks are present. The lock area is small. Main and lunar tubercles are normal, the minor tubercle is absent. A second lock system is present. The growth line pattern is normally developed. There is no hump. The protoconch II area is not far projecting. In the holotype the caudal joint is $1.20 \mathrm{~mm}$; the caudal fold is $1.20 \mathrm{~mm}$, somewhat moon-shaped. There are no lip flaps; the lip bellies are pronounced and the lip shoulders are rather small. The aperture is wide. In the holotype the lip angle is smaller than $150^{\circ}$, the side angle is $80^{\circ}$, and the lock angle is $78^{\circ}$.

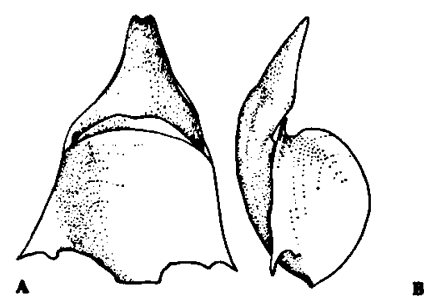

Fig. 13. Diacavolinia souleyeti $\mathrm{n}$. sp., holotype from ventral (A) and lateral (B).

The aperture rim is sharp and the ventral rim is slightly thicker.

Remarks. - The morphologically closest species $D$. souleyeti differs from $D$. deblainvillei in having a larger lip angle and in lacking a lip shoulder.

Diacavolinia souleyeti n. sp.

(Figs. 13A-B, Pl. I fig. 16)

Type material. - Holotype (ZMUC GAS 160) in ZMUC and one paratype (ZMA Moll 3.92.014) in ZMA.

Type locality. - Dana Exped., sta. 3860 xi-xv, 20 October 1929, $2^{\circ} 57^{\prime} \mathrm{S} 99^{\circ} 36^{\prime} \mathrm{E}, 0-100 \mathrm{~m}$ depth.

Etymology. - The name is given in honour of Dr. F.L.A. Souleyet who described many pteropod species.

Description. - The holotype has a shell length of $6.00 \mathrm{~mm}$ and a width of $4.72 \mathrm{~mm}$, the range for shell length is $6.64-6.00 \mathrm{~mm}$ and for width it is 4.96-3.92 $\mathrm{mm}(n=3)$. The colourless, hyaline shell is triangular.

The dorsal lip has a small notch in a slender rostrum; there is no pronounced gutter and no constriction in the rostrum. The ventral lip is of normal size and shows a clear median depression. The lateral spines, bending dorsally, are sharp and hooked. The dorsal side is convex, the central and laterodorsal ribs are well developed and the lock ribs are small. The ventral ribs, 28 in number, are pronounced thin lines, in which regularly arranged tubercles can be distinguished. The flanks are not pronounced and the lateral lines are concave. The lock area is clearly visible; the lock mechanism is of 
medium size and the main tubercle is not pointed but forms a broad fold (Pl. I fig. 16). Due to lack of material no data are available on the second lock system. The growth lines are normally developed. There is no hump. The protoconch II area is moderately projecting. In the holotype the caudal joint is $1.12 \mathrm{~mm}$ and the caudal fold is $1.12 \mathrm{~mm}$ and nearly straight. There are no lip flaps; the lip bellies are weak and the lip shoulders are very small or absent. The aperture is well open. In the holotype the lip angle is $158^{\circ}$, the side angle is $76^{\circ}$, and the lock angle is $69^{\circ}$. The aperture rims are sharp.

\section{Diacavolinia striata n. sp.}

(Figs. 14A-B; Pl. I fig. 17)

Type material. - Holotype (ZMUC GAS 161) and 6 paratypes (ZMUC GAS 162) in ZMUC, 8 paratypes (ZMA Moll. 3.92.015) in ZMA.

Type locality. - Dana Exped., sta. 3860 xi-xv, 20 October 1929, $2^{\circ} 57^{\prime} \mathrm{S} 99^{\circ} 36^{\prime} \mathrm{E}, 0-400 \mathrm{~m}$ depth.

Etymology. - The name is given as the shell looks entirely striated by the very strong rib pattern.

Description. - The holotype has a shell length of $4.56 \mathrm{~mm}$ and a width of $3.12 \mathrm{~mm}$, the range for shell length is 5.60-3.92 $\mathrm{mm}$ and for width $4.24-2.88 \mathrm{~mm}(n=15)$. The hyaline shell is triangular and colourless.

The dorsal lip has a notch in the rostrum; there is a shallow gutter but no constriction. The ventral lip is of normal size and shows a clear median depression. The reduced, rounded, lateral spines do not bend dorsally. The dorsal side is flattened, the central dorsal rib is well developed and the laterodorsal ribs and lock ribs are moderately developed. The ventral ribs, 19 in number, are strongly developed thin lines; the same type of ribs covers the dorsal side. This constitutes a striking difference with $D$. aspina. The flanks are slightly developed and the lateral lines are nearly straight. The lock area is small. Main, lunar and minor tubercle are normally developed. A second lock system is, though also small, present. The growth line pattern is taken over by the ribs on ventral and dorsal sides. There is a vague indication of a hump. The pro-
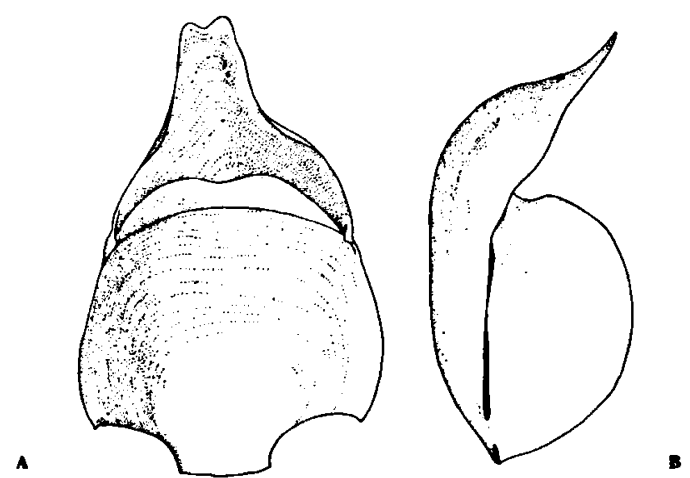

Fig. 14. Diacavolinia striata n. sp., holotype from ventral (A) and lateral (B).

toconch II area is distinctly projecting. In the holotype the caudal joint is $1.04 \mathrm{~mm}$; the caudal fold is $1.04 \mathrm{~mm}$ and nearly straight, the left and right fold make in ventral view an angle with each other. There are no lip flaps; the lip bellies are moderately developed and the lip shoulders are very small. The aperture is wide. In the holotype the lip angle is $149^{\circ}$, the side angle is 80 to $90^{\circ}$, and the lock angle is $74^{\circ}$. The dorsal aperture rim is sharp and the ventral rim is slightly thickened.

Diacavolinia pacifica $\mathrm{n}$. sp.

(Figs. 15A-D; Pl. II figs. 18-19)

Type material. - Holotype (ZMA Moll. 3.92.016) and 2 paratypes (ZMA Moll. 3.92.017) in ZMA.

Type locality. - Snellius II Exped., sta. 33 cast 2, 6 August 1984, $06^{\circ} 29.9^{\prime} \mathrm{S} 131^{\circ} 09.2^{\prime} \mathrm{E}, 98-280 \mathrm{~m}$ depth.

Etymology. - This species seems to occur mainly in the Pacific Ocean, hence the name pacifica.

Description. - The holotype has a shell length of $4.40 \mathrm{~mm}$ and the width is $4.16 \mathrm{~mm}$, the length range is $4.76-3.92 \mathrm{~mm}$ and the width range is $4.32-3.84$ $\mathrm{mm}(n=11)$. The hyaline shell is not very triangular; it has a brown hue, especially near lock and hump and on the dorsal side.

The dorsal lip has a notch in the rather broad rostrum and a small gutter, but no constriction; the inner hump is pronounced but not continuous with the underside of the lip shoulders, as in $D$. angu- 

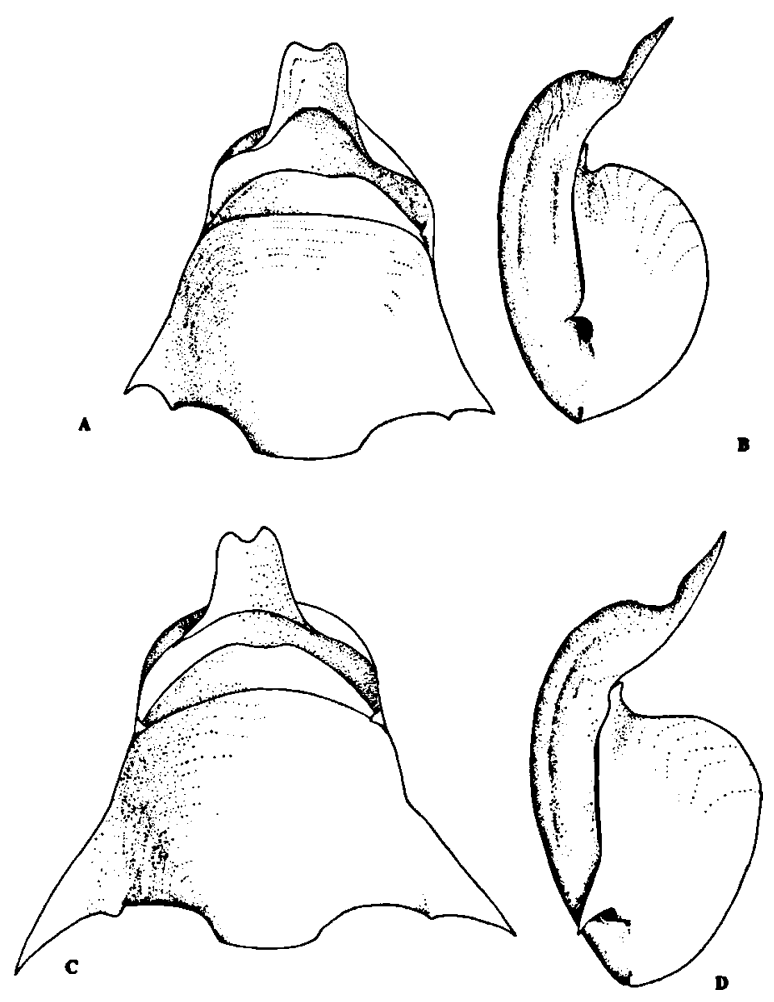

Fig. 15. Diacavolinia pacifica n. sp., holotype in ventral view (A), lateral view (B), long-spined form from ventral (C) and lateral (D).

losa. In some specimens a flat nose is present. The ventral lip is large and shows a clear median depression. The lateral spines are straight, projecting laterally except for the right spine that bends slightly dorsally in some specimens. The spines are sharp and hooked; the gutter corners are large. Like in $D$. angulosa, populations with short-spined shells (Fig. 15A) and with long-spined shells (Fig. 15C) are found. No special taxa for both forms are proposed as growth seems the only factor causing this difference. The 15 thin ventral ribs are showing vaguely a comb-like shape; the 5 ribs near the aperture are much stronger than the other ones. The lateral lines are nearly straight and the flanks are moderately developed. The dorsal side is convex with weak central rib, laterodorsal ribs, and lock ribs. The lock area is of moderate size, like the main tubercle and link. The lunar tubercle is well developed, the minor tubercle is reduced (Pl. II fig. 18). The same lock mechanism is found in the long-spined form (Pl. II fig. 19). There is no second lock mechanism. The growth lines are well developed and there are about 10 stronger ones at the top of the dorsal side. A hump is present with a strongly developed inner hump. The protoconch II area is moderately projecting. In the holotype the caudal joint is $\mathbf{0 . 9 6}$ $\mathrm{mm}$ and the caudal fold, $0.96 \mathrm{~mm}$ in length, is nearly straight. There are no lip flaps; well-developed lip bellies and moderate lip shoulders are present. The aperture is narrow. In the holotype the lip angle is $143^{\circ}$, the lock angle is $76^{\circ}$, and the side angle is $70^{\circ}$.

Remarks. - Morphologically $D$. angulosa is the closest relative, but the present species has a more hollow rostrum and the shell is triangular in ventral view which is different in $D$. angulosa.

Diacavolinia aspina $\mathrm{n} . \mathrm{sp}$.

(Figs. 16A-B, Pl. II fig. 20)

Type material. - Holotype (ZMUC GAS 163) and 9 paratypes in ZMUC (ZMUC GAS 163), 12 paratypes (ZMA Moll. 3.92.018) in ZMA.

Type locality. - Dana Exped., sta. 3860 xi-xv, 20 October 1929, $2^{\circ} 57^{\prime} \mathrm{S} 99^{\circ} 36^{\prime} \mathrm{E}, 0-400 \mathrm{~m}$ depth.

Etymology. - The shell has no projecting spines, hence the name.

Description. - The holotype has a shell length of $4.80 \mathrm{~mm}$ and a width of $3.48 \mathrm{~mm}$, the range for shell length is $5.04-3.12 \mathrm{~mm}$ and for width it is $3.60-2.48 \mathrm{~mm}(n=22)$. The colourless, hyaline shell is not very triangular.

The dorsal lip has no notch in the broad rostrum; there is no gutter and no constriction. The ventral lip is of normal size and shows a moderate median depression. The lateral spines are reduced and do not bend dorsally; they are rounded. The dorsal side is flattened, the central rib and laterodorsal ribs are moderately developed and the lock ribs are small. Among the ventral ribs, the five near the aperture are strongly developed and about eight more posteriorly are only weakly developed; they are all line-shaped. The flanks are slightly devel- 


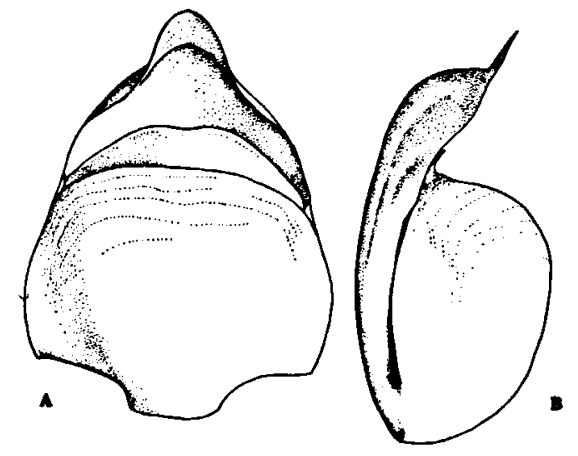

Fig. 16. Diacavolinia aspina n. sp., holotype from ventral (A) and lateral (B).

oped; the lateral lines are slightly concave. The lock area is visible and the lock mechanism is of small size. The main tubercle is high and conical, the lunar one is normal, and the minor one is strongly reduced. A second lock system is visible but rudimentary. The growth lines are normally developed except for the anterior part of the dorsal side where they are stronger developed, forming about 10 ribs. There is a clear but shallow hump. The protoconch II area is moderately projecting. In the holotype the caudal joint is $1.00 \mathrm{~mm}$ and the caudal fold is $1.00 \mathrm{~mm}$ and nearly straight, the left and right fold form in ventral view an angle. There are no lip flaps; the lip bellies are weak and the lip shoulders are small. The aperture is well open. In the holotype the lip angle is $158^{\circ}$, the side angle is $75^{\circ}$, and the lock angle is $69^{\circ}$. The aperture rim is sharp.

Remarks. - $D$. aspina can not be a juvenile of $D$. striata though the former is somewhat smaller, but the hump in $D$. aspina is not found in D. striata and it can not disappear during growth.

\section{Diacavolinia grayi n. sp.}

(Figs. 17A-B; Pl. II fig. 21)

Type material. - Holotype (ZMA Moll. 3.92.019) and 8 paratypes (ZMA Moll. 3.92.020) in ZMA.

Type locality. - Banda Sea, Snellius II Exped., sta. C trawl 2, 28 August $1984,5^{\circ} 22.8^{\prime} \mathrm{S} 130^{\circ} 0 \mathrm{~S}^{\prime} \mathrm{E}, 90-196 \mathrm{~m}$ depth.

Etymology. - The name is given in honour of Dr. J.E. Gray, author of the species given below.

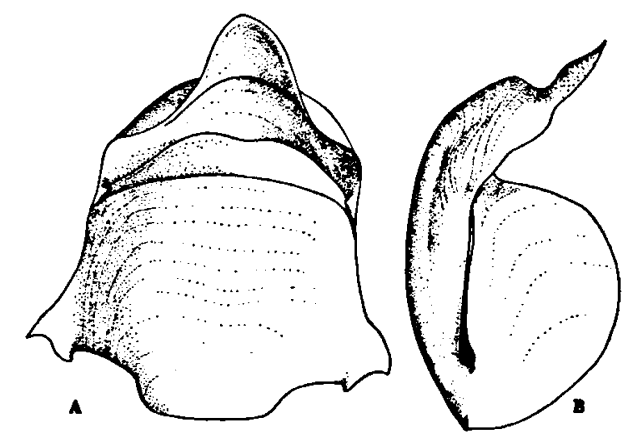

Fig. 17. Diacavolinia grayi n. sp., holotype from ventral (A) and lateral (B).

Description. - The holotype has a shell length of $4.24 \mathrm{~mm}$ and a width of $3.82 \mathrm{~mm}$, the length range is $5.36-3.16 \mathrm{~mm}$ and the width range is $5.28-2.40$ $\mathrm{mm}(n=10)$. The hyaline shell is triangular; it has a brown hue over the entire surface, especially along the dorsal ribs and there are dark spots marking the closing apparatus in the aperture.

The dorsal lip has no notch in the broad rostrum and no constriction; a gutter is present and the inner hump is strongly developed. A nose comparable to that in $D$. angulosa is developed. The ventral lip is large and shows a clear median depression. The lateral spines are not bent, they are short, sharp, and hooked; the gutter corners are moderately developed. The 16 well-developed ventral ribs are thin, line-shaped. The lateral lines are straight; flanks are present. The dorsal side is flattened, with strong central rib and weak laterodorsal ribs; the lock ribs are weak. The lock area, the main tubercle, and the link are rather small. The lunar tubercle is normal and the minor tubercle is absent. There is no second lock system. The growth lines are well developed and on the dorsal side some ribs are found as well. A hump is present with strong inner hump. The protoconch II area is broad, with a not far projecting caudal joint. In the holotype the caudal joint is $1.08 \mathrm{~mm}$ and the caudal fold, $0.80 \mathrm{~mm}$ long, is nearly straight. There are no lip flaps but pronounced lip bellies; the lip shoulders are large. The aperture is narrow. In the holotype the lip angle is $140^{\circ}$, the lock angle is $70^{\circ}$, and the side angle is $75^{\circ}$. Both ventral and dorsal rims are thick. 
Remarks. - Like in the next species both shells with long spines and short-spined shells are found. As this is probably only due to growth, no special taxa are described for these different populations.

\section{Diacavolinia angulosa (Gray, 1850)}

(Figs. 18A-D; Pl. II figs. 22-23)

Refs.: Cavolina angulosa (ms. Eydoux \& Souleyet) Gray, 1850: 8.

Cavolinia longirostris forma angulosa; Van der Spoel, 1976: 54 (more synonymy).

Cavolinia angulosa; Richter, 1979: 19.

Type material. - A lectotype and 3 paralectotypes are preserved in the Laboratoire de Malacologie, Muséum National d'Histoire Naturelle, in Paris.

Type locality. - The type locality is herewith restricted to the Indian Ocean (it was originally Indian Ocean with 4 specimens, Atlantic Ocean with 6 specimens, and China Sea with 3 specimens).

Description. - The shell length range is 4.80-3.00 $\mathrm{mm}$ and the width range is $3.72-2.32 \mathrm{~mm}(n=$ 53). The transparent shell is rather triangular; it has a brown colour, especially near the hump, the dorsal lip, the joint, and near the central part of dorsal and ventral side.

The dorsal lip has a notch in the broad rostrum, but no constriction; very characteristic is the nose placed in the middle of the rostrum. Owing to the strong inner hump, which is continuous with the underside of the lip shoulder, the central dorsal rib is not continuous in the rostrum. The ventral lip is of moderate size and shows a clear median depression. The lateral spines are perfectly straight and point laterally; they are hooked and have a sharp tip in the holotype (Figs. 18A-B); in some populations the lateral spines are reduced (Figs. 18C-D). The gutter corners are small. The 18 ventral ribs are thin and line-shaped; the anterior part of the shell has no ribs. The dorsal side is convex, with well-developed central rib and laterodorsal ribs; the lock ribs are small though rather thick. The lock area is clearly visible with a small main tubercle and link. The lunar tubercle is well developed, the minor tubercle is absent (Pl. II fig. 23a) or sometimes replaced by
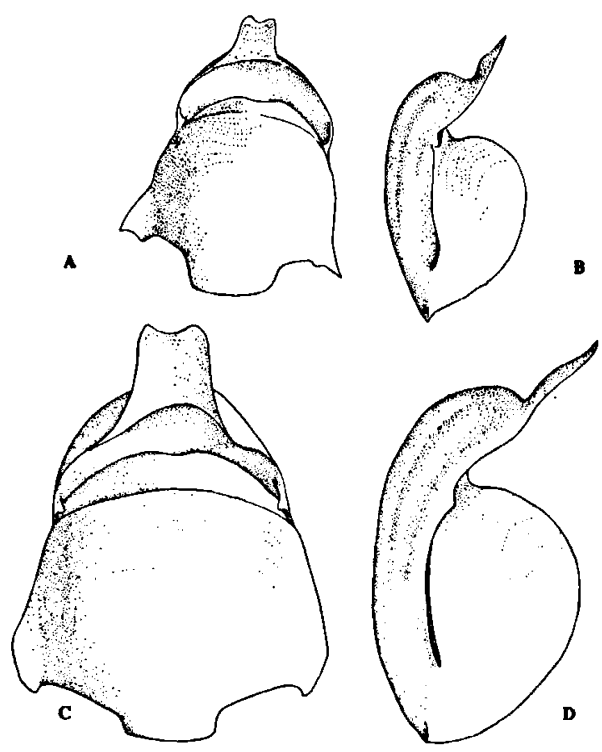

Fig. 18. Diacavolinia angulosa (Gray, 1850), from ventral (A) and lateral (B); specimen with reduced spines from ventral (C) and lateral (D).

a hole (Pl. II fig. 22). A second lock mechanism is absent although a slight irregularity in the laterodorsal margin of the aperture may be a rudiment of it; in the N.W. Pacific specimens small tubercles of the second lock system are found and in these the reduction of the minor tubercle does not occur (PI. II fig. 23b). The growth lines are normally developed. A strong hump is present with a marked inner hump. On the dorsal side, especially near the hump, strong transversal ribs are found. These ribs, about 14 in number, are imbricate. The protoconch II area is strongly projecting with a clear caudal joint of about $1.04 \mathrm{~mm}$. The caudal fold, about $0.66 \mathrm{~mm}$ in length, is moon-shaped and the left and right fold make in ventral view an angle. There are no lip flaps; the lip bellies are moderate and the lip shoulders are small as they continue directly into the inner hump. The aperture is narrow. The lip angle is about $138^{\circ}$, the lock angle is $72^{\circ}$, and the side angle is $71^{\circ}$.

Remarks. - For the specimens that show reduced lateral spines no special taxon is described as the spine length, the only difference, may be due to growth. $D$. angulosa without spines differs from 
$D$. bandaensis in the presence of a notch and the larger size of the first species.

Diacavolinia bandaensis $\mathrm{n}$. sp.

(Figs. 19A-B; Pl. II fig. 24)

Type material. - Holotype (ZMA Moll. 3.92.021) and 5 paratypes (ZMA Moll. 3.92.022) in ZMA.

Type locality. - Snellius II Exped., sta. 9 trawl 1, 2 August 1984, $4^{\circ} 36.4^{\prime} \mathrm{S} 130^{\circ} 21.7^{\prime} \mathrm{E}, 0-102 \mathrm{~m}$ depth.

Etymology. - This species was first collected in the Banda Sea, hence the name bandaensis.

Description. - The holotype has a shell length of $4.24 \mathrm{~mm}$ and a width of $3.92 \mathrm{~mm}$, the length range is $4.60-3.72 \mathrm{~mm}$ and the width range is $4.24-3.00$ $\mathrm{mm}(n=9)$. The hyaline shell is clearly triangular and has an intense brown colour especially along the ventral lip rim, the joint, and the centre of dorsal and ventral sides.

The dorsal lip has no notch in the broad rostrum, and no constriction; a small gutter crossed by the strong inner hump is present. The ventral lip is large and shows a clear median depression. Ventral and dorsal lip rims are thickened. The sometimes reduced lateral spines are not bent, lanceolate and sharp; the gutter corners are moderately developed. The 13 ventral ribs are line-shaped and composed of series of tubercles. The lateral lines are convex; the flanks are clearly present. The dorsal side is flattened, with well-developed central and moderate laterodorsal ribs; the lock ribs are weak. The lock area is well visible with a ridge-like main tubercle and a well-developed lunar tubercle; the minor tubercle is absent and the link is well developed. There is no secondary lock system. The growth lines are normal and on the upper side of the dorsal shell sculpture ribs are found. A strong hump is present with strong inner hump. The protoconch II area is only moderately projecting. In the holotype the rounded caudal joint is $0.96 \mathrm{~mm}$ and the caudal fold, $0.56 \mathrm{~mm}$ in length, is moon-shaped. There are no lip flaps; moderate lip bellies and large lip shoulders are present. In the holotype the lip angle is $155^{\circ}$, the lock angle is $73^{\circ}$, and the side angle is $76^{\circ}$. The aperture is narrow.

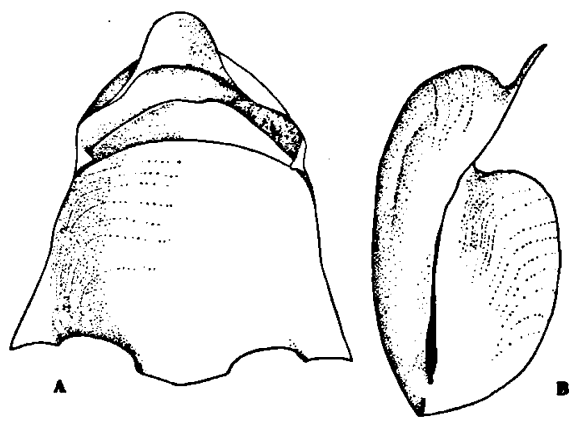

Fig. 19. Diacavolinia bandaensis n. sp., holotype from ventral (A) and lateral (B).

Remarks. - The species most related to the present one are $D$. angulosa and $D$. pacifica. These are smaller than $D$. bandaensis and already have a fully developed notch so that the present species can neither be a growth form of $D$. angulosa nor of $D$. pacifica. $D$. bandaensis may resemble sometimes specimens of $D$. grayi but in the present species the caudal joint is always near the level of the lateral spine tips, while in $D$. grayi the joint projects distinctly posteriorly below that level.

Diacavolinia ovalis $\mathrm{n}$. sp.

(Figs. 9C, 20A-B; Pl. II fig. 25)

Type material. - Holotype (ZMA Moll. 3.92.023) in ZMA. Type locality. - Deepwater Dumpsite 106 project cruise 2, sta. $67-\mathrm{M}$, July $1975,38^{\circ} 50^{\prime} \mathrm{N} 72^{\circ} 25^{\prime} \mathrm{W}, 0-100 \mathrm{~m}$ depth.

Etymology. - The ventral shell side, the constriction, and the aperture all show oval shapes, hence the name ovalis.

Description. - The holotype has a shell length of $5.25 \mathrm{~mm}$ and a width of $4.64 \mathrm{~mm}$, the length range is $6.08-4.00 \mathrm{~mm}$ and the width range is $5.04-3.12$ $\mathrm{mm}(n=13)$. The hyaline shell is colourless and triangular.

The dorsal lip has a notch in the rather broad rostrum; there is a shallow gutter and a strong constriction. The ventral lip is of normal size and shows a median depression. A little nose is present at the basis of the rostrum. The long lateral spines bend dorsally; they are hooked. The dorsal side is convex, the central rib and laterodorsal ribs are well devel- 


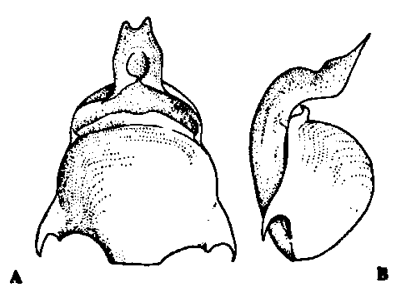

Fig. 20. Diacavolinia ovalis n. sp., holotype from ventral (A) and lateral (B).

oped, and the lock ribs are well developed, though small. The ventral ribs, 19 to 23 in number, are strongly developed comb-shaped. The flanks are present; the lateral lines are convex. The lock area is small with moderately developed main and lunar tubercle and very small minor tubercle. The second lock system is present. The growth line pattern is normally developed. There is a vague indication of a hump but an inner hump is absent. The protoconch II area is not far projecting. In the holotype the caudal joint is $1.12 \mathrm{~mm}$ and the caudal fold is $1.20 \mathrm{~mm}$ and somewhat moon-shaped. There is an indication of lip flaps; the lip bellies are strong and low and the lip shoulders are well developed. The aperture is narrow. In the holotype the lip angle is $125^{\circ}$, the side angle is $71^{\circ}$, and the lock angle is $72^{\circ}$. The dorsal aperture rim is sharp and the ventral rim is slightly thickened.

Diacavolinia deshayesi $\mathrm{n}$. sp.

(Figs. 21A-B; Pl. II fig. 26)

Type material. - Holotype (ZMUC GAS 164) in ZMUC and 8 paratypes (ZMA Moll. 3.92.024) in ZMA.

Type locality. - Dana Exped., sta. 1175 iii, 17 September 1929, $5^{\circ} 06^{\prime} \mathrm{N} 51^{\circ} 35^{\prime} \mathrm{W}, 0-50 \mathrm{~m}$ depth.

Etymology. - The name is given in honour of Dr. G.P. Deshayes who described taxa in this group.

Description. - The holotype has a shell length of $5.04 \mathrm{~mm}$ and a width of $4.64 \mathrm{~mm}$, the length range is $8.16-3.12 \mathrm{~mm}$ and the width range is $6.72-2.80$ $\mathrm{mm}(n=20)$. The hyaline shell is not very triangular; there is a faint brown to rose hue over the whole shell.

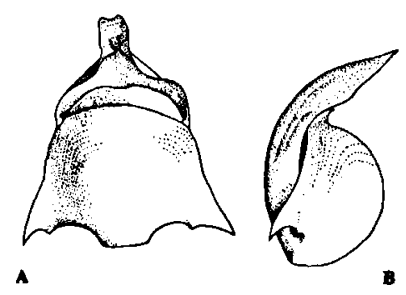

Fig. 2I. Diacavolinia deshayesi n. sp., holotype from ventral (A) and lateral (B).

The dorsal lip has a, sometimes very small, notch in the rather slender rostrum, a constriction, and a gutter. The ventral lip is relatively large and shows a clear median depression. The well-developed lateral spines are slightly bent, sharply pointed and hooked; the gutter corners are large. The 27 distinct ventral ribs are comb-shaped. In some specimens a lower (20) or a higher number (40) of ribs can be found. On the dorsal side ribs are found as well. The lateral lines are slightly convex and the flanks are slightly developed. The dorsal side is convex, with strong central rib and laterodorsal ribs; the lock ribs are small. The lock area is large like the main tubercle and link. Lunar and minor tubercle are normally developed. A very tiny second lock system is present. The growth lines are well developed also on the dorsal side. A hump is absent. The protoconch II area is moderately projecting. In the holotype the caudal joint is $0.64 \mathrm{~mm}$ and the caudal fold, $1.20 \mathrm{~mm}$ in length, is nearly straight. There is an indication of lip flaps; moderate lip bellies and well-developed lip shoulders are present. The aperture is narrow. In the holotype the lip angle is $140^{\circ}$, the lock angle is $74^{\circ}$, and the side angle is $72^{\circ}$.

Diacavolinia constricta n. sp.

(Figs. 22A-B; P1. II figs. 27-28)

Ref.: Cavolinia fissilabris Benson, 1860 may be a synonym of this species, but as its description was incomplete and the material is probably lost, it is impossible to be sure of this synonymy.

Type material. - Holotype (ZMA Moll. 3.92.025) in ZMA. Type locality. - AMNAPE Exped., sta. 88 trawl 4, 1 June 1983, $28^{\circ} 27.5^{\prime} \mathrm{N} 29^{\circ} 51.2^{\prime} \mathrm{W}, 0-47 \mathrm{~m}$ depth. 


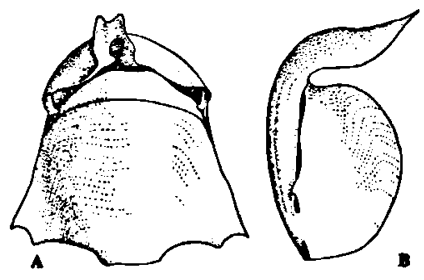

Fig. 22. Diacavolinia constricta n. sp., holotype from ventral (A) and lateral (B).

Etymology. - The name is based on the very strong constriction in the rostrum.

Description. - The holotype has a shell length of $5.60 \mathrm{~mm}$ and a width of $5.12 \mathrm{~mm}$, the shell length range is $5.60-4.08 \mathrm{~mm}$ and the width range is $5.28-3.44 \mathrm{~mm}(n=4)$. The hyaline shell is not very triangular; it has a brown hue over the entire surface.

The strongly bent dorsal lip has a notch in the rather broad rostrum, a constriction, and a gutter. The ventral lip is large and shows a weak median depression. The lateral spines are not bent; they are in a high position and hooked but not very sharp ending. The gutter corners are small. The 19 clear ventral ribs are comb-shaped. The lateral lines are slightly convex and the flanks are clearly present. The dorsal side is flattened, with moderately developed central and laterodorsal ribs; the lock ribs are moderate. The lock area is large with large main tubercle, large link (Pl. II fig. 27), large lunar and a small minor tubercle. A second lock system is present (Pl. II fig. 28). The growth lines are normal and on the dorsal side sculpture ribs are found as well. A hump is absent. The protoconch II area is not projecting; it has a moderate caudal joint. In the holotype the caudal joint is $1.28 \mathrm{~mm}$ and the moderately developed caudal fold, $1.36 \mathrm{~mm}$ in length, is moon-shaped. There are no lip flaps; large lip bellies and strong lip shoulders are present. The aperture is very narrow. In the holotype the lip angle is $105^{\circ}$, the lock angle is $67^{\circ}$, and the side angle is $75^{\circ}$.

Remarks. - This is a very rare species, closely related to $D$. strangulata. It is considered a separate species mainly on account of the difference in the rostrum and its allopatry with $D$. strangulata.
Diacavolinia strangulata (Deshayes, 1823)

(Figs. 23A-B; Pl. Il fig. 29)

Refs.: Cleodora strangulata Deshayes, 1823: 204.

Cavolinia longirostris forma strangulata; Van der Spoel, 1976: 54 (more synonymy).

Type material. - Could not be located.

Type locality. - This locality has never been indicated clearly but it should be the Indo-Pacific Ocean (cf. Tesch, 1948), so that it is incorrect to restrict it to the locality of the present specimens: the Atlantic Ocean (see the section on distribution).

Description. - Lateral spines as in D. longirostris. An abrupt lateral constriction in the rostrum gives rise to a tubercle distally, separated from the rest of the dorsal side. The shell length range is 4.64-3.36 $\mathrm{mm}(3.80 \mathrm{~mm}$ in the specimen figured) and the width range is $4.16-2.76 \mathrm{~mm}(3.20 \mathrm{~mm}$ in the specimen figured $(n=12)$. The hyaline shell is triangular; it has a brown colour especially along the centre of the dorsal side.

The dorsal lip has a small notch in the broad rostrum, a gutter and a strong constriction. The ventral lip is of moderate size and shows a normal median depression. The lateral spines are only very slightly bent, sharp and hooked; the gutter corners are small. The 18 ventral ribs are strong, lineshaped and composed of rows of tubercles. The lateral lines are nearly straight, the flanks are well pronounced. The dorsal side is slightly flattened, with well-developed central and weaker laterodorsal ribs; the lock ribs are small. The lock area, main tubercle and link are well developed. The lunar tubercle is relatively small and the minor tubercle is strongly reduced. There is a very small second lock mechanism (Pl. II fig. 29). Its place is marked by a little curve in the lateral border of the dorsal side. The growth lines are normally developed and there are ribs on the dorsal side. A moderate hump is present without inner hump; the rostrum projects anteriorly. The protoconch II area is not far projecting with a relatively broad caudal joint. In the holotype the caudal joint is $0.64 \mathrm{~mm}$ and the caudal fold, $0.72 \mathrm{~mm}$ in length, is moon-shaped. There are no lip flaps; moderate lip bellies and well-developed lip shoulders are present. The aperture is rather narrow. In the holotype the lip angle is $140^{\circ}$, the lock angle is $71^{\circ}$, and the side angle is $76^{\circ}$. 


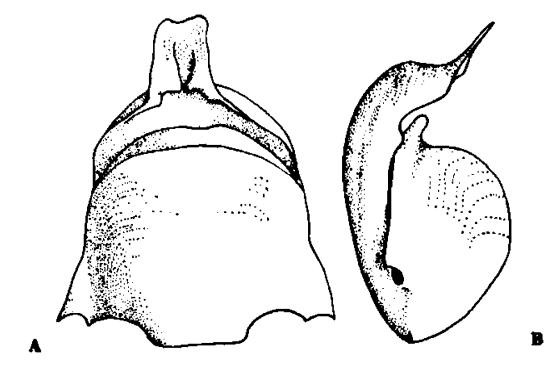

Fig. 23. Diacavolinia strangulata (Deshayes, 1823), from ventral (A) and lateral (B).

Remarks. - It was very hard to select one of the forms in this genus as the "real" strangulata. The one with a clear constriction as the most typical character and a rostrum directed anteriorly was finally taken as most agreeing with the original description. Representatives of this species are very rare. The closest relatives of this species are $D$. constricta and $D$. ovalis. They differ in the position of the lateral spines, bending more dorsally, and the shape of the rostrum, showing parallel sides in D. strangulata.

Diacavolinia flexipes (Van der Spoel, 1971) (Figs. 24A-D; Pl. II fig. 30)

Refs.: Cavolinia longirostris (De Blainville, 1821) forma flexipes Van der Spoel, 1971a: 16, figs. 15-16, 19, 21; 1976: 54 (more synonymy).

Cavolinia longirostris forma flexipes; Richter, 1979: 19.

Type material. - Holotype and 17 paratypes in Department of Zoology, University of Tel Aviv, three paratypes in ZMA.

Type locality. - David Bay, Entedeber, Red Sea; Coll. E 62/317, Dr. L. Fishelson leg.

Etymology. - The spines are bent like foots to the dorsal side, hence the name flexipes.

Description. - The holotype has a shell length of $4.80 \mathrm{~mm}$ and a width of $4.10 \mathrm{~mm}$, the length range is $8.00-4.50 \mathrm{~mm}$ and the width range is $6.60-3.60$ $\mathrm{mm}(n=6)$. The hyaline, not very triangular, shell is colourless except for a brown strip medially on the dorsal side.

The dorsal lip has no notch in the broad rostrum and no constriction, but it is gutter-shaped. The

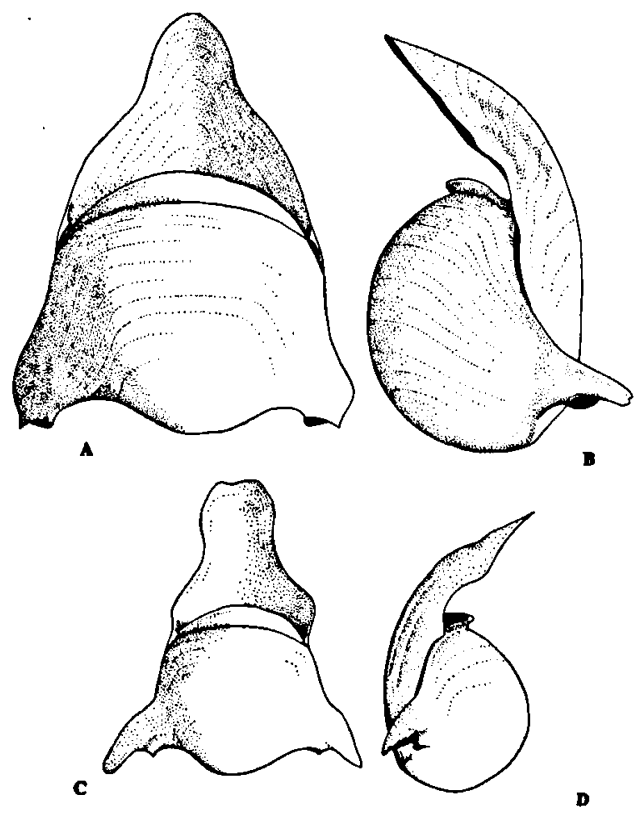

Fig. 24. Diacavolinia flexipes (Van der Spoel, 1971), holotype from ventral (A) and lateral (B), specimens from the Oman coast from ventral (C) and lateral (D).

ventral side is strongly swollen (Figs. $24 \mathrm{~A}-\mathrm{B}$ ). The ventral lip is of medium size and shows no, or a small, median depression. The lateral spines curve strongly dorsally, over $40^{\circ}$ to $90^{\circ}$, being hooked and sharp; the gutter corners are well developed. The spine surface bears a strong characteristic groove from gutter corners to spine tips. The ventral ribs are composed of about 4-8 strong ones near the aperture and about 8 very small ribs; they are line-shaped. The lateral lines are straight and the flanks are weak. The dorsal side is clearly convex, with a strong central rib and small laterodorsal ribs; the lock ribs are more faint. The lock area is just visible, the main tubercle and link are of moderate size. The lunar tubercle is very large and the minor tubercle is of normal size. A second lock system is present with a dorsal tubercle. The growth lines are well developed on both shell sides. Only a slight indication of a hump may be present in some specimens but there is no inner hump. The protoconch II area is not projecting. In the holotype the caudal joint is $2.00 \mathrm{~mm}$, shifted far to the dorsal side; the caudal fold, $1.92 \mathrm{~mm}$ in length, is slightly moon-shaped. There are no lip flaps; clear 


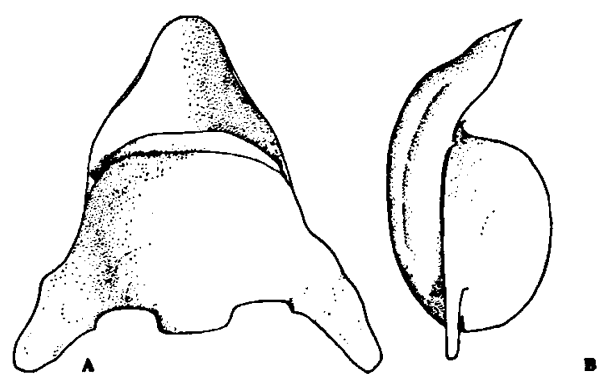

Fig. 25. Diacavolinia mcgowani (Van der Spoel, 1973), holotype from ventral (A) and lateral (B) (damaged ventral side shown in original position).

lip bellies and small or no lip shoulders are found. The aperture is very wide. In the holotype the lip angle is $155^{\circ}$, the lock angle is $63^{\circ}$, and the side angle is $80^{\circ}$.

Remarks. - This species is characterized by the very strong curving of the lateral spines. Specimens from the Oman coast differ in general shape from Red Sea specimens in having a more tongue-shaped dorsal lip and a more slender shell. In some of the Oman specimens a very shallow notch has developed (Figs. 24C-D). Also typical of the Oman population is the brown colour of the dorsal lip.

Diacavolinia mcgowani (Van der Spoel, 1973)

(Figs. 25A-B; PI. II figs. 31-32)

Refs.: Cavolinia longirostris (De Blainville, 1821) forma mcgowani Van der Spoel, 1973: 100, figs. 1-4; 1976: 55 (more synonymy).

Type material. - Holotype (ZMUC J. 1973) and two damaged paratypes (ZMUC J. 1973) in ZMUC.

Type locality. - Dana Exped., sta. 1205 v, 14 January 1922, $6^{\circ} 49^{\prime} \mathrm{N} 80^{\circ} 25^{\prime} \mathrm{W}, 0-100 \mathrm{~m}$ depth.

Description. - The holotype has a shell length of $4.20 \mathrm{~mm}$ and a width (spines included) of $4.82 \mathrm{~mm}$, the length range is $4.88-3.36 \mathrm{~mm}$ and the width range is $5.68-2.80 \mathrm{~mm}(n=2)$. The hyaline shell has a faint yellowish hue; it is not very triangular.

The relatively short dorsal lip has no notch in the broad rostrum and no constriction; it is guttershaped. The ventral lip is of normal size and shows a small median depression. The lateral spines are very long (Pl. II fig. 31), not curved dorsally, blunt, and composed nearly entirely by prolongation of the ventral side; the gutter corners are small. The seven very weak ventral ribs are line-shaped. The lateral lines are convex and the flanks are not developed. The dorsal side is slightly convex, with weakly developed central and laterodorsal ribs; the lock rib is very small. The lock area is well visible, the main tubercle is well developed like the lunar one, and the minor tubercle is reduced. A second lock system is absent. The growth lines are very faint. A hump is absent. The protoconch II area is rather strongly projecting with a marked caudal joint. In the holotype the caudal joint is $1.04 \mathrm{~mm}$ and the caudal fold, $0.88 \mathrm{~mm}$ in length, is nearly straight. There is no lip flap; the lip belly is small and the lip shoulder is small or absent. The aperture is wide. In the holotype the lip angle is $144^{\circ}$, the lock angle is $65^{\circ}$, and the side angle is $62^{\circ}$.

Remarks. - The type specimens, originally preserved in formalin, have been put into alcohol in 1973 but still show decay after 20 years. The paratypes are nearly dissolved and the ventral side of the holotype has partly detached.

Diacavolinia triangulata $\mathrm{n} . \mathrm{sp}$.

(Figs. 26A-D; Pl. II figs. 33-34)

Type material. - Holotype (ZMA Moll. 3.92.026) and 32 paratypes (ZMA Moll. 3.92.027) in ZMA.

Type locality. - Albatross Philippine Expedition, Philippine Sea.

Etymology. - The shell makes a perfect triangular impression, hence the name triangulata.

Description. - The holotype has a shell length of $9.20 \mathrm{~mm}$ and a width of $8.80 \mathrm{~mm}$, the length range is $9.20-4.88 \mathrm{~mm}$ and the width range is $8.80-4.40$ $\mathrm{mm}(n=14)$. The shell is triangular and transparent.

The large dorsal lip has a notch in the rostrum and a gutter but no constriction; an inner hump is not present in the holotype. In specimens from the Banda Sea a clear hump is developed and the spines are sharply ending (Figs. 26C-D). The thickened 
ventral lip is of moderate size and shows a weak median depression. The lateral spines do not bend (only in a few specimens they were not perfectly pointing laterally), they are not hooked but elongated, ending in a blunt tip; the gutter corners are large. The 17 thin ventral ribs are line-shaped. The ventral side is swollen, the lower half is flattened in profile view, the lateral lines are nearly straight, and the flanks are not developed. The dorsal side is somewhat flattened, with large central rib and moderate laterodorsal ribs and lock ribs. The lock area is large with large main tubercle and link. The main tubercle and the lunar tubercle are separated by a large flat open area; the minor tubercle is very small. A very small second lock system is present. The growth lines are strong and on the dorsal side some ribs are formed. A small outer hump is present but the inner hump is not developed. The protoconch II area is not projecting. In the holotype the caudal joint is $1.92 \mathrm{~mm}$ and the caudal fold, $1.60 \mathrm{~mm}$ in length, is nearly straight. There are no lip flaps; lip bellies are present and the lip shoulders are small. The aperture is wide. In the holotype the lip angle is $148^{\circ}$, the lock angle is $72^{\circ}$, and the side angle is $65^{\circ}$.

Remarks. - The closest relative is $D$. mcgowani but this species has more blunt lateral spines and no hump, nor lip shoulders. $D$. triangulata and $D$. grayi resemble each other but the latter species is smaller. In specimens with sharp spines, which may be confused with $D$. longirostris, the hump stays as a discriminating character. Specimens of $D$. pacifica with long spines strongly resemble $D$. triangulata with an inner hump, but in $D$. pacifica the first 1/4 of the lateral lines of the dorsal lip runs parallel to the shell axis, which is never found in the present species.

\section{Key to the Diacavolinia taxa}

1 - Outer hump present $\ldots \ldots \ldots \ldots \ldots \ldots \ldots \ldots \ldots, \ldots, 2$

- No outer hump present .................... 9

2 - Constriction present in the rostrum ............ 3

- No constriction in the rostrum ...............4

3 - Dorsal lip bent strongly ventrally, spines bent dorsally ........................... ovalis (Fig. 20)

- Dorsal lip slightly bent, spines not bent dorsally ...... strangulata (Fig. 23)
4 - Rostrum with a notch $\ldots \ldots \ldots \ldots \ldots \ldots \ldots \ldots \ldots$. 5

- Rostrum without notch .................. 7

5 - Caudal joint far projecting, its length $>50 \%$ of its width ..................... angulosa (Fig. 18)

- Caudal joint not far projecting, its length $<50 \%$ of its width $\ldots . \ldots \ldots \ldots \ldots \ldots \ldots \ldots \ldots \ldots . \ldots 6$

6 - Rostrum with a nose, aperture narrow, dorsal lip not narrowing directly ............ pacifica (Fig. 15)

- Rostrum without nose, aperture not narrow, dorsal lip narrowing directly ............ triangulata (Fig. 26)

7 - Spines completely reduced ......... aspina (Fig. 16)

- Spines very small hooked ......... robusta (Fig. 10)

- Spines well developed $\ldots \ldots \ldots \ldots \ldots \ldots \ldots \ldots .8$

8 - Spines lanceolate, tips close to level of caudal joint, gutter corners small .......... bandaensis (Fig. 19)

- Spines hooked, tips well above level of caudal joint, gutter corners pronounced ......... grayi (Fig. 17)

9 - Notch in rostrum ..................... 10

- No notch in rostrum ................... 19

10 - Constriction present $\ldots \ldots \ldots \ldots \ldots \ldots \ldots \ldots \ldots 11$

- No constriction present $\ldots \ldots \ldots \ldots \ldots \ldots \ldots \ldots . . \ldots$

11 - Aperture width very small $( \pm 0.2 \mathrm{~mm}) \ldots \ldots \ldots \ldots$ ..................... constricta (Fig. 22)

- Aperture wider $>0.2 \mathrm{~mm} \ldots \ldots \ldots \ldots \ldots \ldots \ldots . . \ldots 12$

12 - Shell length $<8 \mathrm{~mm}$, dorsal lip strongly bent ventrally ............................. 22

- Shell length $>8 \mathrm{~mm}$, dorsal lip not strongly bent ventrally ............................ 13

13 - Lip angle $<145^{\circ} \ldots \ldots \ldots \ldots \ldots$ atlantica (Fig. 6)

- Lip angle $>145^{\circ}$... . limbata forma africana (Fig. 5)

14 - Lateral spines absent ............ striata (Fig. 14)

- Lateral spines longer ................... 15

15 - Rostrum narrow, nearly no lip shoulders ........... ........................ souleyeti (Fig. 13)

- Rostrum broad, lip shoulders present .......... 16

16 - Lateral spines not bent .......... bicornis (Fig. 11)

- Lateral spines bent ................... 17

17 - Shell length $>8 \mathrm{~mm}$... limbata forma limbata (Fig. 4)

- Shell length $<8 \mathrm{~mm} \ldots \ldots \ldots \ldots \ldots \ldots \ldots \ldots \ldots 18$

18 - Lateral spines short, hooked, ventral ribs $>20 \ldots \ldots$. ..................... deblainvillei (Fig. 12)

- Lateral spines short, hooked, ventral ribs < 20 . . 21

- Lateral spines long, lanceolate to hooked, ventral ribs $<20 \ldots \ldots \ldots \ldots \ldots \ldots \ldots \ldots$ longirostris (Fig. 3)

19 - Spines elongated laterally ....... mcgowani (Fig. 25)

- Spines not elongated laterally ............... 20

20 - Spines bending strongly dorsally .... flexipes (Fig. 24)

- Spines bending slightly dorsally ............. 21

21 - Lip shoulders small, no second lock mechanism ..... ....................... elegans (Fig. 9)

- Lip shoulders larger, second lock mechanism present $\ldots \ldots \ldots \ldots$ vanutrechti forma vanutrechti (Fig. 7)

22 - Constriction strong, lateral spines projecting laterally ....................... deshayesi (Fig. 21)

- Constriction small, lateral spines not projecting laterally vanutrechti forma meisenheimeri (Fig. 8) 

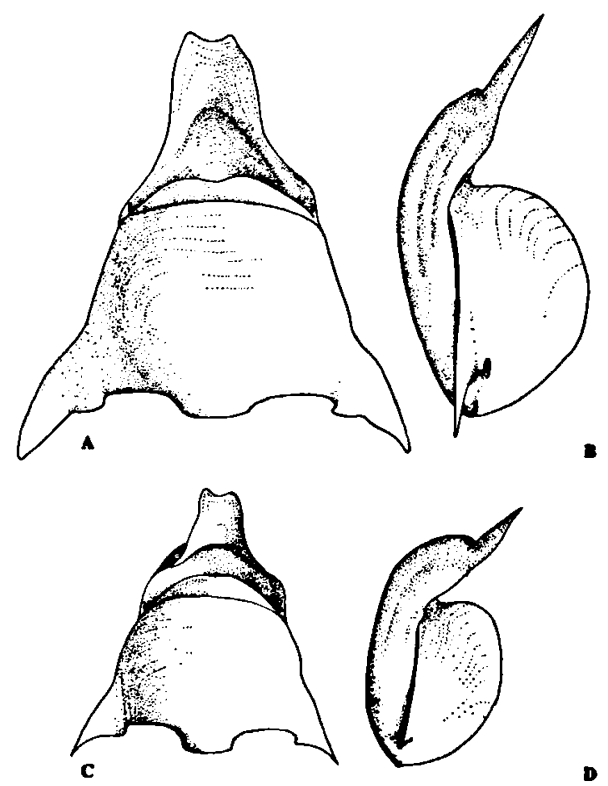

D

Fig. 26. Diacavolinia triangulata $\mathrm{n}$. sp., holotype from ventral (A) and lateral (B); Banda Sea specimen from ventral (C) and lateral (D).

\section{Distribution}

Diacavolinia shows a distribution over four disjunct ranges, viz.: the Atlantic, the Indo-W. Pacific, the Central Pacific and the E. Pacific range (Meisenheimer, 1905; Tesch, 1946, 1948).

Diacavolinia angulosa (Fig. 27) is considered by most authors to be an Indo-Pacific taxon though Gray (1850) described this species also from the Atlantic Ocean. It is presently reported from the Banda Sea and the entire Indian Ocean and N.W. Pacific. In our opinion the Atlantic Ocean specimens described by Gray (1850) do not belong to this species which is now considered endemic to the IndoPacific Ocean. It is a common epipelagic species exclusively found in shallow hauls, not collected by closing nets from layers below $200 \mathrm{~m}$.

\begin{tabular}{|c|c|c|c|c|}
\hline $\begin{array}{l}\text { Localitie } \\
21^{\circ} 59.3^{\prime}\end{array}$ & \multicolumn{4}{|c|}{ Localities: } \\
\hline $14^{\circ} 46^{\prime}$ & $\mathbf{N}$ & $137^{\circ} 00.1^{\prime}$ & $\mathbf{E}$ & $300 \mathrm{~m}$ \\
\hline $11^{\circ} 21.8^{\prime}$ & $\mathbf{N}$ & $148^{\circ} 59.9^{\prime}$ & E & $0-100 \mathrm{~m}$ \\
\hline $05^{\circ} 28^{\prime}$ & $\mathbf{N}$ & $080^{\circ} 00^{\prime}$ & $\mathbf{E}$ & $0-100 \mathrm{~m}$ \\
\hline $03^{\circ} 45^{\prime}$ & $\mathbf{N}$ & $056^{\circ} 33^{\prime}$ & $\mathbf{E}$ & $0-50 \mathrm{~m}$ \\
\hline
\end{tabular}

$\begin{array}{llllr}00^{\circ} 08^{\prime} & \text { S } & 097^{\circ} 15^{\prime} & \mathrm{E} & 0-100 \mathrm{~m} \\ 02^{\circ} 57^{\prime} & \mathrm{S} & 099^{\circ} 36^{\prime} & \mathrm{E} & 0-400 \mathrm{~m} \\ 03^{\circ} 45^{\prime} & \mathrm{S} & 056^{\circ} 33^{\prime} & \mathrm{E} & 0-50 \mathrm{~m} \\ 04^{\circ} 36.4^{\prime} \mathrm{S} & 130^{\circ} 21.7^{\prime} \mathrm{E} & 0-102 \mathrm{~m} \\ 05^{\circ} 21.2^{\prime} \mathrm{S} & 128^{\circ} 45 .^{\prime} \mathrm{E} & 0-101 \mathrm{~m} \\ 05^{\circ} 23.9^{\prime} \mathrm{S} & 130^{\circ} 04.7^{\prime} \mathrm{E} & 0-100 \mathrm{~m} \\ 05^{\circ} 31^{\prime} 1^{\prime} \mathrm{S} & 130^{\circ} 02.6^{\prime} \mathrm{E} & 0-100 \mathrm{~m} \\ 06^{\circ} 01^{\prime} \mathrm{S} & 093^{\circ} 12^{\prime} \mathrm{E} & 0-200 \mathrm{~m} \\ 06^{\circ} 29.2^{\prime} \mathrm{S} & 131^{\circ} 08.6^{\prime} \mathrm{E} & 0-80 \mathrm{~m} \\ 07^{\circ} 28.4^{\prime} \mathrm{S} & 130^{\circ} 42.9^{\prime} \mathrm{E} & 100-305 \mathrm{~m} \\ 09^{\circ} 09^{\prime} \mathrm{S} & 114^{\circ} 47^{\prime} \mathrm{E} & 0-300 \mathrm{~m} \\ 21^{\circ} 13^{\prime} \mathrm{S} & 042^{\circ} 26^{\prime} & \mathrm{E} & 0-284 \mathrm{~m}\end{array}$

Diacavolinia aspina (Fig. 28) is found in the IndoMalayan and adjacent Indian Ocean, in the epipelagic zone.

Localities:

$\begin{array}{llll}02^{\circ} 57^{\prime} \text { S } & 099^{\circ} 36^{\prime} \text { E } & 0-400 \mathrm{~m} \\ \text { Banda Sea } & & & 0-500 \mathrm{~m}\end{array}$

Diacavolinia atlantica (Fig. 29) is endemic to the N.E. Atlantic but it lives in as well as outside the upwelling area. It is collected frequently sympatric with $D$. limbata.

Localities:

\begin{tabular}{|c|c|c|c|c|}
\hline $30^{\circ} 33.5^{\prime}$ & $\mathbf{N}$ & $\begin{array}{l}030^{\circ} 00.8^{\prime} \\
020^{\circ} 559^{\prime}\end{array}$ & $\begin{array}{l}\mathbf{W} \\
\mathbf{w}\end{array}$ & $0-50 \mathrm{~m}$ \\
\hline $5 \circ 31^{\prime}$ & $\mathbf{N}$ & $018^{\circ} 05^{\prime}$ & W & $0-5 \mathrm{~m}$ \\
\hline $14^{\circ} 37^{\prime}$ & $\mathbf{N}$ & $019^{\circ} 52^{\prime}$ & W & $0-100 \mathrm{~m}$ \\
\hline
\end{tabular}

Diacavolinia bandaensis (Fig. 30) is so far only found in the Banda Sea and may be endemic to this area.

Localities:

$\begin{array}{lll}04^{\circ} 39.1^{\prime} \mathrm{S} & 130^{\circ} 30.4^{\prime} \mathrm{E} & 0-100 \mathrm{~m} \\ 04^{\circ} 36.4^{\prime} \mathrm{S} & 130^{\circ} 21.7^{\prime} \mathrm{E} & 0-102 \mathrm{~m}\end{array}$

Diacavolinia bicornis (Fig. 31) is found in the N.W. Atlantic Ocean and W. Indian Ocean. Probably it has a wide distribution.

\begin{tabular}{|c|c|c|c|c|}
\hline \multicolumn{5}{|c|}{ Localities: } \\
\hline $21^{\circ} 04^{\prime}$ & $\mathbf{N}$ & $073^{\circ} 48^{\prime}$ & $\mathbf{w}$ & $0-600 \mathrm{~m}$ \\
\hline $05^{\circ} 28^{\prime}$ & $\mathbf{N}$ & $080^{\circ} 00^{\prime}$ & $\mathbf{E}$ & $0-100 \mathrm{~m}$ \\
\hline $03^{\circ} 45^{\prime}$ & $\mathbf{S}$ & $056^{\circ} 33^{\prime}$ & $\mathbf{E}$ & $0-50 \mathrm{~m}$ \\
\hline
\end{tabular}

Diacavolinia constricta (Fig. 32) is so far only found in the central N. Atlantic Ocean. 


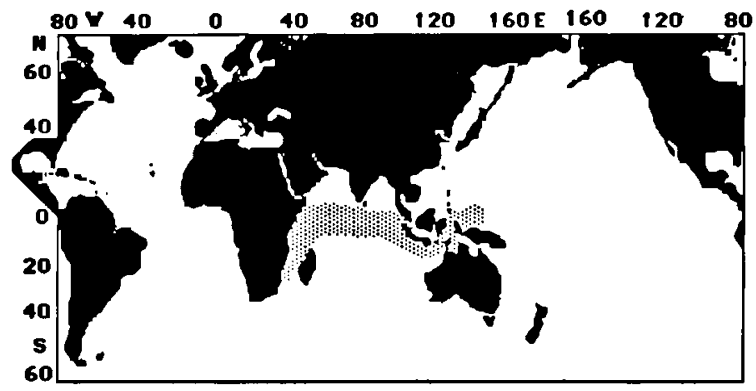

Fig. 27. Geographic distribution of $D$. angulosa.

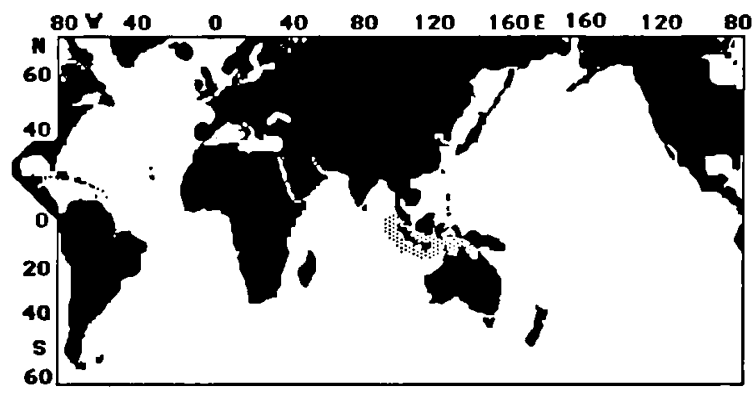

Fig. 28. Geographic distribution of D. aspina.

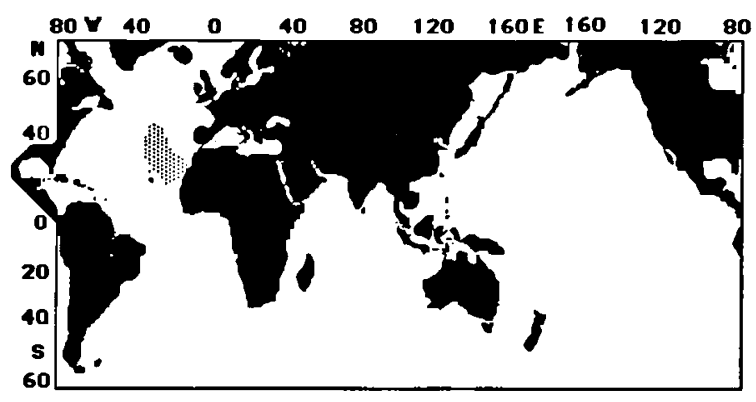

Fig. 29. Geographic distribution of D. atlantica.

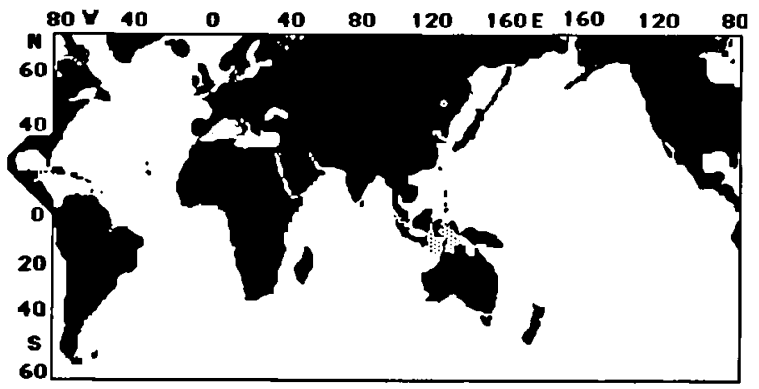

Fig. 30. Geographic distribution of $D$. bandaensis.

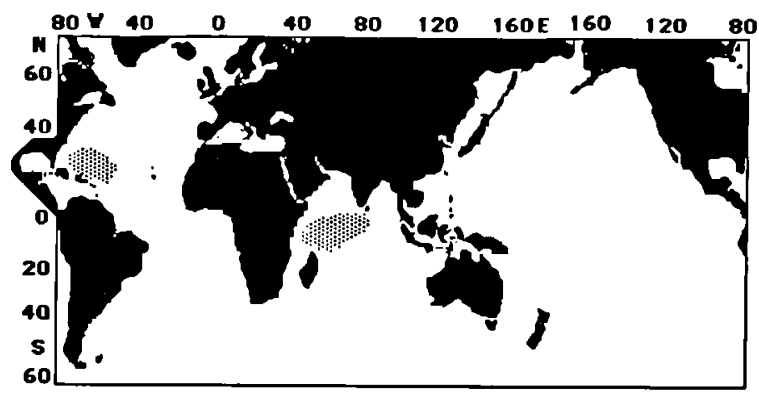

Fig. 31. Geographic distribution of $D$. bicornis.

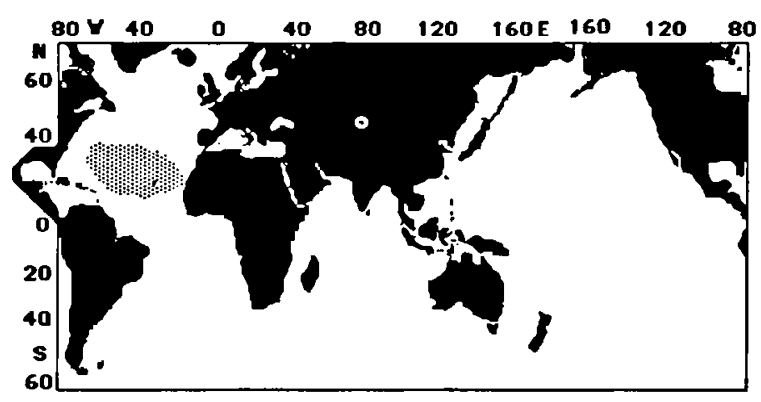

Fig. 32. Geographic distribution of $D$. constricta.

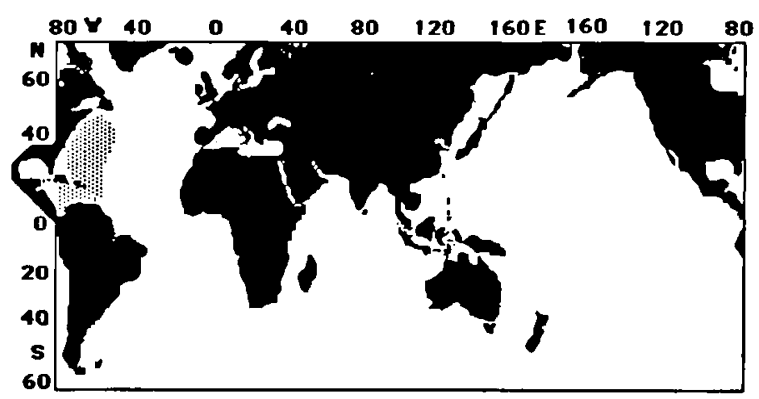

Fig. 33. Geographic distribution of $D$. deblainvillei.

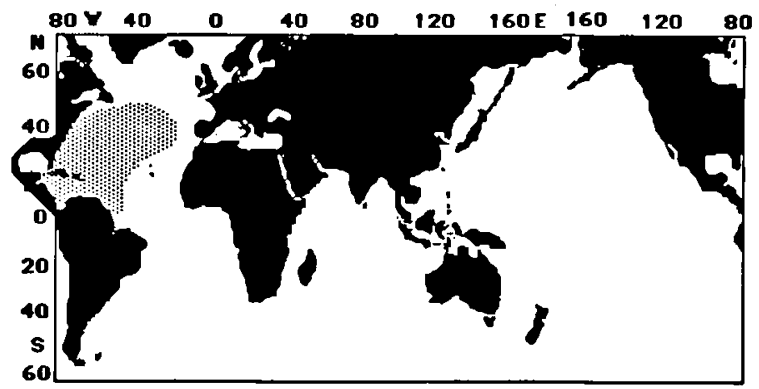

Fig. 34. Geographic distribution of $D$. deshayesi. 
Localities:

$\begin{array}{llllr}12^{\circ} 09^{\prime} & \mathrm{N} & 068^{\circ} 17^{\prime} & \mathrm{W} & \text { bottom } \\ 27^{\circ} 02^{\prime} & \mathrm{N} & 053^{\circ} 39^{\prime} & \mathrm{W} & 0-150 \mathrm{~m} \\ 28^{\circ} 27.5^{\prime} & \mathrm{N} & 029^{\circ} 51.2^{\prime} & \mathrm{W} & 0-47 \mathrm{~m} \\ 28^{\circ} 15^{\prime} & \mathrm{N} & 056^{\circ} 00^{\prime} & \mathrm{W} & 0-50 \mathrm{~m} \\ 31^{\circ} 56^{\prime} & \mathrm{N} & 063^{\circ} 57^{\prime} & \mathrm{W} & 0-1690 \mathrm{~m} \\ 31^{\circ} 50^{\prime} & \mathrm{N} & 064^{\circ} 21^{\prime} & \mathrm{W} & 0-110 \mathrm{~m} \\ 31^{\circ} 39^{\prime} & \mathrm{N} & 063^{\circ} 35^{\prime} & \mathrm{W} & \text { surface } \\ 32^{\circ} 33^{\prime} & \mathrm{N} & 064^{\circ} 21^{\prime} & \mathrm{W} & 75-125 \mathrm{~m}\end{array}$

Diacavolinia deblainvillei (Fig. 33) is restricted to the W. Atlantic and probably restricted to epipelagic zones.

\begin{tabular}{|c|c|c|c|c|}
\hline \multicolumn{5}{|c|}{ Localities: } \\
\hline $11^{\circ} 00^{\prime}$ & $\mathbf{N}$ & $077^{\circ} 40^{\prime}$ & $\mathbf{w}$ & $0-300 \mathrm{~m}$ \\
\hline $28^{\circ} 15^{\prime}$ & $\mathbf{N}$ & $056^{\circ} 00^{\prime}$ & $\mathbf{w}$ & $0-50 \mathrm{~m}$ \\
\hline $31^{\circ} 48^{\prime}$ & $\mathbf{N}$ & $063^{\circ} 38^{\prime}$ & $\mathbf{w}$ & $0-100 \mathrm{~m}$ \\
\hline $38^{\circ} 50^{\prime}$ & $\mathbf{N}$ & $072^{\circ} 25^{\prime}$ & $\mathbf{w}$ & $0-100 \mathrm{~m}$ \\
\hline
\end{tabular}

Diacavolinia deshayesi (Fig. 34) occurs in the Atlantic range and is here described from the N. Atlantic Ocean.

\begin{tabular}{llllr}
\multicolumn{2}{l}{ Localities: } & & & \\
$05^{\circ} 06^{\prime}$ & $\mathrm{N}$ & $051^{\circ} 35^{\prime}$ & $\mathrm{W}$ & $0-50 \mathrm{~m}$ \\
$09^{\circ} 40^{\prime}$ & $\mathrm{N}$ & $079^{\circ} 56^{\prime}$ & $\mathrm{W}$ & $0-100 \mathrm{~m}$ \\
$27^{\circ} 02^{\prime}$ & $\mathrm{N}$ & $053^{\circ} 59^{\prime}$ & $\mathrm{W}$ & $0-150 \mathrm{~m}$ \\
$27^{\circ} 27^{\prime}$ & $\mathrm{N}$ & $052^{\circ} 43^{\prime}$ & $\mathrm{W}$ & $0-500 \mathrm{~m}$ \\
$28^{\circ} 15^{\prime}$ & $\mathrm{N}$ & $056^{\circ} 00^{\prime}$ & $\mathrm{W}$ & $0-50 \mathrm{~m}$ \\
$28^{\circ} 30^{\prime}$ & $\mathrm{N}$ & $029^{\circ} 50^{\prime}$ & $\mathrm{W}$ & $95-202 \mathrm{~m}$ \\
$29^{\circ} 56^{\prime}$ & $\mathrm{N}$ & $059^{\circ} 33^{\prime}$ & $\mathrm{W}$ & $0-200 \mathrm{~m}$ \\
$30^{\circ} 25^{\prime}$ & $\mathrm{N}$ & $044^{\circ} 46^{\prime}$ & $\mathrm{W}$ & $0-100 \mathrm{~m}$ \\
$30^{\circ} 50^{\prime}$ & $\mathrm{N}$ & $072^{\circ} 25^{\prime}$ & $\mathrm{W}$ & $0-100 \mathrm{~m}$ \\
$31^{\circ} 56^{\prime}$ & $\mathrm{N}$ & $063^{\circ} 57^{\prime}$ & $\mathrm{W}$ & $0-1690 \mathrm{~m}$
\end{tabular}

Diacavolinia elegans (Fig. 35) is a widespread species recorded from the Indo-Malayan and Banda Sea and the adjacent W. and Central Pacific Ocean and N. Atlantic Ocean.

\section{Localities:}

$\begin{array}{llllr}03^{\circ} 40^{\prime} & \mathrm{N} & 137^{\circ} 53^{\prime} & \mathrm{E} & 0-100 \mathrm{~m} \\ 13^{\circ} 58.2^{\prime} & \mathrm{N} & 154^{\circ} 59.9^{\prime} \mathrm{E} & 0-318 \mathrm{~m} \\ 27^{\circ} 02^{\prime} & \mathrm{N} & 053^{\circ} 39^{\prime} & \mathrm{W} & 0-150 \mathrm{~m} \\ 32^{\circ} 05^{\prime} & \mathrm{N} & 064^{\circ} 04^{\prime} & \mathrm{W} & 375-394 \mathrm{~m} \\ 38^{\circ} 50^{\prime} & \mathrm{N} & 072^{\circ} 25^{\prime} & \mathrm{W} & 0-100 \mathrm{~m} \\ 05^{\circ} 21.2^{\prime} & \mathrm{S} & 128^{\circ} 451^{\prime} \mathrm{E} & 0-101 \mathrm{~m} \\ 07^{\circ} 28^{\prime} & \mathrm{S} & 130^{\circ} 42.9^{\prime} \mathrm{E} & 100-305 \mathrm{~m} \\ 13^{\circ} 14^{\prime} & \mathrm{S} & 169^{\circ} 51^{\prime} & \mathrm{W} & 0-50 \mathrm{~m}\end{array}$

Diacavolinia flexipes (Fig. 36) thought to be restricted to the Red Sea, is now also found in the eastern Indian Ocean. It seems endemic to the $\mathrm{N}$. Indian Ocean and Red Sea.

Localities:

\begin{tabular}{|c|c|c|c|c|}
\hline \multicolumn{4}{|c|}{ David Bay Entedeber (Red Sea) } & bottom \\
\hline $03^{\circ} 45^{\prime}$ & $\mathbf{S}$ & $056^{\circ} 33^{\prime}$ & $\mathbf{E}$ & $0-50 \mathrm{~m}$ \\
\hline $01^{\circ} 45^{\prime}$ & $\mathbf{N}$ & $096^{\circ} 20^{\prime}$ & $\mathbf{E}$ & $0-300 \mathrm{~m}$ \\
\hline \multicolumn{4}{|c|}{ Qurm Beach, Oman } & san \\
\hline
\end{tabular}

Diacavolinia grayi (Fig. 37) is an Indo-Malayan and Indian Ocean species found so far in the Banda Sea and N.E. Indian Ocean.

Localities:

$\begin{array}{llllr}03^{\circ} 45^{\prime} \mathrm{S} & 056^{\circ} 33^{\prime} & \mathrm{E} & 0-50 \mathrm{~m} \\ 05^{\circ} 22.8^{\prime} \mathrm{S} & 130^{\circ} 05^{\prime} & \mathrm{E} & 90-196 \mathrm{~m} \\ 06^{\circ} 33.4^{\prime} \mathrm{S} & 132^{\circ} 6^{\prime} & \mathrm{E} & 0-100 \mathrm{~m}\end{array}$

Diacavolinia limbata forma limbata (Fig. 38) is endemic to the upwelling area off N.W. Africa.

Locality:

$15^{\circ} 31^{\prime} \mathrm{N} \quad 018^{\circ} 05^{\prime} \mathrm{W} \quad 0-100 \mathrm{~m}$

Diacavolinia limbata forma africana (Fig. 39) has the same pattern as $D$. atlantica and seems endemic to the N.E. Atlantic.

Localities:

$\begin{array}{llllr}15^{\circ} 31^{\prime} & \mathrm{N} & 018^{\circ} 05^{\prime} \mathrm{W} & 0-50 \mathrm{~m} \\ 15^{\circ} 55^{\prime} & \mathrm{N} & 012^{\circ} 55^{\prime} \mathrm{W} & \text { surface } \\ 24^{\circ} 52^{\prime} & \mathrm{N} & 029^{\circ} 59.5^{\prime} \mathrm{W} & 510-1090 \mathrm{~m} \\ 24^{\circ} 53.6^{\prime} \mathrm{N} & 028^{\circ} 37.3^{\prime} \mathrm{W} & 100-195 \mathrm{~m} \\ 29^{\circ} 48.1^{\prime} \mathrm{N} & 029^{\circ} 57.5^{\prime} \mathrm{W} & 110-205 \mathrm{~m}\end{array}$

Diacavolinia longirostris (Fig. 40) is an Atlantic and Indo-Pacific species with a wide distribution range. It is so far found in the N.W. Atlantic and N. Indian Oceans and Banda Sea.

Localities:

\begin{tabular}{llllr}
\multicolumn{2}{l}{ off Bermuda } & & & $0-100 \mathrm{~m}$ \\
$31^{\circ} 48^{\prime}$ & $\mathrm{N}$ & $063^{\circ} 38^{\prime}$ & $\mathrm{W}$ & bottom \\
$11^{\circ} 00^{\prime}$ & $\mathrm{N}$ & $077^{\circ} 40^{\prime}$ & $\mathrm{W}$ & $0-300 \mathrm{~m}$ \\
$05^{\circ} 06^{\prime}$ & $\mathrm{N}$ & $051^{\circ} 35^{\prime}$ & $\mathrm{W}$ & $0-50 \mathrm{~m}$ \\
$03^{\circ} 45^{\prime} \mathrm{S}$ & $056^{\circ} 33^{\prime}$ & $\mathrm{E}$ & $0-50 \mathrm{~m}$ \\
$04^{\circ} 27.3^{\prime} \mathrm{S}$ & $134^{\circ} 17.2^{\prime}$ & $\mathrm{E}$ & $0-100 \mathrm{~m}$ \\
$06^{\circ} 33.4^{\prime} \mathrm{S}$ & $132^{\circ} 6^{\prime}$ & $\mathrm{E}$ & $0-100 \mathrm{~m}$
\end{tabular}




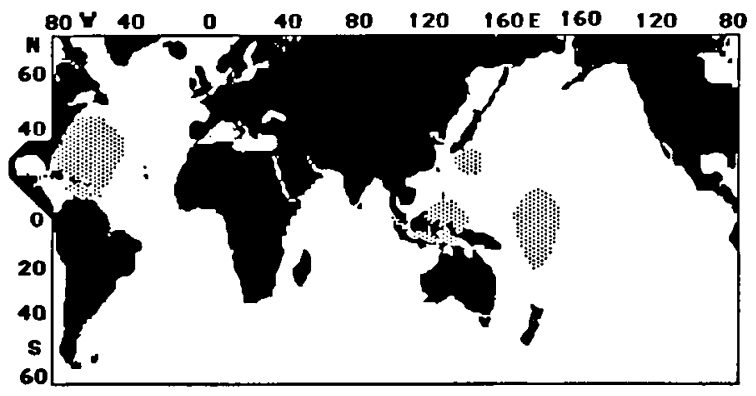

Fig. 35. Geographic distribution of D. elegans.

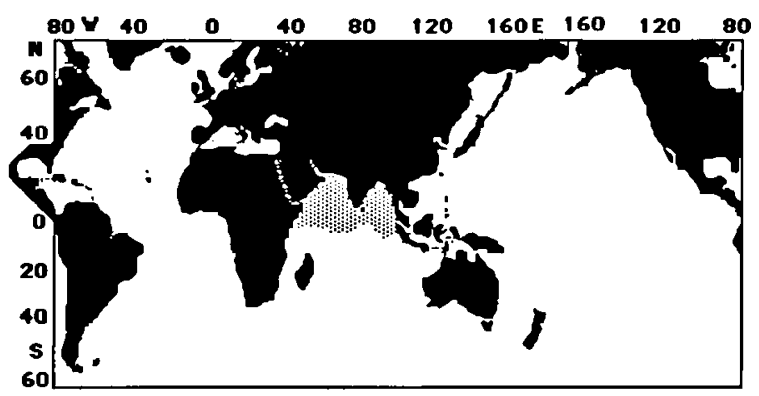

Fig. 36. Geographic distribution of $D$. flexipes.

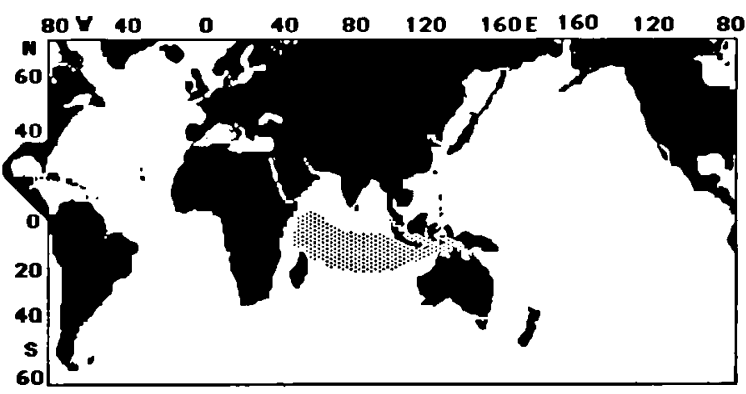

Fig. 37. Geographic distribution of D. grayi.

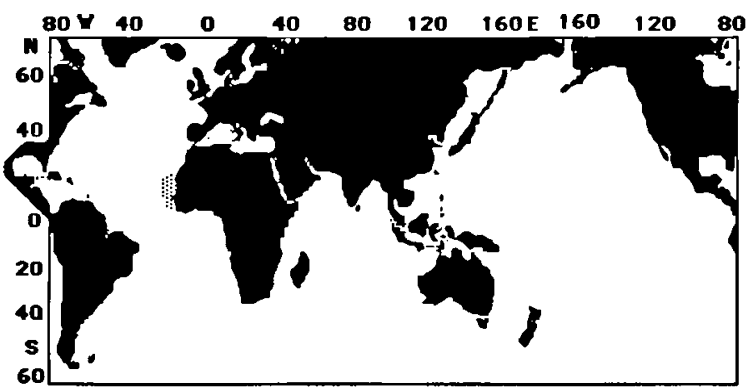

Fig. 38. Geographic distribution of D. l. forma limbata.

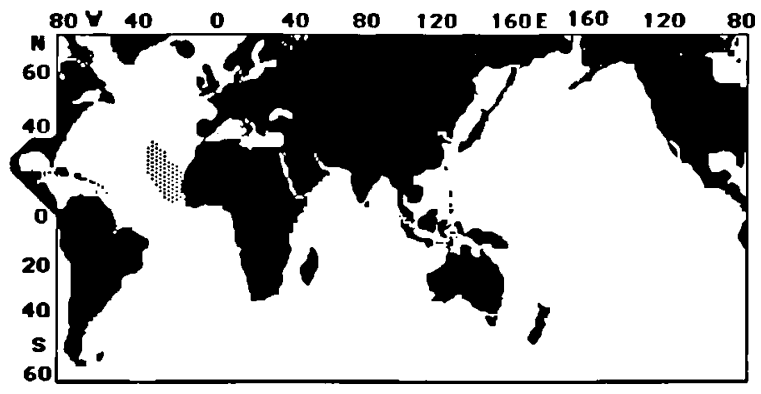

Fig. 39. Geographic distribution of D. I. forma africana.

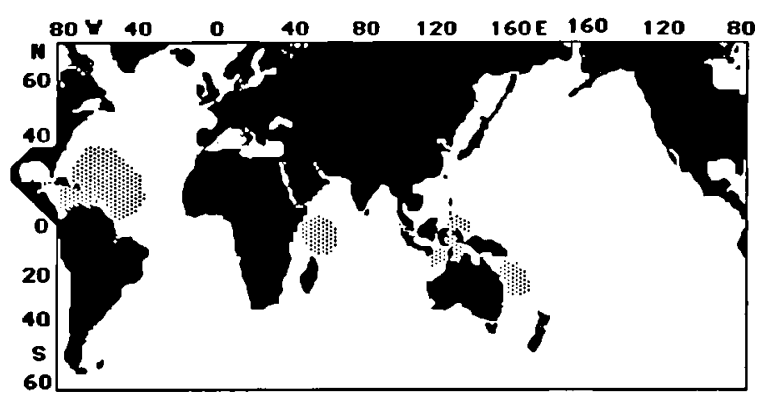

Fig. 40. Geographic distribution of D. longirostris.

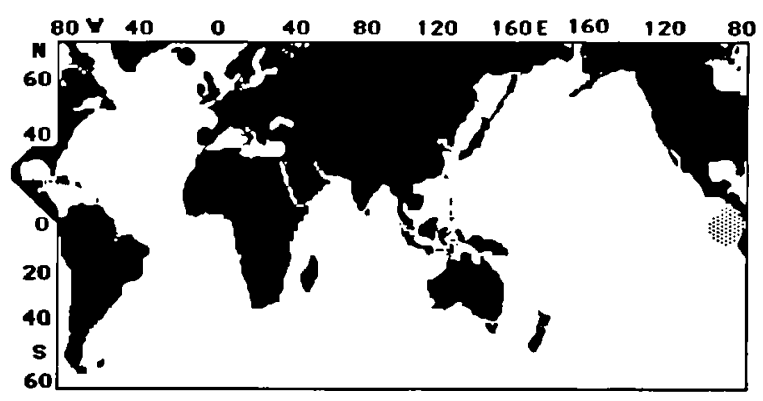

Fig. 41. Geographic distribution of D. mcgowani.

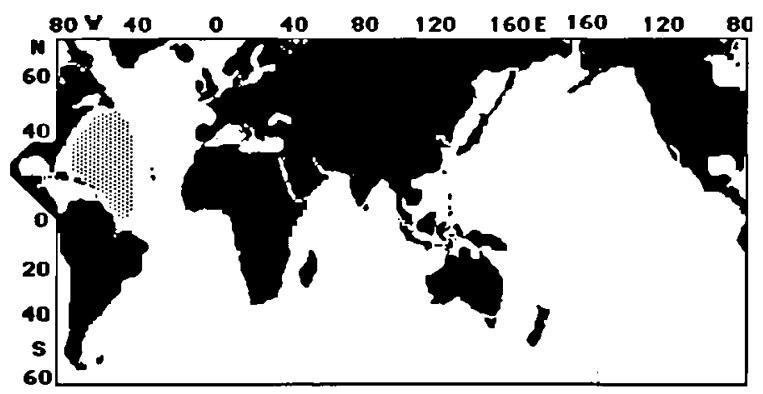

Fig. 42. Geographic distribution of $D$. ovalis. 
Diacavolinia mcgowani (Fig. 41) is restricted to the E. Pacific Ocean, and so far only recorded from its type locality, in the oxygen minimum area.

\section{Locality:}

$06^{\circ} 49^{\prime} \mathrm{N} \quad 080^{\circ} 25^{\prime}$ W $\quad 0-100 \mathrm{~m}$

Diacavolinia ovalis (Fig. 42) is found in the N. Atlantic Ocean.

Localities:

$38^{\circ} 50^{\prime} \mathrm{N} \quad 072^{\circ} 25^{\prime} \mathrm{W} \quad 0-100 \mathrm{~m}$

$05^{\circ} 06^{\prime} \mathrm{N} \quad 051^{\circ} 35^{\prime} \mathrm{W} \quad 0-50 \mathrm{~m}$

Diacavolinia pacifica (Fig. 43) is an Indo-W. Pacific species found in the W. Indian and N.W. Pacific Oceans.

\begin{tabular}{llllr}
\multicolumn{2}{l}{ Localities: } & & & \\
$14^{\circ} 37^{\prime}$ & $\mathrm{N}$ & $119^{\circ} 52^{\prime}$ & $\mathrm{E}$ & $0-100 \mathrm{~m}$ \\
$14^{\circ} 46^{\prime}$ & $\mathrm{N}$ & $137^{\circ} 00.1^{\prime}$ & $\mathrm{E}$ & $300 \mathrm{~m}$ \\
$05^{\circ} 25^{\prime}$ & $\mathrm{S}$ & $130^{\circ} 9.4^{\prime}$ & $\mathrm{E}$ & $0-102 \mathrm{~m}$ \\
$05^{\circ} 23.9^{\prime} \mathrm{S}$ & $130^{\circ} 4.7^{\prime}$ & $\mathrm{E}$ & $0-100 \mathrm{~m}$ \\
$06^{\circ} 29.9^{\prime} \mathrm{S}$ & $131^{\circ} 09.2^{\prime}$ & $\mathrm{E}$ & $89-280 \mathrm{~m}$ \\
$07^{\circ} 28.4^{\prime}$ & $\mathrm{S}$ & $130^{\circ} 42.9^{\prime}$ & $\mathrm{E}$ & $100-305 \mathrm{~m}$ \\
$31^{\circ} 51^{\prime}$ & $\mathrm{N}$ & $130^{\circ} 10^{\prime}$ & $\mathrm{W}$ & $0-183 \mathrm{~m}$
\end{tabular}

Diacavolinia robusta (Fig. 44) is so far only recorded from the N.W. Atlantic Ocean.

Localities:

$\begin{array}{lllll}02^{\circ} 52^{\prime} & \mathrm{N} & 087^{\circ} 38^{\prime} & \mathrm{W} & 0-50 \mathrm{~m} \\ 05^{\circ} 06^{\prime} & \mathrm{N} & 051^{\circ} 35^{\prime} & \mathrm{W} & 0-50 \mathrm{~m} \\ 21^{\circ} 04^{\prime} & \mathrm{N} & 073^{\circ} 48^{\prime} & \mathrm{W} & 0-600 \mathrm{~m}\end{array}$

Diacavolinia souleyeti (Fig. 45) is described from the N.E. Indian Ocean and seems to be restricted in distribution.

Localities:

02 ${ }^{\circ} 57^{\prime}$ S $\quad 099^{\circ} 36^{\prime}$ E $\quad 0-400 \mathrm{~m}$

$06^{\circ} 01^{\prime} \mathrm{S} \quad 093^{\circ} 12^{\prime}$ E $\quad 0-200 \mathrm{~m}$

Diacavolinia strangulata (Fig. 46) is originally described from the W. Pacific ocean. The records described in this paper are from the Atlantic Ocean and probably the species has a wider distribution.

\section{Localities:}

$21^{\circ} 04^{\prime} \mathrm{N} \quad 073^{\circ} 48^{\prime} \mathrm{W} \quad 0-600 \mathrm{~m}$ $09^{\circ} 40^{\prime} \mathrm{N} \quad 079^{\circ} 56^{\prime} \mathrm{W} \quad 0-100 \mathrm{~m}$
Diacavolinia striata (Fig. 47) is an Indian Ocean species described here from the N.E. Indian Ocean.

Locality:

$02^{\circ} 59^{\prime}$ S $099^{\circ} 36^{\prime}$ E $\quad 0-400 \mathrm{~m}$

Diacavolinia triangulata (Fig. 48) occurs in the Indo-Malayan and adjacent areas.

Localities:

$\begin{array}{llrrr}14^{\circ} 37^{\prime} & \mathrm{N} & 119^{\circ} 52^{\prime} & \mathrm{E} & 0-100 \mathrm{~m} \\ 09^{\circ} 17^{\prime} & \mathrm{N} & 123^{\circ} 58^{\prime} & \mathrm{E} & 0-1000 \mathrm{~m} \\ 01^{\circ} 45^{\prime} & \mathrm{N} & 090^{\circ} 20^{\prime} & \mathrm{E} & 0-300 \mathrm{~m} \\ \text { Albatross Exped. Philippines } & \text { bottom } \\ 03^{\circ} 45^{\prime} \mathrm{S} & 056^{\circ} 33^{\prime} & \mathrm{E} & 0-50 \mathrm{~m} \\ 05^{\circ} 22.8^{\prime} \mathrm{S} & 130^{\circ} 05^{\prime} & \mathrm{E} & 90-196 \mathrm{~m} \\ 07^{\circ} 28^{\prime} & \mathrm{S} & 130^{\circ} 42.9^{\prime} \mathrm{E} & 100-305 \mathrm{~m}\end{array}$

Diacavolinia vanutrechti forma vanutrechti (Fig. 49) is an Indo-W. Pacific taxon found in the W. Pacific and N. Indian Oceans.

\begin{tabular}{|c|c|c|c|c|}
\hline \multicolumn{5}{|c|}{ Localities: } \\
\hline $05^{\circ} 28^{\prime}$ & $\mathbf{N}$ & $080^{\circ} 00^{\prime}$ & $\mathrm{E}$ & $0-100 \mathrm{~m}$ \\
\hline $11^{\circ} 21.8^{\prime}$ & $\mathbf{N}$ & $148^{\circ} 59.9^{\prime}$ & E & $0-100 \mathrm{~m}$ \\
\hline $13^{\circ} 58.2^{\prime}$ & $\mathbf{N}$ & $154^{\circ} 59.9^{\prime}$ & $\mathbf{E}$ & $0-318 \mathrm{~m}$ \\
\hline $14^{\circ} 37^{\prime}$ & $\mathbf{N}$ & $119^{\circ} 52^{\prime}$ & E & $0-100 \mathrm{~m}$ \\
\hline $14^{\circ} 46^{\prime}$ & $\mathbf{N}$ & $137^{\circ} 00.1^{\prime}$ & $\mathbf{E}$ & $300 \mathrm{~m}$ \\
\hline $03^{\circ} 36^{\prime}$ & $\mathbf{S}$ & $097^{\circ} 37^{\prime}$ & E & $0-300 \mathrm{~m}$ \\
\hline $8^{\circ} 11^{\prime}$ & $\mathbf{S}$ & $092^{\circ} 41^{\prime}$ & $\mathbf{E}$ & $0-600 \mathrm{~m}$ \\
\hline
\end{tabular}

Diacavolinia vanutrechti forma meisenheimeri (Fig. 50) is a central Pacific taxon found so far in the open ocean only.

Localities:

$\begin{array}{llllr}25^{\circ} 30.5^{\prime} & \mathrm{N} & 125^{\circ} 28^{\prime} & \mathrm{E} & 0-100 \mathrm{~m} \\ 14^{\circ} 46^{\prime} & \mathrm{N} & 137^{\circ} 00.1^{\prime} \mathrm{E} & 300 \mathrm{~m} \\ 07^{\circ} 46^{\prime} & \mathrm{S} & 167^{\circ} 10^{\prime} \mathrm{W} & 0-600 \mathrm{~m} \\ 10^{\circ} & \mathrm{S} & 168^{\circ} 40^{\prime} \mathrm{W} & 0-200 \mathrm{~m} \\ 13^{\circ} 14^{\prime} & \mathrm{S} & 169^{\circ} 57^{\prime} \mathrm{E} & 0-50 \mathrm{~m} \\ 18^{\circ} 53^{\prime} & \mathrm{S} & 163^{\circ} 02.5^{\prime} \mathrm{W} & 0-300 \mathrm{~m}\end{array}$

The material of the present study is collected for more than $90 \%$ from open net hauls, mostly from shallow depth. The epipelagic distribution is clearly shown.

The distribution pattern of Diacavolinia shows four separate areas of occurrence, viz. an Atlantic, an Indo-W. Pacific, a Central Pacific and an E. Pacific range (Meisenheimer, 1905; Tesch, 1946; 


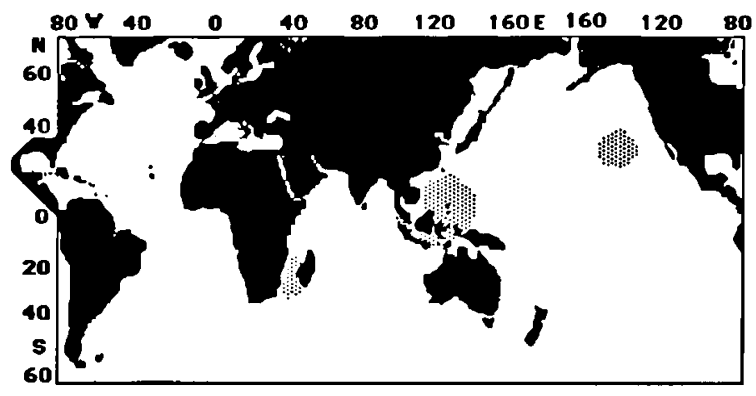

Fig. 43. Geographic distribution of $D$. pacifica.

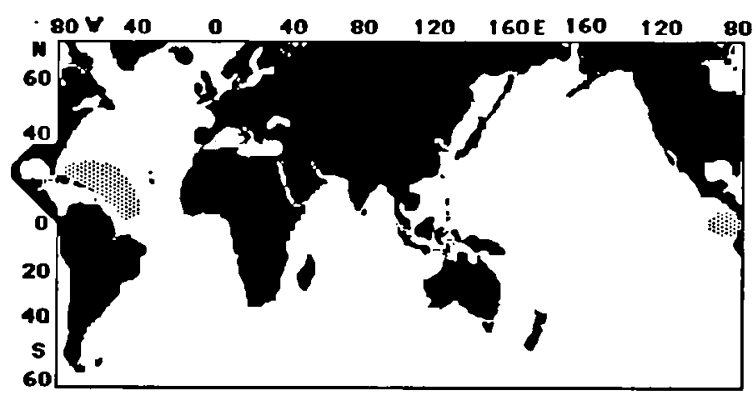

Fig. 44. Geographic distribution of D. robusta.

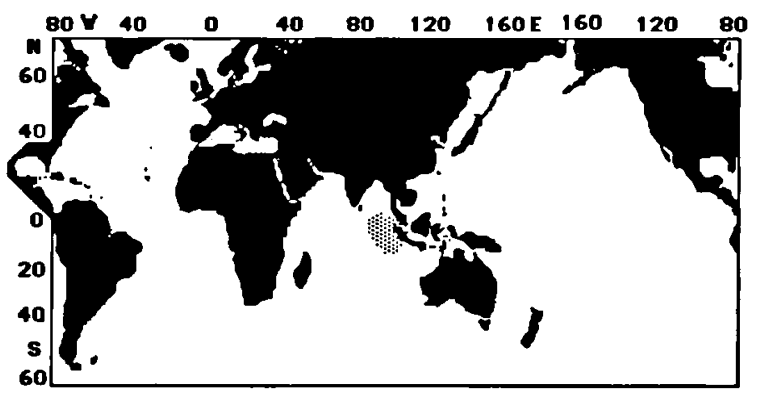

Fig. 45. Geographic distribution of $D$. souleyeti.

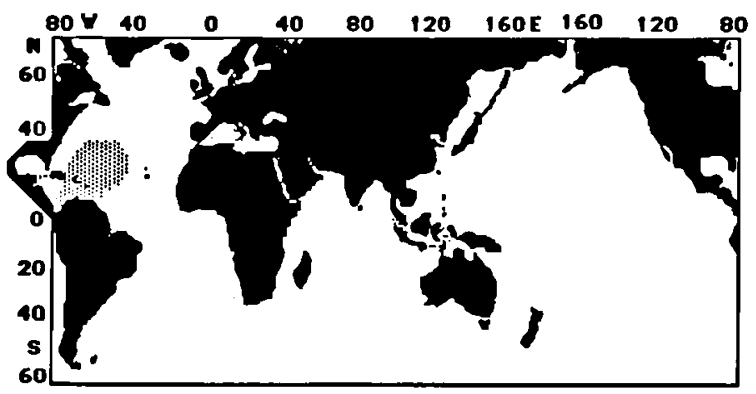

Fig. 46. Geographic distribution of $D$. strangulata.

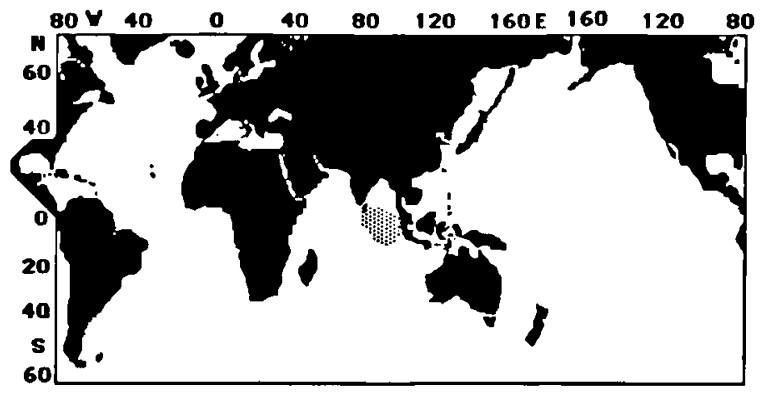

Fig. 47. Geographic distribution of D. striata.

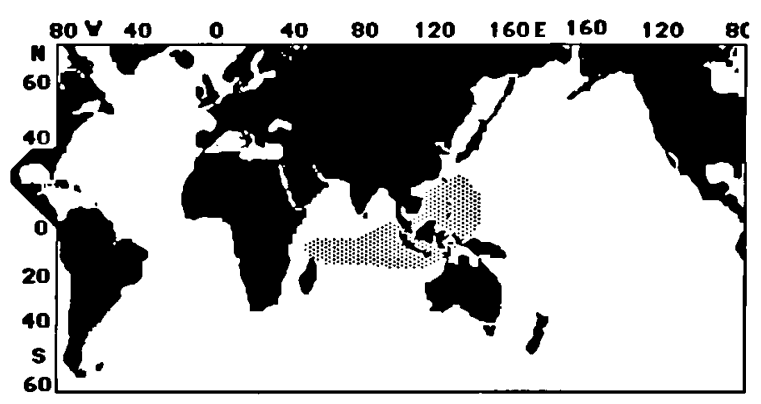

Fig. 48. Geographic distribution of $D$. triangulata.

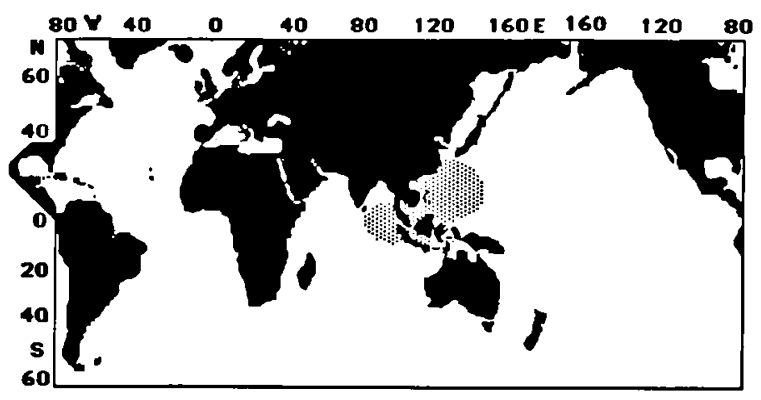

Fig. 49. Geographic distribution of $D$. v. forma vanutrechti.

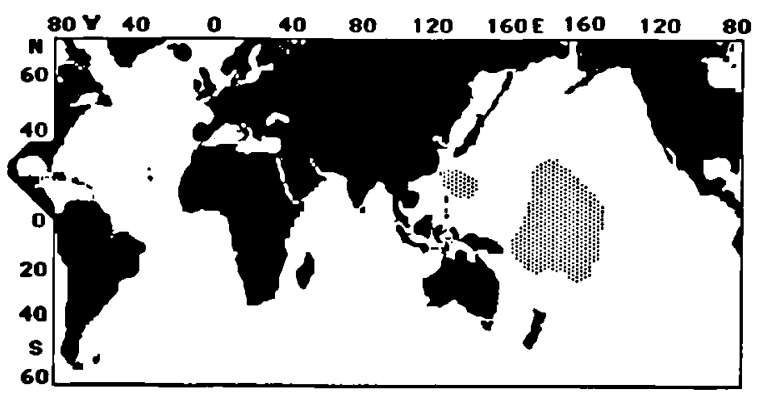

Fig. 50. Geographic distribution of $D$. v. forma meisenheimeri. 
1948). The groups present in the cladogram (Fig. 53) agree with the biogeography as discussed below.

Most records of Diacavolinia are from the epipelagic zone $(0-200 \mathrm{~m})$ of warmer waters $\left(50^{\circ} \mathrm{N}-45^{\circ} \mathrm{S}\right)$, a pattern comparable to the distribution of the heteropod Atlanta. Adaptation to deep water and to colder areas did not develop. Isolation in shallow currents and water masses is to be expected and this may also contribute to the high degree of speciation in this genus.

\section{Reproduction}

Knowers (1894) discovered in Cavolinia longirostris (thus in Diacavolinia) a separate male and female sexual aperture. The separation of male and female parts is in Diacavolinia much better developed than in Clio pyramidata Linnaeus, 1767 forma sulcata (Pfeffer, 1879), the only other pteropod with separate sexual apertures (Van der Spoel, 1965).

Sperm and ova arise from the follicle septa. The gonoduct leaves the gonad at its anterior face, somewhat dorsally and far to the left. This gonoduct first forms a bursa before ending in the accessory sexual gland, called muciparous gland by Knowers. A separate albumen gland was not found by him though it is present. Anteriorly the efferent duct leaves the accessory gland debouching to the left. The efferent duct and the gonoduct connect with the accessory sexual gland quite near to each other. The efferent duct forms over its entire length a closed tube and not an open groove (seminal groove) as in all other Euthecosomata. This closed seminal duct curves around the right side to reach the dorsal side of the body near the wing base; from there it runs anteriorly and opens at the aperture of the penis sac.

On the left side of the accessory sexual gland a second aperture is found. It is a slit-like opening in a small papilla on the anterior left surface of the visceral mass. Without any interruption, the ciliated epithelium of the lumen of the accessory sexual gland merges into the ciliated epithelium covering the body in this area. Quite near to the second opening of the accessory gland the receptaculum is found. The second aperture thus must be consid- ered the female aperture while the original one, in contact with the seminal tube, is the male aperture. This description is based on a histological investigation of $D$. longirostris and $D$. angulosa (Knowers, 1894; Van der Spoel, 1976) but it is supposed to hold true for the other species of this genus as well.

Sperm transport is much better effected by the closed tube than by an open seminal groove, but the differentiation makes a new female aperture necessary. In some other Opisthobranchia double sexual apertures are also found, e.g. in Lobiger and $A C$ teon. The rather complicated copulatory structure may well be responsible for the greater diversity in Diacavolinia.

\section{Shell development}

The adult shell of Diacavolinia never has a protoconch I left. It is composed of the teloconch and a small section of the protoconch II (Fig. 51). The protoconch I developed in the egg. After hatching the protoconch II develops in a few days. As can be concluded from the growth rings, the teloconch grows to its final size in about one month. After this phase only minor additions of material occur along the rim of aperture and spines (Fig. 51). The protoconch II is very flat like in most Cavoliniidae.

Richter (1982) studied the development of the shell of the present genus and showed that it strongly deforms during development to reach a greater dorsoventral width. Though the shell easily changes shape it is evident that growth, in Diacavolinia as well, means size increase and building of structures. Thus the co-occurrence of $D$. elegans, $D$. deblainvillei, and $D$. ovalis in one sample (Figs. 9C-E) cannot illustrate different growth forms of the same species. $D$. ovalis cannot be a juvenile of the other two, though it is smaller, as it cannot loose the constriction in the rostrum. The others can be no growth forms of $D$. ovalis as they are already larger without having the structures of the first. $D$. elegans cannot be a growth form of $D$. deblainvillei as it is already larger without having a notch or larger spines. For the same reason, $D$. deblainvillei cannot be a growth form of $D$. elegans. Another example is that of $D$. angulosa and 

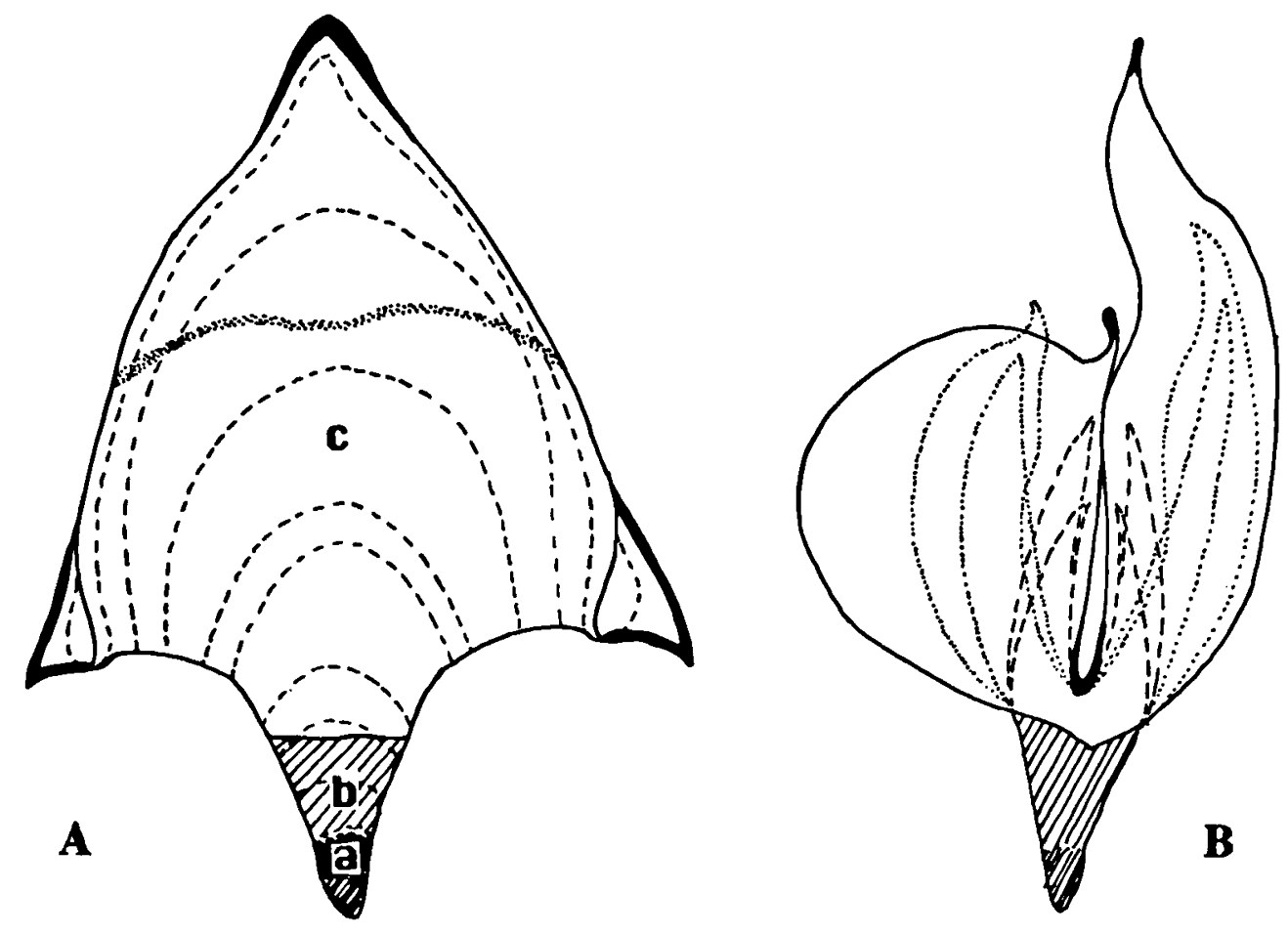

Fig. S1. Ventral view (A) and lateral view (B) of shell growth in Diacavolinia: $\mathrm{a}=$ protoconch $\mathrm{I}, \mathrm{b}=$ protoconch II, $\mathrm{c}=\mathrm{teloconch}$; the shell part that becomes lost in adults is hatched and the final growth of the shell is indicated by dotted and broken lines showing successive growth stages.

D. pacifica, which can neither be growth forms of each other though they resemble each other closely. The larger $D$. pacifica cannot grow from $D$. angulo$s a$ with the projecting protoconch II area, as absorption or withdrawal of this part cannot occur (cf. Tables I \& II). Moreover, the valve angle, which may form an indication for the growth stage of the shell, is in $D$. pacifica only slightly larger than in $D$. angulosa (cf. Table III).

The mechanism of the left and right lock in the aperture of adults fixes the final shape of the shell after this period of blowing up (Richter, 1982). So, for morphological comparison and descriptions only specimens with the lock mechanism fully developed were used. When shell growth is nearly finished in Cavoliniidae (except for Hyalocylis) the aperture rims start thickening. In Diacavolinia it is only or mainly the ventral lip rim that grows thicker in the last growth phase. The shape of spines and notch at the life stage with completed closing mechanism and thickened ventral lip can be con- sidered as the final growth stage of these structures. A lock mechanism is also found in Cavolinia, and in Diacria though this was not yet described in literature. The Cavolinia species show a development comparable to that of Diacavolinia though the two valves are not so extremely bent outwards during growth; they grow directly in a more oblique direction from the protoconch. In Diacria locks completely different from those in Diacavolinia and Cavolinia are found. In the Diacria trispinosa (De Blainville, 1821) group (cf. Bleeker \& Van der Spoel, 1988) the shell stays flat during life and it grows directly rather thick so that a simple lock mechanism may be sufficient. In these species two tubercles on the dorsal side and two on the ventral side (Pl. II fig. 35) only prevent posterior/anterior movements of the valves. In the Diacria quadridentata (De Blainville, 1821) group (cf. Bleeker \& Van der Spoel, 1988) the adult shell is strongly swollen. Though no records are known of the development it can be stated that the stiffness of the shell in the 
Table I. Meristical data, except for length and width, of Diacavolinia, all in $\mathrm{mm}$ ( $n$ is the same as in Table II).

\begin{tabular}{|c|c|c|c|c|c|c|c|}
\hline species & $\begin{array}{l}\text { width } \\
\text { at lock }\end{array}$ & $\begin{array}{l}\text { width of } \\
\text { joint }\end{array}$ & $\begin{array}{l}\text { width of } \\
\text { fold }\end{array}$ & $\begin{array}{l}\text { length of } \\
\text { spine }\end{array}$ & $\begin{array}{l}\text { ventral } \\
\text { lip height }\end{array}$ & $\begin{array}{l}\text { aperture } \\
\text { width }\end{array}$ & $\begin{array}{l}\text { rostrum } \\
\text { length }\end{array}$ \\
\hline D. angulosa & $2.56-1.84$ & $1.04-0.96$ & $0.96-0.48$ & $0.50-0.20$ & $0.40-0.12$ & $0.48-0.40$ & $0.80-0.40$ \\
\hline D. aspina & 2.68 & 1.00 & 1.00 & 0.08 & 0.36 & 1.00 & 0.48 \\
\hline D. atlantica & $5.61-5.10$ & $1.60-1.36$ & $2.21-1.53$ & $2.96-1.02$ & $0.56-0.51$ & $4.08-2.72$ & - \\
\hline D. bandaensis & 1.68 & 0.96 & 0.56 & 0.16 & 0.20 & 0.28 & 0.44 \\
\hline D. bicornis & $3.92-2.80$ & $1.20-1.08$ & $2.00-0.96$ & $1.40-0.28$ & 0.40 & $2.40-1.20$ & - \\
\hline D. constricta & 3.84 & 1.20 & 1.52 & 0.48 & 0.64 & 0.16 & 0.96 \\
\hline D. deblainvillei & $3.44-2.88$ & 1.20 & $1.20-0.88$ & $0.64-0.40$ & $0.40-0.24$ & $2.40-1.68$ & - \\
\hline D. deshayesi & $4.00-3.04$ & $1.52-0.64$ & $1.68-1.20$ & $0.88-0.72$ & $0.48-0.32$ & $0.80-0.20$ & $1.44-1.36$ \\
\hline D. elegans & $3.36-2.56$ & $1.20-1.16$ & $1.36-0.84$ & $0.48-0.24$ & $0.48-0.24$ & $2.00-1.40$ & - \\
\hline D. flexipes & 4.16 & 2.00 & 1.92 & 0.88 & 0.46 & 2.80 & - \\
\hline D. grayi & $2.20-2.12$ & $1.08-1.04$ & $0.80-0.72$ & $0.76-0.40$ & 0.36 & $0.76-0.44$ & $0.69-0.68$ \\
\hline D. I. forma africana & $5.44-5.36$ & $1.92-1.19$ & $2.04-1.92$ & $1.44-1.36$ & $1.02-0.56$ & $3.44-3.40$ & - \\
\hline D. l. forma limbata & 5.36 & 1.87 & 1.70 & 1.27 & 0.77 & 4.42 & - \\
\hline D. longirostris & $3.52-3.36$ & $1.28-1.20$ & $1.60-1.20$ & $0.96-0.88$ & $0.56-0.40$ & $2.48-2.40$ & - \\
\hline D. mcgowani & 3.04 & 1.04 & 0.88 & 1.60 & 0.24 & 1.60 & - \\
\hline D. ovalis & $2.96-2.32$ & $1.12-0.96$ & $1.20-0.80$ & $0.56-0.32$ & $0.48-0.28$ & $1.60-1.28$ & - \\
\hline D. pacifica & $2.68-2.40$ & $1.16-0.96$ & $1.00-0.96$ & $0.64-0.56$ & 0.40 & 0.48 & $0.92-0.64$ \\
\hline D. robusta & $2.84-2.64$ & $1.16-0.80$ & $1.08-0.72$ & $0.40-0.16$ & $0.40-0.24$ & $1.28-0.72$ & - \\
\hline D. souleyeti & $3.60-3.20$ & $1.20-1.12$ & $1.20-1.12$ & $0.40-0.24$ & $0.32-0.24$ & $2.40-2.32$ & - \\
\hline D. strangulata & 2.20 & 0.64 & 0.72 & $0.40-0.20$ & 0.32 & 0.40 & - \\
\hline D. striata & 2.64 & 1.04 & 1.04 & 0.08 & 0.36 & 0.80 & 0.4 \\
\hline D. triangulata & 4.48 & 1.92 & 1.60 & 1.52 & 0.56 & 3.04 & - \\
\hline D. v. forma vanutrechti & 2.60 & 1.08 & 1.00 & 0.20 & 0.28 & 1.40 & - \\
\hline$D . v$. forma meisenheimeri & 3.52 & 1.12 & 1.20 & 0.32 & 0.56 & 2.24 & - \\
\hline
\end{tabular}

Diacria quadridentata group is much greater than in Diacavolinia and Cavolinia so that only a simple lock mechanism seems required. It consists of two tubercles on the ventral side and a link at the dorsal side (Pl. III fig. 36). This is just the reverse of what is found in the other genera of the Cavoliniinae.

In general the lock mechanism in Diacavolinia is smaller than that in the Cavolinia species with a strong main and lunar tubercle and a small but high minor tubercle. Only in Cavolinia inflexa (Lesueur, 1813) the minor tubercle is rudimentary. In some species of Diacavolinia a second lock mechanism is found; in $D$. vanutrechti it is so large that it is clearly visible from the outside. The aperture is divided into five instead of three sections in these species. The second lock mechanism is described here for the first time. This structure is found in Cavolinia globulosa (Gray, 1850) and Diacavolinia but not in any other species of Thecosomata (Pl. III figs. 37-40). In our opinion the lock system of Diacria trispinosa does not show a real second lock though the tubercles are placed far apart.

There is a certain relation between shell size and the presence of the second lock. It is very well possible that the presence of the second lock in thinshelled species makes it possible for them to grow larger. As the second lock is of the same morphology and not a variable adaptation in larger forms, it is to be considered a phylogenetic important feature.

Theoretically in all species a notch may develop when growth proceeds. However, in many species growth seems to have stopped before the notch developed. $D$. mcgowani evidently shows that in fullgrown shells with extremely grown-out lateral spines the notch is still absent. Compare this species with $D$. striata and it is clear that here the notch is fully developed while the spines are not yet formed. So it may be better to consider the species given above as having no notch as species in which notch development is suppressed during growth. 
Table II. Length and width data of Diacavolinia (in $\mathrm{mm}$ ).

\begin{tabular}{|c|c|c|c|c|c|c|c|}
\hline species & length & width & $\begin{array}{l}\text { width as } \% \\
\text { of length }\end{array}$ & $\begin{array}{l}\text { average lock width } \\
\text { as } \% \text { of length }\end{array}$ & $\begin{array}{l}\text { average } \\
\text { length }\end{array}$ & $\begin{array}{l}\text { average } \\
\text { width }\end{array}$ & $n$ \\
\hline D. angulosa & $4.80-3.00$ & $3.72-2.32$ & 88 & 57 & 3.39 & 2.76 & 53 \\
\hline D. aspina & $5.04-3.12$ & $3.60-2.48$ & 73 & 65 & 4.07 & 3.12 & 22 \\
\hline D. atlantica & $10.88-8.33$ & $9.60-7.14$ & 83 & 56 & 9.58 & 8.11 & 20 \\
\hline D. bandaensis & $4.60-3.72$ & $4.24-3.00$ & 76 & 40 & 4.10 & 3.55 & 9 \\
\hline D. bicornis & $7.84-4.60$ & $7.84-3.88$ & 90 & 55 & 5.81 & 5.57 & 4 \\
\hline D. constricta & $5.60-4.80$ & $5.28-3.44$ & 94 & 68 & 4.92 & 4.54 & 4 \\
\hline D. deblainvillei & $6.88-3.60$ & $5.36-3.04$ & 88 & 64 & 5.39 & 4.25 & 46 \\
\hline D. deshayesi & $8.16-3.12$ & $6.72-2.80$ & 87 & 66 & 5.77 & 4.94 & 20 \\
\hline D. elegans & $6.16-3.36$ & $5.44-2.80$ & 77 & 65 & 4.75 & 3.96 & 24 \\
\hline D. flexipes & $8.00-4.50$ & $6.60-3.60$ & 89 & 66 & 6.25 & 5.10 & 6 \\
\hline D. grayi & $5.36-3.16$ & $5.28-2.40$ & 91 & 54 & 4.27 & 3.76 & 10 \\
\hline idem long-spined & $5.28-4.48$ & $5.60-4.24$ & & & 4.96 & 4.85 & 5 \\
\hline D. I. forma africana & $10.40-7.84$ & $8.64-7.04$ & 85 & 60 & 9.16 & 7.91 & 16 \\
\hline D. l. forma limbata & $12.75-8.33$ & $10.37-6.12$ & 78 & 51 & 10.25 & 8.00 & 20 \\
\hline D. longirostris & $7.28-5.20$ & $6.80-4.96$ & 92 & 52 & 6.52 & 5.74 & 20 \\
\hline idem long-spined & $9.18-7.99$ & $8.84-7.99$ & & & 8.74 & 8.33 & 6 \\
\hline D. mcgowani & $4.88-3.36$ & $5.68-2.80$ & 116 & 62 & 4.12 & 4.24 & 3 \\
\hline D. ovalis & $6.08-4.00$ & $5.04-3.12$ & 85 & 53 & 4.83 & 3.97 & 13 \\
\hline D. pacifica & $4.76-3.92$ & $4.32-3.84$ & 93 & 58 & 4.28 & 4.11 & 11 \\
\hline idem long-spined & $4.80-3.84$ & $5.28-3.60$ & & & 4.24 & 4.22 & 6 \\
\hline D. robusta & $5.36-3.84$ & $4.48-3.04$ & 86 & 61 & 4.43 & 3.70 & 10 \\
\hline D. souleyeti & $6.64-6.00$ & $4.96-3.92$ & 77 & 53 & 6.21 & 4.53 & 3 \\
\hline D. strangulata & $4.64-3.36$ & $4.16-2.76$ & 82 & 51 & 3.88 & 3.33 & 12 \\
\hline D. striata & $5.60-3.92$ & $4.24-2.88$ & 68 & 55 & 4.61 & 3.41 & 15 \\
\hline D. triangulata & $9.20-4.88$ & $8.80-4.40$ & 96 & 56 & 7.63 & 7.66 & 14 \\
\hline D. v. forma vanutrechti & $4.88-3.76$ & $3.64-2.40$ & 74 & 60 & 4.16 & 3.06 & 14 \\
\hline D. $v$. forma meisenheimeri & $7.76-4.32$ & $4.96-2.96$ & 61 & 51 & 6.00 & 4.00 & 22 \\
\hline
\end{tabular}

The shell size (Fig. 52) needs also attention as it may differ strongly in different populations of one species. The occurrence of small-sized shells in Central Waters, of medium-sized shells in Equatorial Waters and of large shells at higher latitudes, in neritic and upwelling waters, can be recognized as a general trend. Productivity of the environment seems thus also to determine the size of the shells.

\section{Phylogeny}

When so many species exist in Diacavolinia it is a successful group indeed. The ability to radiate is probably dependent on the reproductive apparatus. The success of the group must be based on an ecological factor. In the evolution of the non-coiled pteropods a constant trend is visible to shorten the calcareous shell. In Hyalocylis, Cuvierina, Diacria,

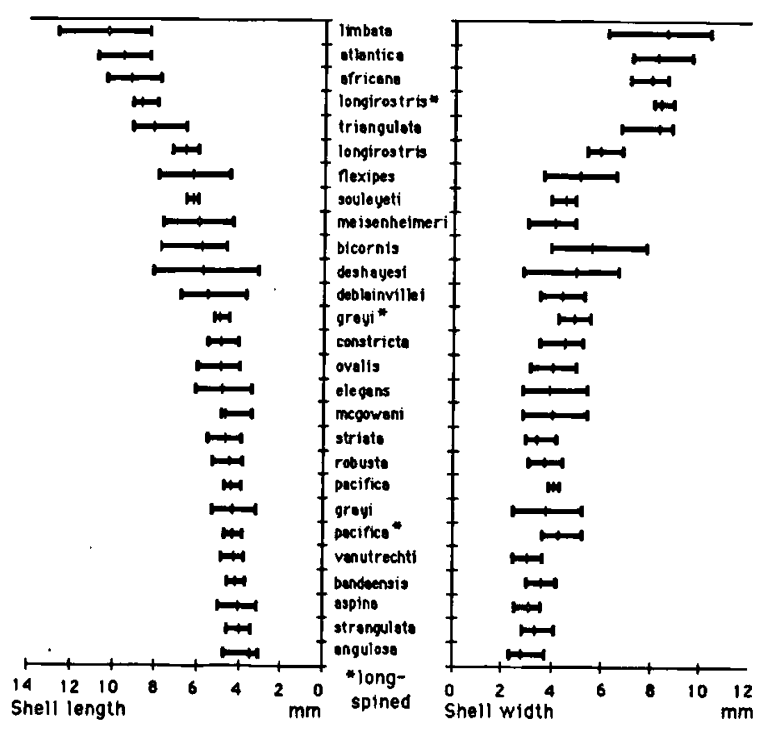

Fig. 52. Minimum, average, and maximum length and width for the Diacavolinia taxa. 
Table III. Angles measured in the shells of Diacavolinia ( $n$ is the same as in Table II).

\begin{tabular}{|c|c|c|c|c|}
\hline species & lock angle & side angle & lip angle & valve angle \\
\hline D. angulosa & $74-71$ & $76-72$ & $138-135$ & 67 \\
\hline D. aspina & 69 & 75 & 150 & $70-55$ \\
\hline D. atlantica & $82-64$ & $74-70$ & $140-110$ & 72 \\
\hline D. bandaensis & 74 & 81 & 155 & \\
\hline D. bicornis & $74-70$ & $69-66$ & $150-136$ & 72 \\
\hline D. constricta & 67 & 75 & 105 & 64 \\
\hline D. deblainvillei & $78-69$ & $80-71$ & $150-146$ & 83 \\
\hline D. deshayesi & $74-67$ & $72-70$ & $140-115$ & 77 \\
\hline D. elegans & $79-73$ & $82-71$ & $161-144$ & 64 \\
\hline D. flexipes & $70-67$ & 75 & 155 & $76-75$ \\
\hline D. grayi & $72-71$ & $73-69$ & 145 & 80 \\
\hline D. l. forma africana & $67-61$ & 76 & $154-130$ & 76 \\
\hline D. . forma limbata & 69 & 68 & 142 & 70 \\
\hline D. longirostris & $78-67$ & $71-65$ & $145-132$ & $71-69$ \\
\hline D. mcgowani & 65 & 62 & 144 & 71 \\
\hline D. ovalis & $72-67$ & 71 & $125-118$ & 70 \\
\hline D. pacifica & $79-76$ & $70-68$ & 143 & 73 \\
\hline D. robusta & $76-68$ & $85-72$ & $130-112$ & 60 \\
\hline D. souleyeti & $80-69$ & $83-76$ & 155 & 72 \\
\hline D. strangulata & $74-71$ & $79-76$ & $140-105$ & 69 \\
\hline D. striata & 74 & $80-90$ & 140 & 67 \\
\hline D. triangulata & 72 & 65 & 150 & $69-60$ \\
\hline D. v. forma vanutrechti & $76-70$ & $75-73$ & 150 & 70 \\
\hline D. $v$. forma meisenheimeri & 75 & 83 & 153 & 67 \\
\hline
\end{tabular}

and some Cavolinia species this shortening is reached by dropping the embryonic shell or part of it and the opening thus left is directly closed by a special membrane in the mark left. In Diacavolinia this loss of the embryonic parts is realized in the most perfect way, no mark is left, no membrane has to be made, and the shell has no fragile hind portion like in the other genera mentioned. Infections through a half-closed membrane are not possible and there is no irregular surface on which parasites and epiphytes can attach, while the hydrodynamic shape of the shell is most perfect.

It is evident that Diacavolinia developed from Cavolinia as a more evolved group which entirely lost the caudal spine composed of protoconch elements. The second lock system is also found in Cavolinia globulosa and in this species the protoconch is usually shed as well (Van der Spoel, 1967). An ancestor of $C$. globulosa, also endemic to the Indo-Pacific, gave probably rise to Diacavolinia and the other species of Cavolinia that lost the ability to throw off the embryonic shell. Diacavolinia has the caudal closing joint replacing the membrane as a unique feature.

Cladistic analysis of the Euthecosomata (Fig. 53), using the computer programme "MacClade; W. Maddison \& D. Maddison, 1987', shows that the Cavoliniidae developed from the Limacinidae by loss of shell coiling. The life strategy in which minute stages occur started with the Clioinae. In this subfamily Clio separated by the development of two lateral ribs and Styliola by the development of one lateral rib. From this subfamily also all other Cavoliniinae developed that share the throwing off of the embryonic shell. Hyalocylis stayed apart as the throwing off occurs at a very young age, probably in the veliger stage, and growth is giving unlimited length increase in this genus. In the Cuvierininae and Cavoliniinae the aperture rim grows thicker during the last growth phase without further size increase of the shell. In these two subfamilies the throwing off of the embryonic shell is also occurring at a later stage in life, just between the juvenile and minute stage. 


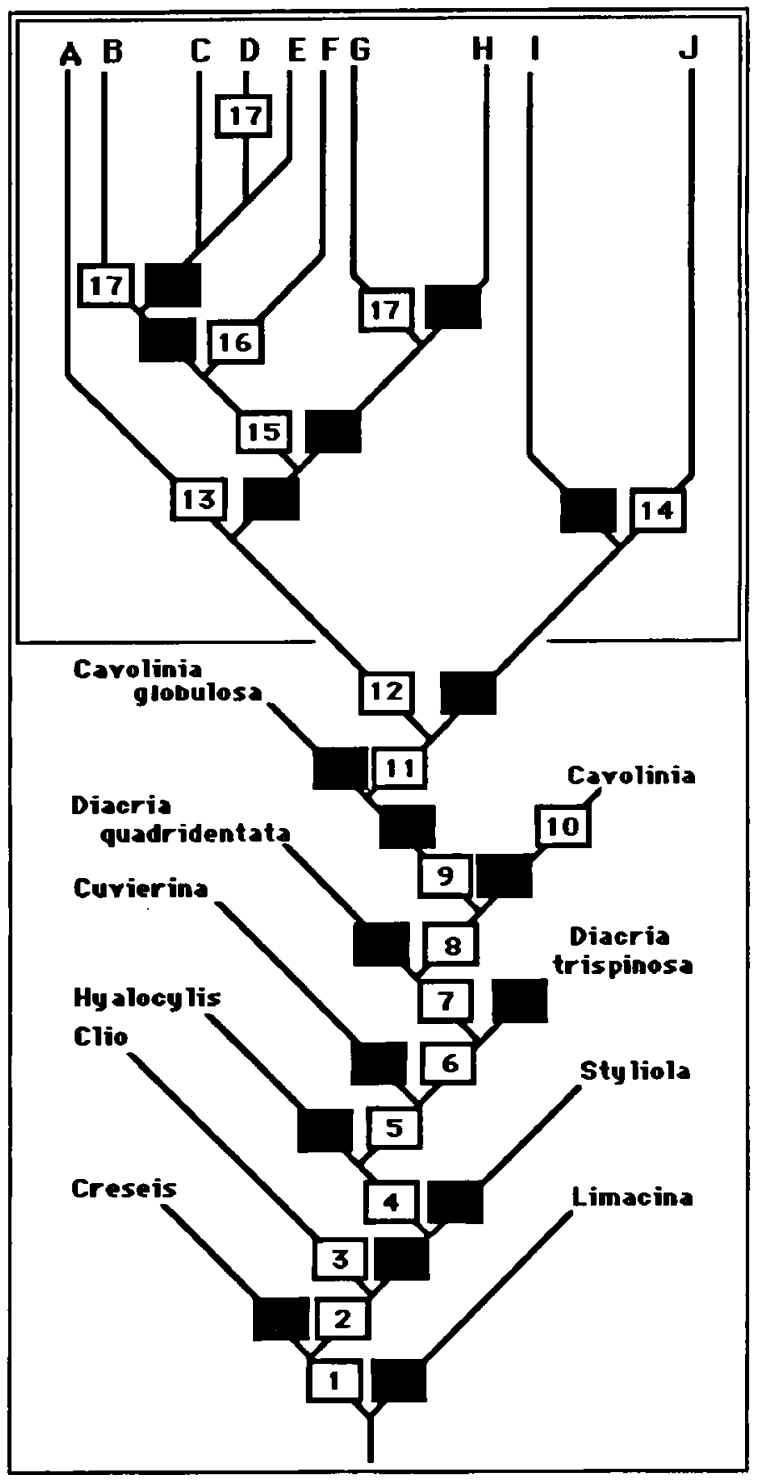

Fig. 53. Diagram of the phylogeny of Euthecosomata: $1=$ loss of shell coiling; 2 = minute stages occur in development; 3 = lateral ribs develop; 4 = embryonic shell is shed, in the other clade one lateral rib develops; 5 = aperture rim is thickened in last growth phase; $6=$ loss of circular aperture, development of "bivalve" structure; $7=$ ventral side becomes swollen; $8=$ the main closing mechanism develops; $9=$ the second closing system develops; $10=$ secondary disappearances of embryonic shell loss; 11 = closing joint replaces membrane; 12 = spines become dorsally bent; $13=$ notch develops; $14=$ hump develops; 15 = secondary flattening in part of ventral side; $16=$ secondary straight spines and hump development; $17=$ development of incision.

The groups distinguished by dichotomy are: $A(D$. elegans, $D$. flexipes), B (D. v. vanutrechti, D. v. meisenheimeri), C (D. deblainvillei), D (D. atlantica, D. l. africana), E (D. l. limbata,
The Cavoliniinae separated from the Cuvierininae as the first were loosing the tubular shape and circular aperture; the shell then started to be "bivalved". In the Cavoliniinae the dorsoventral flattening of the shell got lost when in Diacria quadridentata the ventral side became strongly swollen. At this point also an increase of the length of the slit of the aperture developed so that the aperture reached the anterior parts of the shell. From these swollen Diacria quadridentata-like types with a closing system with the link in dorsal position, a group developed with a closing mechanism characterized by the ventrally placed lock link in the aperture. This group splitted into a further evolving clade of Cavolinia globulosa that developed a second lock system and a second group that shows secondary loss of the throwing off of the embryonic shell and that did not develop the second lock; these are the remaining Cavolinia species. From $C$. globulosa the Diacavolinia clade developed in which the closing membrane (that developed at point 4 in Fig. 53) is replaced by the caudal joint.

Diacavolinia subdivided most parsimoniously at the point where the lateral spines start to bend dorsally. Also very evident is the splitting of the taxa with straight spines into a group with hump ( $\mathrm{J}$ in Fig. 53) and a group without hump (I in Fig. 53). The group with bent spines splits into taxa without notch (A in Fig. 53) and taxa with a notch. In the group having a notch the programme separated two groups, one with secondary flattening of the ventral side and one without $(\mathrm{G}+\mathrm{H}$ in Fig. 53). The further division into separate clades is very arbitrary and though more clades were produced by the programme the parsimony was too low to be discussed here. Based on this cladogram one can conclude that the Indo-Pacific Cavolinia globulosa clade is ancestral to an Indo-Pacific group (J) in Diacavolinia that gave rise to the other groups in that genus, some of which stay endemic to the IndoPacific, like B and F, and some of which are endemic to the Atlantic Ocean, like D and C. A cladogram

D. souleyeti), F (D. triangulata), G (D. bicornis, $D$. deshayesi, $D$. striata, $D$. constricta, $D$. ovalis, $D$. strangulata), H (D. longirostris), I (D. mcgowani, D. robusta), J (D. angulosa, D. bandaensis, D. aspina, D. grayi, D. pacifica). 
constructed mainly on the basis of the lock tubercles gave a comparable picture with the same groups.

Many characters available in the shell do not show any phylogenetic trend and are not giving any results in analyses, so the very rough diagram in Fig. 53 is the only possible result at this moment. The groups indicated in the descriptions as morphological groups have no relation to phylogeny.

\section{Conclusions}

Diacavolinia was split off from Cavolinia to comprise the very variable species $C$. longirostris by Van der Spoel (1987). To describe this variability the detailed analysis of characters requires an accurate terminology for shell structures. Moreover, all characters should be considered separately avoiding the use of types, like e.g. the "angulosa" type. Tesch (1948) stated that the types angulosa and strangulata were both absent from Atlantic waters. However, species with characters of both forms are here given from the Atlantic, and to conclude from the labels Tesch identified specimens with humps and constrictions from Atlantic Dana material as "Cavolinia longirostris" probably as these specimens did neither show all characters of the form angulosa nor those of strangulata.

As many of the taxa described as new occur sympatric, it was evident that no subspecies, forms or ecological races were concerned. In sympatry we would only expect valid species or morphotypes of one population. There are two arguments against polymorphism in the present group. Such a polymorphism is unknown in the Thecosomata and it is not likely that this mechanism should occur isolated in one species (Mayr, 1971). The geographic variation in taxa did not indicate a link between the climate or water masses and the different relative abundance of the taxa which is also common in polymorphic species (Mayr, 1971). So for the time being it seems only logical to consider most presently described taxa as valid species.

Many discriminating characters in the newly described species were derived from the lips and spines. In Thecosomata the lip shape and spine shape are not very variable, and when different shapes occur in species like Cavolinia uncinata and C. tridentata, geographically separated taxa are concerned or even different species as in Diacria.

The discovery of the presence of a double lock mechanism in some specimens and of striking differences in colour pattern, shell shape and sculpture, did not only prove that there are more species in the planktonic pteropods than was expected for many years but it also shows that a critical approach of the observations made in the past is no luxury. The restricted vertical distribution, the special shell development, and the complicated reproductive system in Diacavolinia favour a high degree of speciation.

Twenty-four taxa are described here for Diacavolinia with restricted Atlantic and Indo-Pacific distributions or with circumglobal occurrences. The phylogeny of the group could only be incompletely reconstructed but the cladograms all point to an Indo-Pacific origin from a Cavolinia globulosa-like type of ancestor.

\section{Acknowledgements}

The authors are indebted to Mr. T. Schiøtte (Zoological Museum, Copenhagen) and Dr. C.F.E. Roper (Smithsonian Institution) for providing material used in this study. Dr. P.H. Schalk is acknowledged for collecting and sorting the Snellius II material and Mr. R.G. Moolenbeek for providing Indian Ocean material. We are most grateful to Drs. F.F.J.M. Pieters, Dr. H.E. Coomans and two anonymous reviewers for critically reading the manuscript. Mr. L.A. van der Laan made the photographs on which the colour study was based.

\section{References}

Blainville, [H.M.D.] de, 1821a. Hyale, Hyaloea (Malacoz.). In: F.[G.] Cuvier (ed.), Dictionnaire des sciences naturelles, 22: 65-83 (F.G. Levrault, Strasbourg/Paris \& Le Normant, Paris).

Blainville, [H.M.D.] de, 1821b. Mémoire sur le genre Hyale. J. Phys. Chim. Hist. nat., 93: 81-97.

Bleeker, J. \& S. van der Spoel, 1988. Diacria piccola and Diacria maculata: two new pteropod mollusc species from the Atlantic and Pacific Oceans. Proc. biol. Soc. Washington, 101(1): 60-66.

Deshayes, [G.P.], 1823. Cléodore. Cleodora. In: [J.B.G.M.] 
Bory de Saint-Vincent (ed.), Dictionnaire classique d'histoire naturelle, 4: 203-204 (Rey et Gravier \& Baudouin, Paris).

Gray, J.E., 1850. Catalogue of the Mollusca in the collection of the British Museum, 2. Pteropoda: i-iv, 1-45 (British Museum/E. Newman, London).

Jespersen, J. \& A.V. Tåning, 1934. Foreword. Introduction to the reports from the Carlsberg Foundation's Oceanographical Expedition round the world 1928-1930. Dana Rep., 1: 7-16.

Knowers, H.M., 1894. Pteropods with two separate sexual openings. Ann. Mag. nat. Hist., (6)13: 529-530.

Krueger, W.H., R.H. Gibbs, R.C. Kleckner, A.A. Keller \& M.J. Keene, 1977. Distribution and abundance of mesopelagic fishes. Baseline report of environmental conditions in Deepwater Dumpsite 106. NOAA Dumpsite Evaluation Rep., 77-1: 377-422 (U.S. Dept. Commerce, Washington).

Mayr, E., 1971. Populations, species and evolution. An abridgment of animal species and evolution: $i-x v, 1-453$ (Belknap Press of Harvard University Press, Cambridge, Mass.).

Meisenheimer, J., 1905. Pteropoda. Wiss. Ergebn. dt. TiefseeExped. "Valdivia", 9: [i-iii], i-vi, 1-314, Atlas Pls. I-XXVII, [1-56], maps I-IX.

Orbigny, A. d', 1836-1846. Voyage dans l'Amérique méridionale (le Brésil, la république orientale de l'Uruguay, la république Argentine, la Patagonie, la république du Chili, la république de Bolivia, la république du Pérou), exécuté pendant les années 1826, 1827, 1828, 1829, 1830, 1831, 1832 et 1833, 5(3). Mollusques: 49-184 (1836); Atlas Pls. 1-20 (1846) (P. Bertrand, Paris \& Levrault, Strasbourg).

Richter, G., 1979. Die thecosomen Pteropoden der "Meteor"Expedition in den Indischen Ozean 1864/65. "Meteor" Forsch.-Ergebn., (D) 29: 1-29.

Richter, G., 1982. Wachstum und funktionelle Bedeutung des bilateralsymmetrischen Gehäuses von Cavolinia longirostris (Pteropoda, Thecosomata, Gastropoda). N. Jahrb. Geol. Paläontol., 164: 107-116.

Schalk, P.H., 1988. Monsoon influences on biogeography and ecology of zooplankton and micronekton of the IndoMalayan region: [i-vii], 1-144 (Ph.D. thesis, Univ. Amsterdam).

Spoel, S. van der, 1965. Differentiation in the pteropod Clio pyramidata L., 1767 forma sulcata (Pfeffer, 1879). Basteria, 29(1/4): 61-65.

Spoel, S. van der, 1967. Euthecosomata, a group with remarkable developmental stages (Gastropoda, Pteropoda): 1-375 (Ph.D. thesis, Univ. Amsterdam; J. Noorduijn \& Zoon, Gorinchem).
Spoel, S. van der, 1970. Morphometric data on Cavoliniidae, with notes on a new form of Cuvierina columnella (Rang, 1827) (Gastropoda, Pteropoda). Basteria, 34(5/6): 103151.

Spoel, S. van der, 1971a. Some problems in infraspecific classification of holoplanktonic animals. Z. zool. Syst. Evolut.forsch., 9(2): 107-138.

Spoel, S. van der, 1971b. New forms of Diacria quadridentata (de Blainville, 1821), Cavolinia longirostris (de Blainville, 1821) and Cavolinia uncinata (Rang, 1829) from the Red Sea and the East Pacific Ocean (Mollusca, Pteropoda). Beaufortia, 19(243): 1-20.

Spoel, S. van der, 1973. Variation in Cavolinia longirostris (De Blainville, 1821) from the Pacific Ocean with description of a new forma (Mollusca, Pteropoda). Bull. zool. Mus. Univ. Amsterdam, 3(14): 99-102.

Spoel, S. van der, 1976. Pseudothecosomata, Gymnosomata and Heteropoda (Gastropoda): 1-484 (Bohn, Scheltema \& Holkema, Utrecht).

Spoel, S. van der, 1981. List of discrete depth samples and open net hauls of the Amsterdam Mid North Atlantic Plankton Expedition 1980 (Project 101A). Bull. zool. Mus. Univ. Amsterdam, 8(1): 1-10.

Spoel, S. van der, 1985. List of discrete depth samples and open net hauls of the Amsterdam Mid North Atlantic Plankton Expedition 1982 and 1983 (project 101A). Bull. zool. Mus. Univ. Amsterdam, 10(17): 129-152.

Spoel, S. van der, 1987. Diacavolinia nov. gen. separated from Cavolinia (Pteropoda, Gastropoda). Bull. zool. Mus. Univ. Amsterdam, 11(9): 77-80.

Spoel, S. van der \& A.G.H.A. Meerding, 1983. List of discrete depth samples and open net hauls of the Amsterdam Mid North Atlantic Plankton Expedition 1981 (project 101A). Bull. zool. Mus. Univ. Amsterdam, 9(9): 77-91.

Tesch, J.J., 1913. Mollusca. Pteropoda. In: F.E. Schulze (ed.), Das Tierreich. Eine Zusammenstellung und Kennzeichnung der rezenten Tierformen, 36: i-xvi, 1-154 (R. Friedländer \& Sohn, Berlin).

Tesch, J.J., 1946. The thecosomatous pteropods, 1. The Atlantic. Dana Rep., 28: 1-82, pls. I-VIII.

Tesch, J.J., 1948. The thecosomatous pteropods, 2. The IndoPacific. Dana Rep., 30: 1-45, pls. I-III.

Received: 13 July 1992

Revised: 6 October 1992 


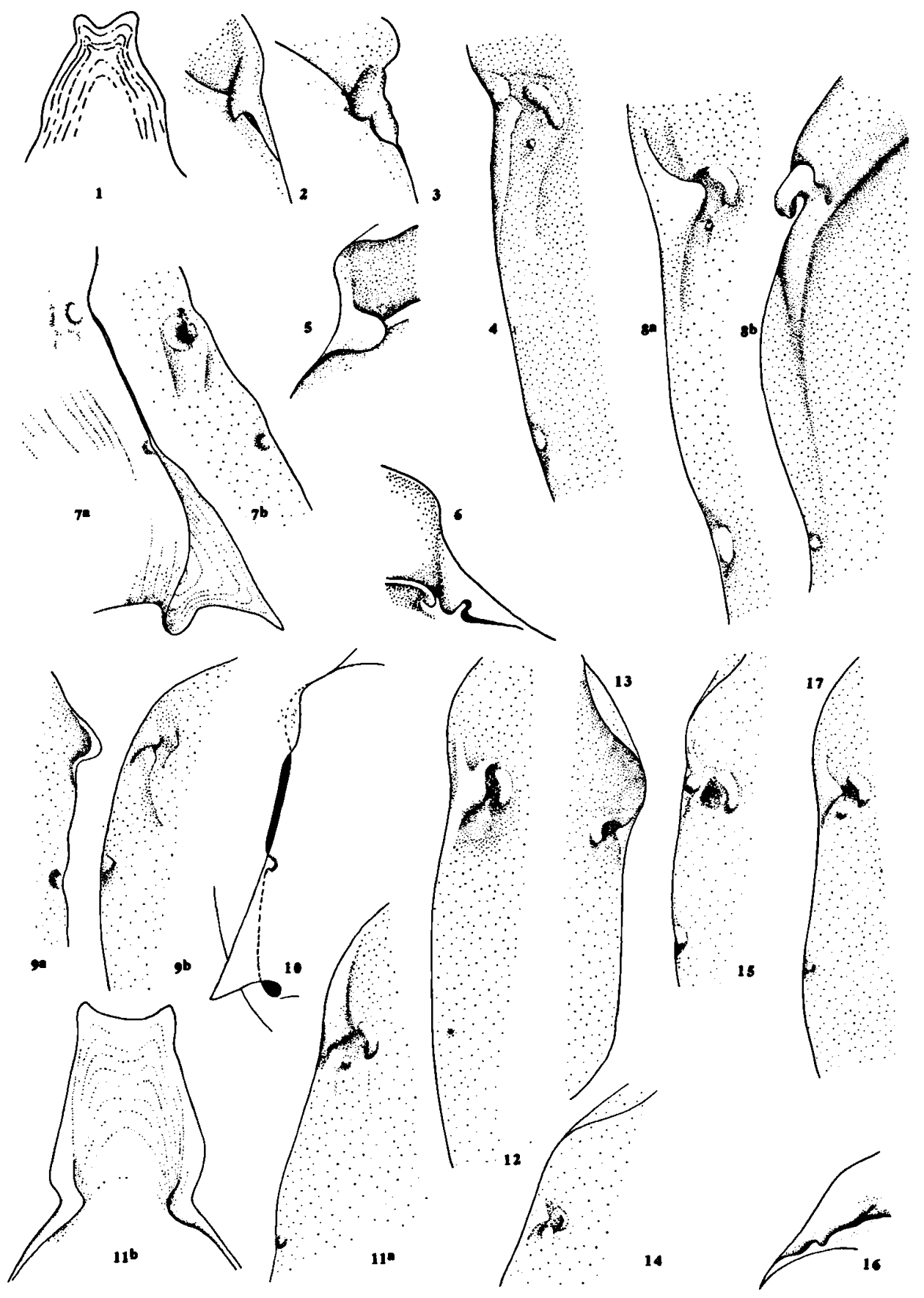

Plate I. Shell details: $1=$ notch with growth lines of $D$. longirostris; 2 = main lock tubercle of $D$. longirostris; $3=$ lock area of $D$. longirostris; 4 = lock mechanism from inside of $D$. longirostris (long-spined form); $5=$ lock area of $D$. l. forma limbata; $6=$ lock area of another $D$. $l$. forma limbata; $7=$ lock system from dorsal (a) and lock tubercles from inside (b) of $D$. $l$. forma africana; $8=$ D. atlantica, lock mechanism from inside at dorsal (a) and ventral (b) side; $9=D$. v. forma vanutrechti, lock tubercles at ventral (a) and dorsal (b) side from inside; $10=D$. v. forma vanutrechti, lock area from lateral; $11=$ lock tubercles from inside (a) and notch and incision (b) of $D$. v. forma meisenheimeri; $12=$ lock tubercles in dorsal shell of $D$. elegans; $13=D$. robusta, lock tubercles at dorsal side from inside; $14=D$. bicornis, dorsal lock tubercles from inside; $15=$ lock mechanism from inside of $D$. deblainvillei; $16=$ lock area of $D$. souleyeti; $17=D$. striata, dorsal tubercles of the lock mechanism from inside. 

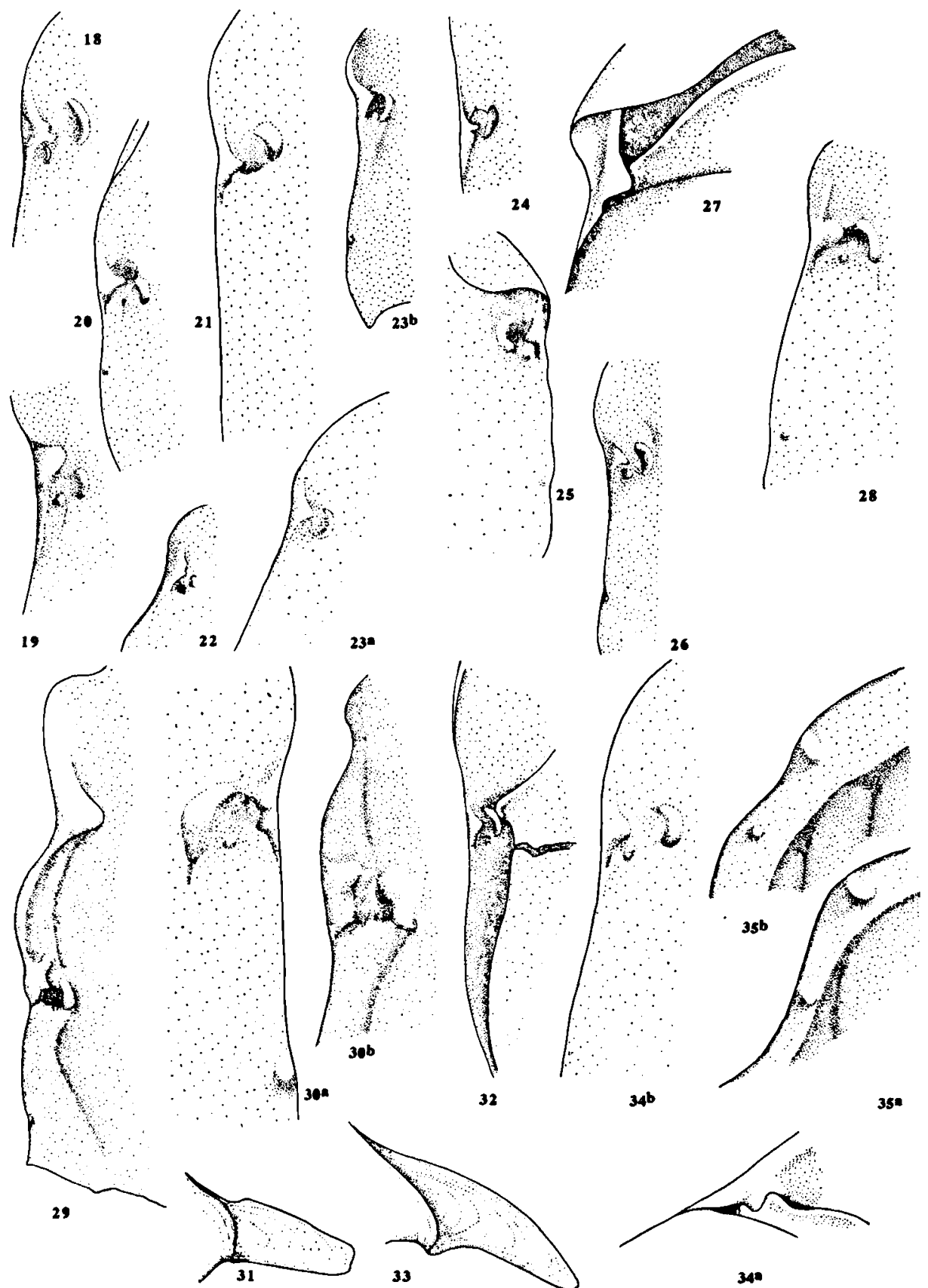

34b

35*

Plate II. Shell details: $18=D$. pacifica, dorsal lock tubercles from inside; $19=D$. pacifica (long-spined form), lock mechanism from inside; $20=D$. aspina, dorsal tubercles of the lock mechanism from inside; $21=D$. grayi, lock mechanism from inside; $22=D$. angulo$s a$, dorsal lock tubercles from inside; $23=D$. angulosa, dorsal lock tubercles from inside from Atlantic (a) and Pacific specimens (b); 24 = dorsal lock tubercles from inside of $D$. bandaensis; $25=$ lock mechanism from inside of $D$. ovalis; $26=$ lock mechanism from inside of $D$. deshayesi; $27=D$. constricta, lock area; $28=$ lock mechanism from inside of $D$. constricta; $29=$ lock mechanism from inside in D. strangulata; $30=$ lock tubercles of Diacavolinia flexipes: (a) specimen from the Red Sea, (b) specimen from the coast of Oman, second lock not illustrated; $31=$ lateral spine of $D$. mcgowani; $32=D$. mcgowani, lock area from ventral with displaced ventral valve showing the lock tubercles; $33=D$. triangulata, spine; $34=D$. triangulata, lock area (a) and dorsal lock tubercles from inside (b); 35 = ventral (a) and dorsal (b) shell with lock of Diacria trispinosa. 

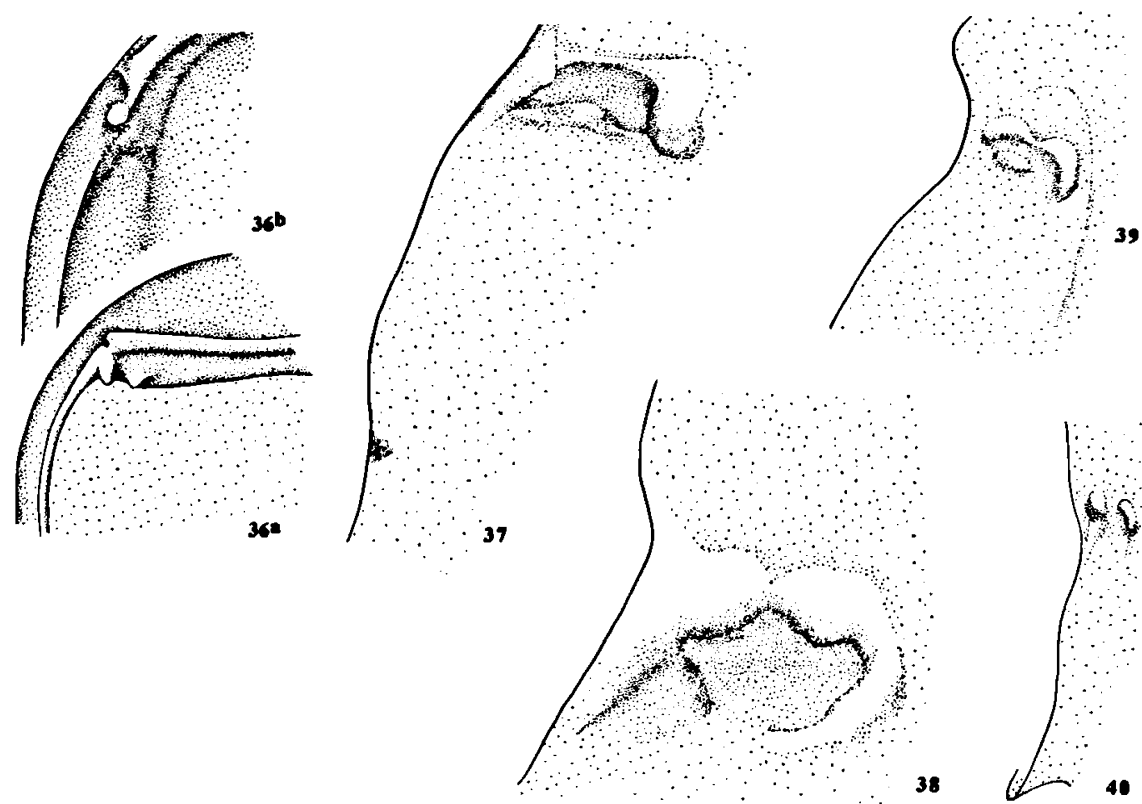

38

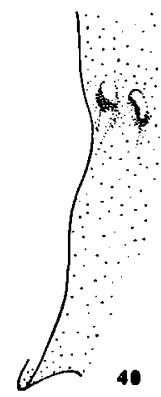

Plate III. Shell details: 36 = ventral (a) and dorsal (b) shell parts with lock of Diacria quadridentata; $37=$ lock tubercles in dorsal shell of Cavolinia globulosa, with second lock visible; $38=$ lock tubercles in dorsal shell of Cavolinia tridentata bermudensis Van der Spoel, 1974; 39 = lock tubercles in dorsal shell of Cavolinia uncinata (Rang, 1829); 40 = lock tubercles in dorsal shell of Cavolinia inflexa (Lesueur, 1813). 